Elizandra Hille

\title{
Análise Quantitativa das Massas de Água dos Mares de Ross e Weddell, Antártica
}

Dissertação apresentada ao Instituto Oceanográfico da Universidade de São Paulo, como parte dos requisitos para obtenção do título de Mestre em Ciências, Programa de Oceanografia, Área de Concentração Oceanografia Física.

Orientadora: Profa. Dra. Ilana E. K. C. Wainer

São Paulo 
Universidade de São Paulo

Instituto Oceanográfico

Análise Quantitativa das Massas de Água dos Mares de Ross e Weddell, Antártica

\author{
Elizandra Hille
}

Dissertação apresentada ao Instituto Oceanográfico da Universidade de São Paulo, como parte dos requisitos para obtenção do título de Mestre em Ciências, Programa de Oceanografia, Área de concentração Oceanografia Física.

Julgada em __ l__ $/$

$\operatorname{Prof}(a) . \operatorname{Dr}(a)$

Conceito

$\operatorname{Prof}(\mathrm{a}) . \operatorname{Dr}(\mathrm{a})$

Conceito

Prof(a). Dr(a).

Conceito 


\section{Sumário}

Resumo xii

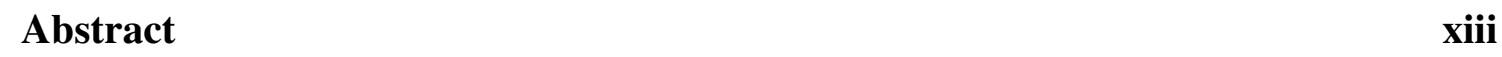

\begin{tabular}{lll}
\hline 1 & Introdução & 1
\end{tabular}

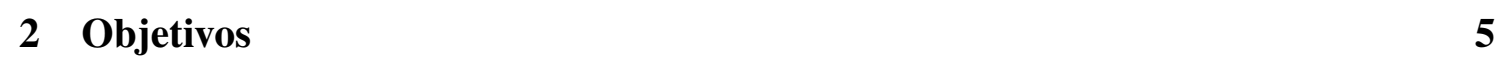

3 Área de Estudo 6

$3.1 \quad$ Marde $\operatorname{Ross} \ldots \ldots \ldots \ldots \ldots \ldots$

3.2 Mar de Weddell . . . . . . . . . . . . . . . . . . . . . . . . . 10

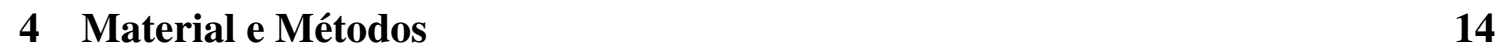

$4.1 \quad \operatorname{Dados} \ldots \ldots \ldots \ldots \ldots \ldots$

$4.1 .1 \quad$ Simple Ocean Data Assimilation . . . . . . . . . . . . . . . . 14

4.2 Análise Multiparamétrica Ótima (AMO) . . . . . . . . . . . . . . . 16

4.3 Descrição do método $\ldots \ldots \ldots$. . . . . . . . . . . . . . 17

4.3.1 Determinação dos Tipos de Água para o Mar de Ross . . . . . . . 20

4.3.2 Determinação dos Tipos de Água para o Mar de Weddell . . . . . 23

5 Resultados e Discussão

$5.1 \quad$ Marde Ross . . . . . . . . . . . . . . . . . . . . . . 26

5.1 .1 Seções de Temperatura . . . . . . . . . . . . . . . . 26

5.1 .2 Seções de Salinidade . . . . . . . . . . . . . . . . . . 31

5.1 .3 Diagramas TS . . . . . . . . . . . . . . 36

5.1 .4 Distribuição das Massas de Água . . . . . . . . . . . . . . 40

5.1.4.1 Distribuição da UCDW . . . . . . . . . . . . . 42

5.1 .4 .2 Distribuição da LCDW . . . . . . . . . . . . . 49

5.1 .4 .3 Distribuição da LSSW . . . . . . . . . . . . 56

5.2 Mar de Weddell . . . . . . . . . . . . . . . . . . . . 63

5.2 .1 Seções de Temperatura . . . . . . . . . . . . . . . 63

5.2 .2 Seções de Salinidade . . . . . . . . . . . . . . . . . 68 


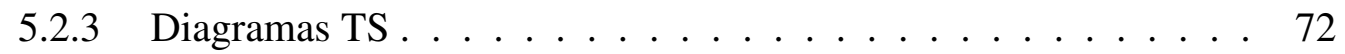

5.2 .4 Distribuição das Massas de Água . . . . . . . . . . . . . . 75

5.2 .4 .1 Distribuição da WDW . . . . . . . . . . . . . . 78

5.2 .4 .2 Distribuição da WSDW . . . . . . . . . . . 86

5.2 .4 .3 Distribuição da WSBW $\ldots \ldots \ldots$. . . . . . . 93

\begin{tabular}{lll}
\hline 6 & Conclusões & 100
\end{tabular}

\begin{tabular}{lr}
\hline Referências & 102
\end{tabular} 


\section{Lista de Figuras}

1 Mapa de localização dos principais elementos oceanográficos que atuam no Oceano Austral . . . . . . . . . . . . . . . . . . . 2

2 Representação esquemática da Circulação Termohalina Global (THC) . . 3

3 Mapa Topográfico da Plataforma Continental do Mar de Ross. . . . . . . 7

4 Diagrama esquemático representando a formação, transformação e circulação

das massas de água no Mar de Ross $\ldots \ldots \ldots$

5 Mapa Topográfico do Mar de Weddell . . . . . . . . . . . . . . . 11

6 Diagrama esquemático representando a formação, transformação e circulação das massas de água no Mar de Weddell . . . . . . . . . . . . . . 13

$7 \quad$ Mapa do Mar de Ross e suas respectivas radiais, R1 e R2. . . . . . . . . . 20

$8 \quad$ Mapa do Mar de Weddell e suas respectivas radiais, W1 e W2. . . . . . . 23

$9 \quad$ Média climatológica (1871-2008) da Temperatura $\left({ }^{\circ} \mathrm{C}\right)$ nas radiais R1 e R2 28

10 Anomalias de Temperatura $\left({ }^{\circ} \mathrm{C}\right)$ na R1 . . . . . . . . . . . . . . . . . . 29

$11 \quad$ Anomalias de Temperatura $\left({ }^{\circ} \mathrm{C}\right)$ na R2 $\ldots \ldots \ldots$

12 Média climatológica (1871-2008) da Salinidade nas radiais R1 e R2 . . . 33

13 Anomalias de Salinidade na R1 . . . . . . . . . . . . . . . . . . . . . 34

14 Anomalias de Salinidade na R2 . . . . . . . . . . . . . . . . . . . 35

15 Diagrama TS relativo à média climatológica (1871-2008) para o Mar de Ross. . . . . . . . . . . . . . . . . . . . . . . 38

16 (a) Diagrama TS para os três períodos no Mar de Ross: 1925-1949, 19501974 e 1975-1999; (b) Diagrama TS contínuo para 7 décadas no Mar de Ross: $1880,1900,1920,1940,1960,1980$ e 2000 . . . . . . . . . . . . 39

17 Distribuição Média (\%) da UCDW, LCDW e LSSW na R2 . . . . . . . . 41

18 Distribuições $(\%)$ da UCDW na R1 . . . . . . . . . . . . . . . . 44

19 Anomalias da distribuição (\%) da UCDW na R1 . . . . . . . . . . . . . . 45

20 Distribuições $(\%)$ ) da UCDW na R2 . . . . . . . . . . . . . . 46

21 Anomalias da distribuição (\%) da UCDW na R2 . . . . . . . . . . . . . . 47

22 (a) Distribuição (\%) média da UCDW no Mar de Ross para a profundidade de 60m; (b) 400m; (c) 1000m; (d) 1600m . . . . . . . . . . . . . 48 
23 Distribuições (\%) da LCDW na R1 . . . . . . . . . . . . . . . 51

24 Anomalias da distribuição (\%) da LCDW na R1 . . . . . . . . . . . 52

25 Distribuições (\%) da LCDW na R2 . . . . . . . . . . . . . . . 53

26 Anomalias da distribuição (\%) da LCDW na R2 . . . . . . . . . . . 54

27 (a) Distribuição (\%) média da LCDW no Mar de Ross para a profundidade de 60m; (b) 400m; (c) 1000m; (d) 1600m … . . . . . . . . . . 55

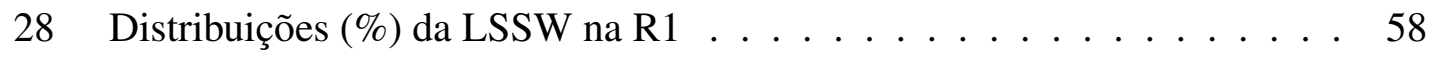

$29 \quad$ Anomalias da distribuição (\%) da LSSW na R1 . . . . . . . . . . . . 59

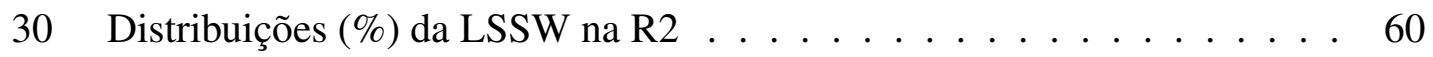

31 Anomalias da distribuição (\%) da LSSW na R2 . . . . . . . . . . . 61

32 (a)Distribuição (\%) média da LSSW no Mar de Ross para a profundidade de 60m; (b) 400m; (c) 1000m; (d) 1600m . . . . . . . . . . . . 62

33 Média climatológica $(1871-2008)$ da Temperatura $\left({ }^{\circ} \mathrm{C}\right)$ nas radiais $\mathrm{W} 1 \mathrm{e}$

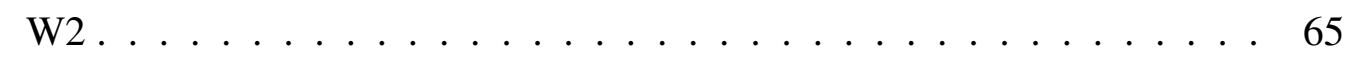

34 Anomalias de Temperatura $\left({ }^{\circ} \mathrm{C}\right) \mathrm{na} \mathrm{W1} \ldots \ldots \ldots \ldots \ldots$

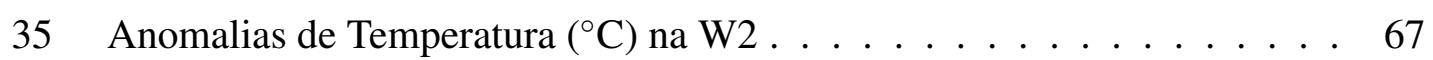

36 Média climatológica (1871-2008) da Salinidade nas radiais W1 e W2 . . 69

37 Anomalias de Salinidade na W1 . . . . . . . . . . . . . . . 70

38 Anomalias de Salinidade na W2 . . . . . . . . . . . . . . 71

39 Diagrama TS relativo à média climatológica (1871-2008) para o Mar de Weddell . . . . . . . . . . . . . . . . . . . . . . . . 73

40 Diagrama TS para os três períodos no Mar de Weddell: 1925-1949, 19501974 e 1975-1999; (b) Diagrama TS contínuo para 7 décadas no Mar de Weddell: $1880,1900,1920,1940,1960,1980$ e 2000 . . . . . . . . . 74

41 Distribuição Média (\%) da WDW, WSDW e WSBW na W1 $\ldots . . . .77$

42 Distribuições (\%) da WDW na W1 . . . . . . . . . . . . . . . 81

43 Anomalias da distribuição (\%) da WDW na W1 . . . . . . . . . . . 82

44 Distribuições (\%) da WDW na W2 $\ldots \ldots \ldots \ldots \ldots$

45 Anomalias da distribuição (\%) da WDW na W2 $\ldots \ldots \ldots \ldots$. . . . . 84 
46 (a) Distribuição (\%) média da WDW no Mar de Weddell para a profundidade de 1000m; (b) 2000m; (c) 3000m; (d) 4000m . . . . . . . . . . . . 85

$47 \quad$ Distribuições $(\%)$ da WSDW na W1 . . . . . . . . . . . . . . . . . . 88

48 Anomalias da distribuição (\%) da WSDW na W1 . . . . . . . . . . . . . 89

49 Distribuições $(\%)$ da WSDW na W2 . . . . . . . . . . . . . . . . . . . . 90

$50 \quad$ Anomalias da distribuição (\%) da WSDW na W2 . . . . . . . . . . . . . 91

51 (a) Distribuição (\%) média da WSDW no Mar de Weddell para a profundidade de 1000m; (b) 2000m; (c) 3000m; (d) 4000m . . . . . . . . . . . 92

52 Distribuições $(\%)$ da WSBW na W1 . . . . . . . . . . . . . . 95

53 Anomalias da distribuição (\%) da WSBW na W1 . . . . . . . . . . . . 96

54 Distribuições $(\%)$ da WSBW na W2 . . . . . . . . . . . . . . . . 97

55 Anomalias da distribuição (\%) da WSBW na W2 . . . . . . . . . . . . . 98

56 (a) Distribuição (\%) média da WSBW no Mar de Weddell para a profundidade de 1000m; (b) 2000m; (c) 3000m; (d) 4000m . . . . . . . . . . . 99 


\section{Lista de Tabelas}

1 Tipos de Água e Pesos para o Mar de Ross . . . . . . . . . . . . . . . . . 21

$2 \quad$ Tipos de Água e Pesos o Mar de Weddell . . . . . . . . . . . . . . . . 24 


\section{Lista de Acrônimos}

ACC - Corrente Circumpolar Antártica

AAIW - Água Antártica Intermediária

AABW - Água Profunda Antártica

AASW - Água de Superfície Antártica

AMO - Análise Multiparamétrica Ótima

CDO - Climate Data Operators 1.4.1

CDW - Água Profunda Circumpolar

COADS - Comprehensive Ocean-Atmosphere Data Set

DWBC - Correntes profundas de contorno oeste

FRIS - Plataforma de Gelo Filchner-Ronne

HSSW - Água de Plataforma de Alta Salinidade

ISW - Água de Plataforma de Gelo

LCDW - Água Profunda Circumpolar Inferior

LIS - Plataforma de Gelo Larsen

LSSW - Água de Plataforma de Baixa Salinidade

mCDW - Água Profunda Circumpolar Modificada

MR - Mar de Ross

MW - Mar de Weddell

NADW - Água Profunda do Atlântico Norte

NASA - National Aeronautics and Space Administration

NCVIEW - NetCDF Data Viewer $1.93 g$

NOAA - National Oceanic and Atmosphere Administration

NODC - National Oceanographic Data Center

OA - Oceano Austral

POP - Parallel Ocean Program

RIS - Plataforma de Gelo do Mar de Ross

SAF - Frente Subantártica

SAMW - Água Modal Subantártica

SODA - Simple Ocean Data Assimilation 
THC - Circulação Termohalina Global

TSM - Temperatura da Superfície do Mar

UCDW - Água Profunda Circumpolar Superior

WDW - Água Profunda Cálida

WOD2001 - World Meteorological Organization

WSBW - Água de Fundo do Mar de Weddell

WSDW - Água Profunda do Mar de Weddell

WW - Água de Inverno 


\section{Agradecimentos}

Primeiramente agradeço à Deus, pois foi Ele quem me deu a vida, e tudo o que sou e tenho. Foi Ele que acreditou em mim quando eu mesma não acreditava, e me disse que sim, que tudo era possível, e que bastava eu somente crer.

Agradeço à minha orientadora, Ilana, por toda paciência comigo nestes quase três anos de Mestrado, por ter me aceito como aluna e por apostar em mim desde 2009, quando o meu sonho era entrar na USP, Muito Obrigada!

Obrigada ao INCT-Criosfera pela bolsa dispobilizada durante o Mestrado.

Aos meus pais, pela ajuda mais do que incondicional em todos os momentos, tanto emocionalmente como financeiramente, e por terem me apoiado a ir atrás deste meu sonho, sempre me dando suporte e palavras de encorajamento, mesmo quando achava que não iria conseguir... Devo esta conquista a vocês!

Ao meu irmão e cunha, Chris e Didi, por todos conselhos, orações e palavras de incentivo, vocês são um verdadeiro exemplo para mim!

Aos meus amigos de turma, que viraram mais chegados do que irmãos, Carol, Márcio e Nair... vocês realmente fizeram a diferença na minha passagem aqui pelo IO, valeu por cada momento que passamos juntos, listas, provas, take home, etc, etc...e Márcio, sem palavras por tudo o que você me ajudou e tem me ajudado desde lá na prova de ingresso até agora. Obrigada por tudo gente!

Às minhas eternas companheiras de apartamento, Poli e Virna, meninas, sem vocês, nem sei o que teria sido esse tempo que passei em Sampa... valeu por tudo, por cada conversa, cada incentivo, cada ida ao sushi, CEPE, nossas caminhadas, enfim, só tenho que agradecer a Deus por ter conhecido vocês!

As minhas mais do que amigas, Beta e Fernanda. A amizade de vocês faz e fez toda a diferença durante este tempo que passei em Sampa. Obrigada por me aguentarem nos momentos de pressão, e por terem paciência comigo quando queria, mas não podia estar com vocês. E Beta, obrigada por ter me incentivado lá em 2009 eu vir pra Sampa e fazer o mestrado aqui na USP, tu e toda família Mayer (Tia Suely, Flá e Lu) tem uma grande parcela de importância nesta conquista! 
Ao pessoal do Laboratório OC ${ }^{2}$, Bruno, Daniel, Thiago, Mineiro, Zé, Dalton, Danilo, Naty e Augusto, todos vocês são demais, vocês realmente me inspiram! E Mineiro, sem palavras por tudo o que você me ajudou, principalmente pelos pontapés iniciais desse trabalho, tentando me fazer entender essas "benditas" OMP's. Muito Obrigada!

À Taty pela amizade e parceria desde a graduação, pelas inúmeras conversas, idas para SC, conversas sobre o futuro... obrigada por tudo mesmo guria!

Aos meus pastores do Bola de Neve Joinville, Darlan e Karina, por sempre estarem me aconselhando a continuar em busca dos meus objetivos! Obrigada por tudo, principalmente pelas conversas motivacionais lá no Niu!

A minha célula Perdizes I. Estar com vocês todas as quartas-feiras durante os períodos de curso aqui em Sampa realmente fizeram toda a diferença na minha caminhada. Amo todos vocês!

And for the last, but not the least, Drew Dillon. You have no idea how much you helped me during these crazy years. Thank you for every word. You always knew how to lift me up, and I can't forget a word you said to me during the finals of a course, that helped me a lot to keep focusing on my dreams "God doesn't give us dreams so that we can fail at them rather He gives them to us so that we may glorify him completely when we succeed in what we longed for so long" 
"Therefore I tell you, whatever you ask for in prayer, believe that you received it, and it will be yours"

Mark 11:24 - Holy Bible, NIV 


\section{Resumo}

A complexa interação que ocorre entre os processos oceânicos e atmosféricos no Oceano Austral afeta a circulação oceânica global em diferentes camadas. O Mar de Weddell e o Mar de Ross possuem reconhecida importância na formação da Água de Fundo Antártica (AABW). O objetivo principal deste trabalho é caracterizar as massas de água dos Mares de Weddell e Ross, através dos dados mais recentes de reanálise oceânica SODA (Simple Ocean Data Assimilation). Através da técnica de separação de massas de água Análise Multiparamétrica Ótima (AMO) foi possível a identificação de 3 principais massas de água no Mar de Ross: Água Profunda Circumpolar Superior (UCDW), Água Profunda Circumpolar Inferior (LCDW) e Água de Plataforma de Baixa Salinidade (LSSW). A UCDW foi a que apresentou a maior variabilidade, não atingindo a Plataforma de gelo do MR durante os anos de 1950-1974. No Mar de Weddell foi possível a identificação das seguintes massas de água: Água Profunda Cálida (WDW), Água Profunda do Mar de Weddell (WSDW) e Água de Fundo do Mar de Weddell (WSBW). A WDW atingiu valores $>70 \%$ à $800 \mathrm{~m}$. A WSDW possui em seu núcleo valores $>90 \%$ entre $2000 \mathrm{e}$ 3500m. A WSBW, apresenta $100 \%$ em profundidades $>4000 \mathrm{~m}$.

Palavras Chaves: Oceano Austral, Mar de Ross, Mar de Weddell, Água de Fundo Antártica, Gelo Marinho, SODA. 


\begin{abstract}
The complex interaction that occurs between the oceanic and atmospheric processes in the Southern Ocean affects global ocean circulation in different layers. The Weddell and Ross Seas have recognized importance in the formation of Antarctic Bottom Water (AABW). This work aims to characterize the water masses of the Weddell and Ross Seas, using the latest ocean data reanalysis SODA (Simple Ocean Data Assimilation). Through the water masses separation technique, Optimum Multiparameter Analysis (OMP), it was possible to identify three main water masses in Ross Sea: Upper Circumpolar Deep Water (UCDW), Lower Circumpolar Deep Water (LCDW) and Low Salinity Shelf Water (LSSW). UCDW showed the greatest variability, not reaching the Ross Sea Ice Shelf during the years 1950-1974. It was possible to identify the following water masses in Weddell Sea: Warm Deep Water (WDW), Weddell Sea Deep Water (WSDW) and Weddell Sea Bottom Water (WSBW). WDW reached values up to $70 \%$ in $800 \mathrm{~m}$. WSDW has in its core values $>90 \%$ between 2000 and $3500 \mathrm{~m}$. WSBW presents a contribution up to $100 \%$ at depths $>4000 \mathrm{~m}$.
\end{abstract}

Keywords: Southern Ocean, Ross Sea, Weddell Sea, Antarctic Bottom Water, Sea Ice, SODA. 


\section{Introdução}

Os oceanos globais exercem importante papel na mudança e variabilidade do clima. Embora muita atenção seja dada para o entendimento das variáveis da interface, tais como temperatura da superfície do mar (TSM), pressão ao nível do mar e ventos superficiais, pouco é conhecido a respeito do comportamento das propriedades hidrográficas do oceano profundo. Estas massas de água densas recebem suas assinaturas nos processos que ocorrem na interação oceano-atmosfera e são, portanto, excelentes indicadoras de mudanças nas condições climáticas (LEFFANUE e TOMCZAK., 2004; KERR et al., 2009a).

Em particular, o Oceano Austral (OA) tem um papel muito importante no clima, devido as interações complexas entre o oceano, atmosfera e gelo marinho. Águas densas e geladas afundam para profundidades abissais em torno das margens da Antártica e, migram em sentido Norte para dentro dos oceanos Atlântico, Índico e Pacífico por meio das chamadas correntes profundas de contorno oeste (DWBC) (Ver Figura 1 - (CARTER et al., 2008)). Durante a migração para as latitudes boreais, essas águas profundas e geladas sobem até o oceano superior, através de um processo bem vagaroso de ressurgência. Na superfície, elas contribuem para as correntes superficias mais quentes. Estas águas, ao se aproximarem novamente de regiões de altas latitudes, começam a resfriar ao interagir com a atmosfera e novamente afundam, formando assim a Água Profunda do Atlântico Norte (NADW), que migra então para o sul entre a Água Antártica Intermediária (AAIW) e a Água Profunda Antártica (AABW) / Água Profunda Circumpolar Inferior (LCDW). Na sua rota para o Sul, a NADW eventualmente se mistura com outras águas, e ao alcançar a margem continental antártica, acaba indo para a superfície novamente. Com isto, o ciclo da Circulação Termohalina Global (THC - Figura 2) é completo (CARTON e GIESE, 2008; BROECKER, 1991; SCHMITZ, 1995; RAHMSTORF, 2002).

A geografia única do OA se extende da costa norte da Antártica até $45^{\circ} \mathrm{S}$ (Figura 11. Os fortes ventos do Hemisfério Sul Ocidental dirigem a Corrente Circumpolar Antártica (ACC), que é uma corrente profunda e bastante vigorosa que flui para leste ao redor do continente Antártico (PARDO et al., 2012). A ACC varia com a longitude e é fortemente influenciada pela topografia de fundo (GILLE, 1994). No inverno a convecção 
existente nas águas profundas no lado equatorial da ACC forma uma camada de mistura conhecida como Água Modal Subantártica (SAMW; (MCCARTNEY, 1977)).

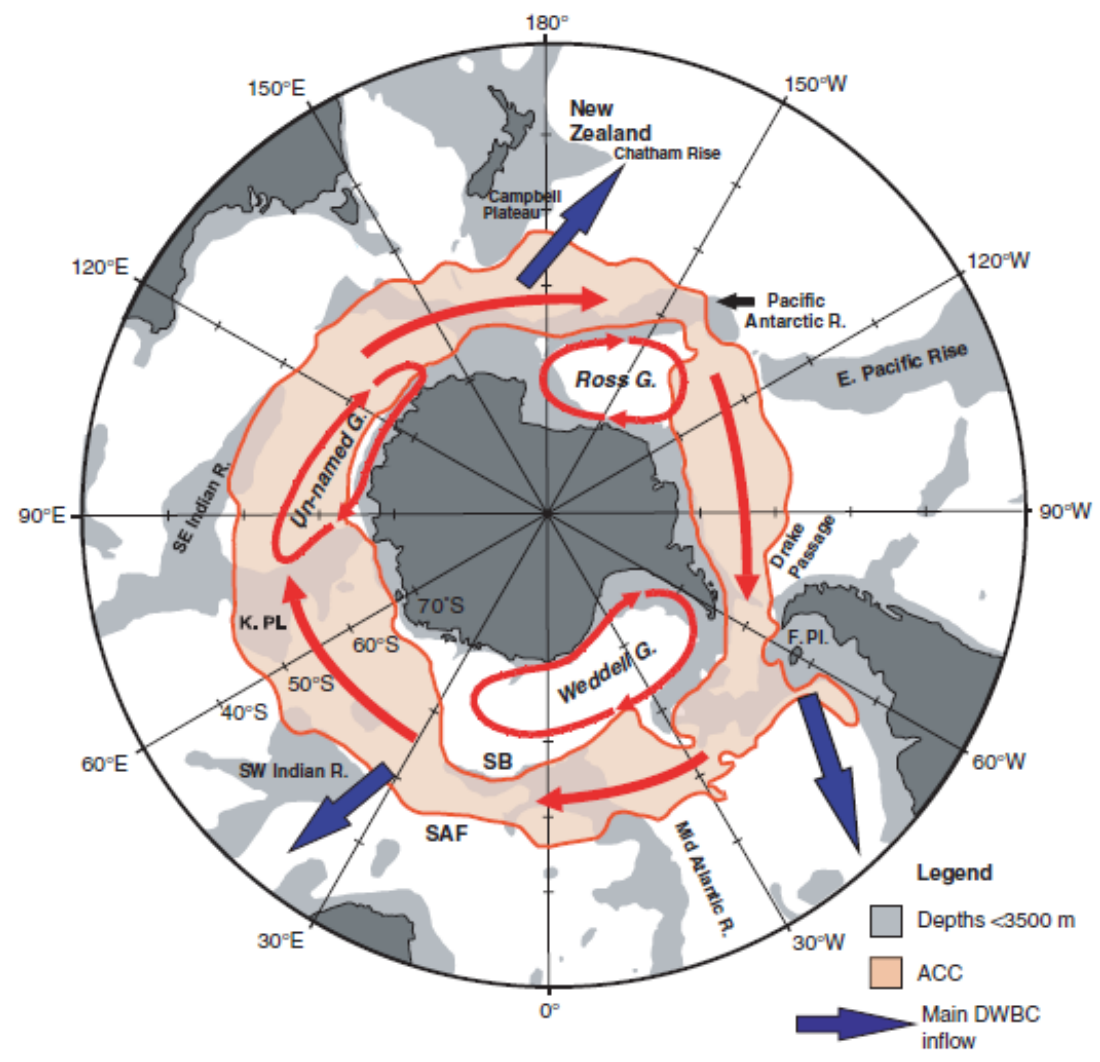

Figura 1: Mapa de localização dos principais elementos oceanográficos que atuam no Oceano Austral (OA): (i) a ACC contida pela Frente Subantártica (SAF); (ii) os giros subpolares de Ross, Weddell e o que ainda não foi nomeado; (iii) os principais pontos de saída das correntes profundas de contorno oeste do OA (flechas azuis) (CARTER et al., 2008).

Neste contexto, tanto o Mar de Ross como o Mar de Weddell (Figuras 3 e 5 , respectivamente) têm um papel dominante na produção e exportação de Água de Fundo Antártica $(\mathrm{AABW})$, sendo, portanto, fontes predominantes de águas de alta densidade que ventilam os fundos do oceano global. Com isso, mudanças nas águas profundas dos Mares de Weddell e Ross podem afetar diretamente a formação da AABW e, por consequencia, a quantidade de calor transportada pela THC e o balanço energético da Terra (GILL, 1973; FOSTER e CARMACK, 1976b; CARMACK, 1977; FAHRBACH et al., 1994a; ORSI et al., 1999, ROBERTSON et al., 2002, KERR et al., 2009a).

É notável que as complexas interações oceano-gelo-atmosfera conferem a região 
antártica um papel fundamental nas mudanças globais e ressaltam a importância dos estudos dos processos oceanográficos na região. A variabilidade das massas de água que compõem a THC será examinada neste trabalho.

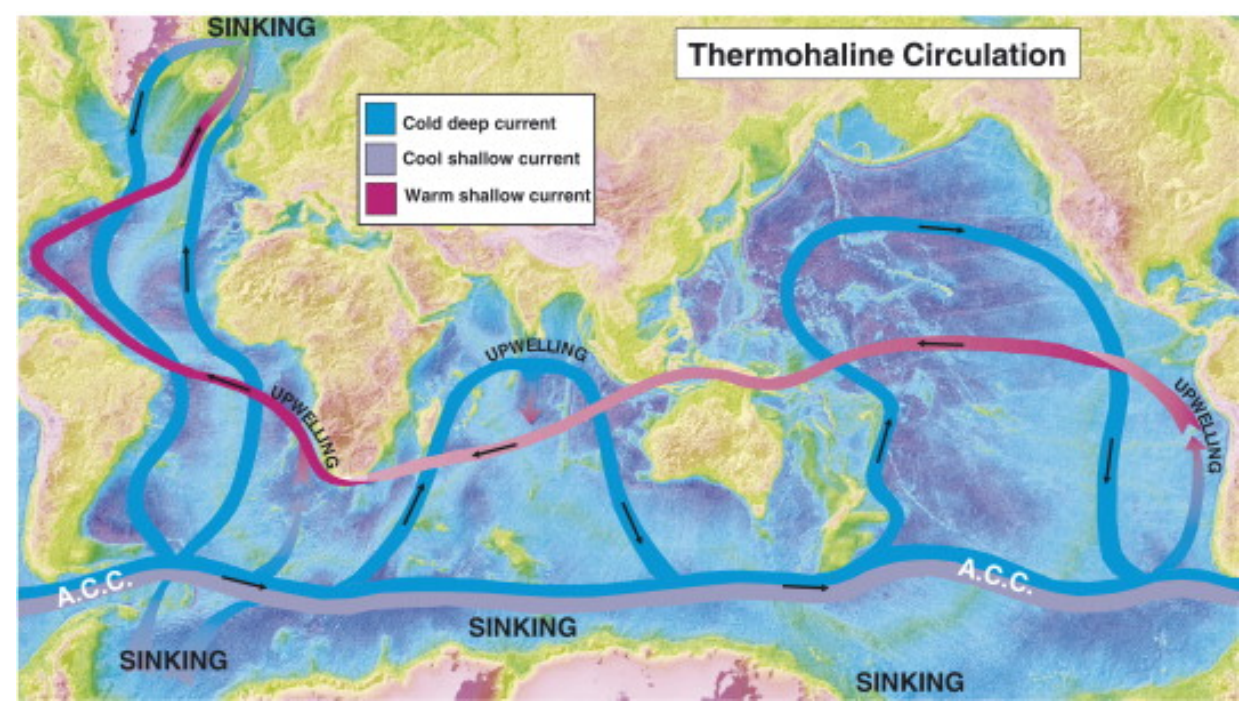

Figura 2: Representação esquemática da Circulação Termohalina Global (THC) mostrando uma série de sistemas de recirculação que transportam calor, sal, nutrientes e gases ventilados por todo o oceano mundial. Somente os principais elementos da THC são apresentados nesta figura (MANIGHETTI, 2001).

Atualmente, além dos métodos tradicionais, como o proposto por Mamayev (1975) utilizando a teoria analítica das curvas T-S, outros métodos também vão sendo empregados com maior frequência, proporcionando novas ferramentas para o estudo das massas de água, tais como: modelagem numérica e métodos inversos (sendo estes capazes de extrair informações sobre as massas de água a partir de diferentes conjuntos de dados hidrográficos). Neste último, inclui-se a Análise Multiparamétrica Ótima (AMO; (TOMCZAK e LARGE, 1989)), método aplicado neste trabalho.

A AMO é um método de análise de massas de água, que utiliza parâmetros hidrográficos conservativos (temperatura potencial, salinidade) e diversos parâmetros semiconservativos (nutrientes inorgânicos, oxigênio dissolvido, entre outros) como traçadores de massas de água.

Estudos mais específicos relacionados a quantificação das mudanças que vêm ocorrendo com as massas de água são um tanto escassos. As quantidades exatas e suas 
respectivas localizações onde as camadas superiores de água são modificadas e eventualmente transformadas em águas densas não são claramente conhecidas. Assim, uma caracterização quantitativa das massas de água dos Mares de Weddell e Ross torna-se necessária para um melhor entendimento sobre questões de variabilidade, e consequentemente de possíveis mudanças climáticas e alterações globais. Este trabalho tem como hipótese científica de que devido a mudança do clima, as massas de água densas (do oceano profundo) tiveram suas características alteradas. Para investigar esta hipótese, as massas de água dos Mares de Ross e Weddell serão examinadas através dos dados mais recentes de reanálise oceânica SODA (Simple Ocean Data Assimilation), usando a técnica da AMO. 


\section{Objetivos}

Este trabalho tem como objetivo geral caracterizar as massas de água nos Mares de Ross e Weddel, a partir de dados da reanálise oceânica Simple Ocean Data Assimilation (SODA). Utilizou-se a técnica de separação de massas de água Análise Multiparamétrica Ótima (AMO) para determinar o percentual de mistura das massas de água presentes na camada profunda desses respectivos mares. Para tanto, foram propostos os seguintes objetivos específicos:

-Determinar a distribuição espacial e estrutural das diferentes massas de água encontradas na região.

-Caracterizar quantitativamente tais massas de água.

-Determinar o percentual de mistura entre as diferentes massas de água

-Examinar as mudanças ocorridas na estrutura de massa de água entre determinados períodos do século XX. 


\section{3 Área de Estudo}

\subsection{Mar de Ross}

O Mar de Ross (MR) está situado sobre a plataforma continental Antártica, se extendendo entre o Cabo Adare e o Cabo Colbeck (Figura 3). Ele cobre uma área de aproximadamente $5 \times 10^{5} \mathrm{~km}^{2}$ e tem uma profundidade média de $500 \mathrm{~m}$, com uma topografia irregular caracterizada pela alternância de bancos elevados e depressões que, eventualmente, alcançam os $1200 \mathrm{~m}$ de profundidade. O limite sul é marcado pela Plataforma de Gelo do Mar de Ross (RIS); uma cobertura de gelo que alcança quase metade da plataforma continental e tem cerca de 250 metros de espessura na sua porção Norte, sob a qual águas de plataforma circulam livremente (JACOBS e COMISO, 1989; BUDILLON et al., 2003).

A salinidade tem um papel fundamental na determinação do campo de densidade em regiões polares. Portanto, qualquer mudança na salinidade vai impactar significativamente a distribuição das massas de água. Uma das tendências mais dramáticas de diminuição de salinidade das últimas décadas tem sido manifestada nas camadas superiores do MR (JACOBS et al., 2002; JACOBS, 2006). Por isso, o MR e sua variabilidade estão intrisecamente relacionados com a Circulação Termohalina Global e o clima dos oceanos (Figura 2).

Diferentes massas de água (usando definições de Carmack (1977); Jacobs e Giulivi (1999), Dinniman et al. (2007)) podem ser encontradas no MR e, especificamente na plataforma continental do MR (Figura 4). A massa de água mais volumosa em todo Oceano Austral (OA) é a Água Profunda Circumpolar (CDW). No Mar de Ross ela é transportada para leste pela ACC (Corrente Circumpolar Antártica), e é identificada como uma camada espessa de água salgada e pobre em oxigênio (CALLAHAN, 1972; SIEVERS e NOWLIN, 1984; WHITWORTH e NOWLIN, 1987), oriunda das profundidades médias do regime subtropical e que tem parte do seu volume capturado pelo Giro de Ross (LOCARNINI, 1994; ORSI et al., 1995). O Giro de Ross se extende de $160^{\circ} \mathrm{E}$ a $140^{\circ} \mathrm{W}$ e é amplamente confinado em profundidades maiores que 4000m, atingindo a Bacia do Pacífico de Sudeste (Figura 11. Ao ser capturada pelo Giro de Ross, a CDW é advec- 
tada para Sul, onde assume uma posição vertical intermediária entre a Água de Superfície Antártica (AASW) e a AABW (WHITWORTH e NOWLIN, 1987; ORSI et al., 1995; ORSI et al., 1999). A importância da CDW reside no fato de ser esta a única massa de água que fornece calor para as águas da plataforma do Mar de Ross (BUDILLON et al., 2003).

Ainda dentro da ACC, a CDW se subdivide em duas variedades, Água Profunda Circumpolar Superior (UCDW) e Água Profunda Circumpolar Inferior (LCDW), o que reflete diferentes propriedades adquiridas de diferentes regiões fontes. A UCDW pode ser traçada sobre a ACC pela localização onde é encontrado oxigênio relativo mínimo e nutriente máximo (CALLAHAN, 1972; SIEVERS e NOWLIN, 1984; SMITH et al., 1999).Ao Sul da Frente Polar, a UCDW é mais caracterizada por uma temperatura subsuperficial máxima, devido a presença de uma temperatura mínima sobrejacente que está associada com a AASW (Água de Inverno - WW). A LCDW, por sua vez, é caracterizada por uma salinidade máxima, que é derivada da Água Profunda do Atlântico Norte (NADW) (GORDON, 1967; REID et al., 1977; WHITWORTH e NOWLIN, 1987), e por uma concentração local de nitrato mínima (SIEVERS e NOWLIN, 1984; WHITWORTH e NOWLIN, 1987).

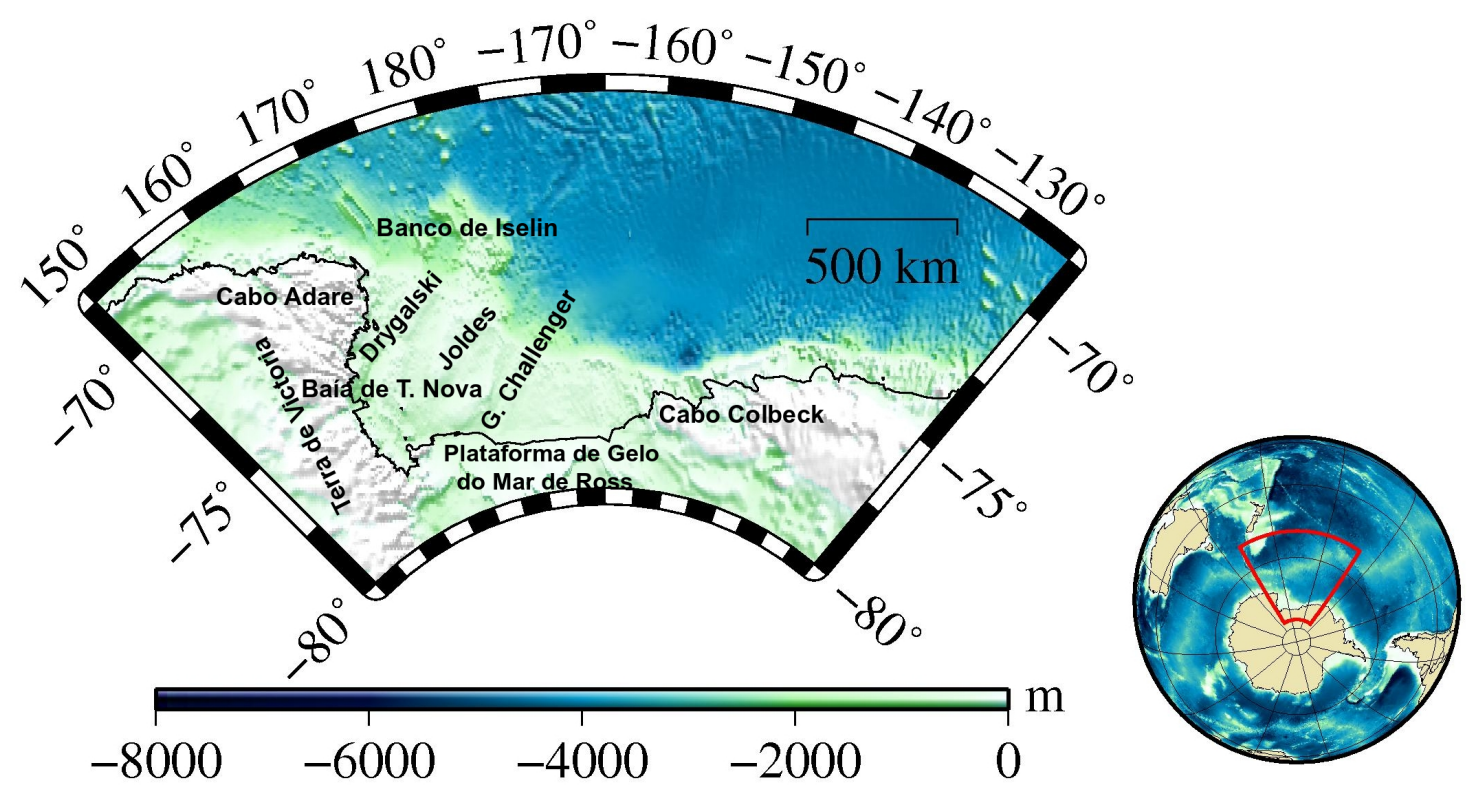

Figura 3: Mapa Topográfico da Plataforma Continental do Mar de Ross. 
Em algumas regiões específicas a CDW penetra dentro da plataforma continental de Ross formando, após a interação com as águas de plataforma, a CDW modificada (mCDW), que pode ser caracterizada por uma temperatura subsuperficial máxima e oxigênio dissolvido mínimo (JACOBS et al., 1985; LOCARNINI, 1994; BUDILLON et al., 2003).

Na porção ocidental do MR, as características físicas da coluna d'água são também afetadas pela presença recorrente de uma área costeira livre de gelo, a polynia da Baía de Terra Nova (BROMWICH e KURTZ, 1984; JACOBS et al., 1985; BUDILLON et al., 2000; FUSCO et al., 2002). Esta região tem sido identificada como a área onde a Água de Plataforma de Alta Salinidade (HSSW) é gerada, em virtude de um ciclo contínuo de formação e remoção de novas áreas com gelo, aumentando assim a salinidade da água (KURTZ e BROMWICH, 1983; KURTZ e BROMWICH, 1985; JACOBS et al., 1985; WOERT, 1999).

A Água de Plataforma de Alta Salinidade (HSSW) é formada na porção oeste do Mar de Ross. Após formada a HSSW se distribui próxima ao fundo e escoa pelo canal Drygalski em ambas as direções, Norte e Sul. A Água da Plataforma de Gelo (ISW) se desloca para Norte sob a RIS até alcançar a quebra da plataforma, onde interage com a mCDW e desce o talude, atuando no processo de formação da AABW (JOHNSON, 2008). Devido à sua participação direta na formação da AABW, a HSSW e a ISW são as massas de água mais importantes no MR para a ventilação do oceano profundo (JACOBS e COMISO, 1989; ASSMANN et al., 2003).

Além das bacias do Pacífico, o MR também ventila efetivamente o setor Índico do OA (Figura 1). Águas de fundo produzidas tanto no setor Índico como no setor Pacífico contribuem com aproximadamente $40 \%$ da produção global de AABW (ORSI et al., 1999). Estes resultados são conhecidos em virtude da existência de escoamentos muito bem documentados de águas profundas no MR, localizados nas proximidades de $173^{\circ} \mathrm{E}, 177^{\circ} \mathrm{E}, 175^{\circ} \mathrm{W}$ (JACOBS et al., 1970; JACOBS et al., 1985), e $168^{\circ} \mathrm{W}$ (LOCARNINI, 1994; BUDILLON et al., 2002).

Por fim, a Água de Plataforma de Baixa Salinidade (LSSW) ocupa camadas intermediárias da porção centro-oriental do Mar de Ross, e tem sua formação associada 
à interações entre a AASW e as águas frias de subsuperfície, após inúmeros ciclos de congelamento (derretimento) entre as águas superficiais e o gelo (JACOBS et al., 1985; SMETHIE e JACOBS, 2005).

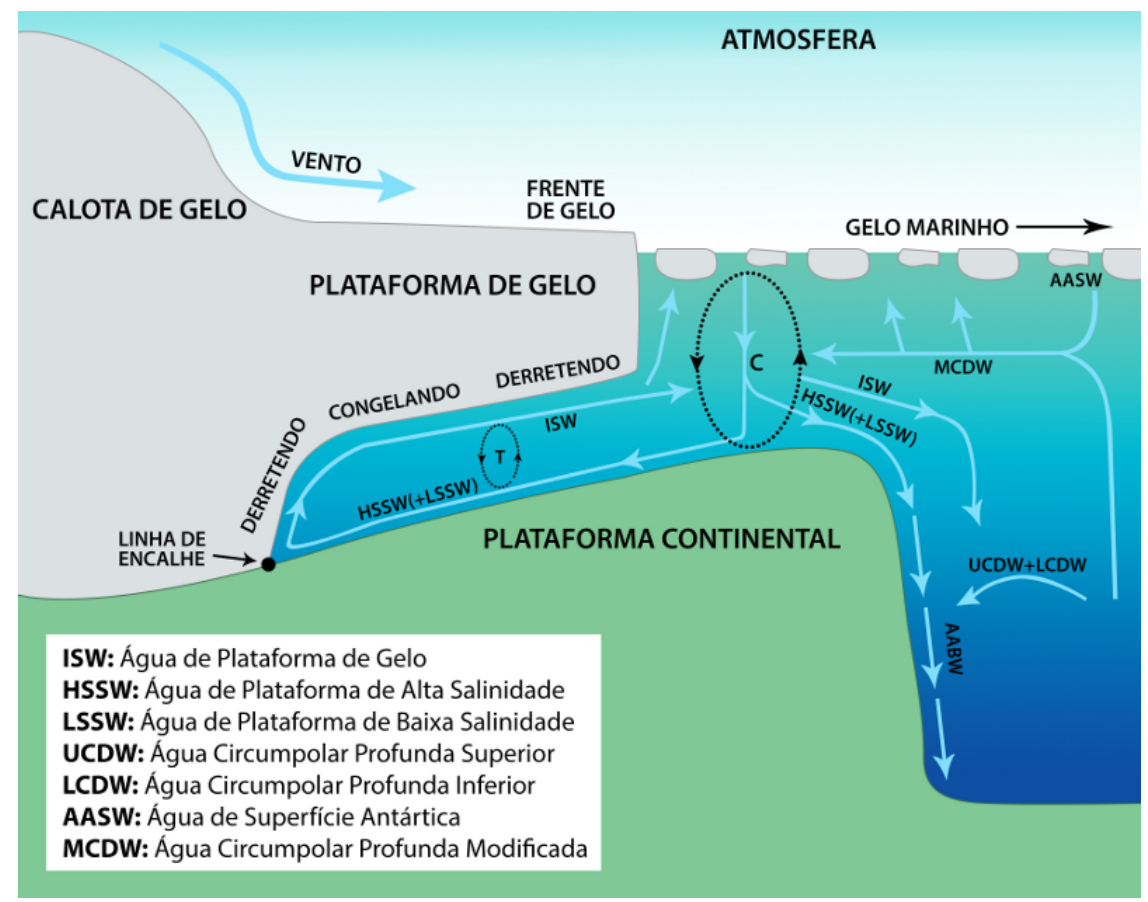

Figura 4: Diagrama esquemático representando a formação, transformação e circulação das massas de água no Mar de Ross (Modificado de Smethie e Jacobs (2005); Østerhus (2005)). 


\subsection{Mar de Weddell}

Os limites do mar de Weddell (MW), que engloba as bacias de Weddell e Enderby (Figura 5), são definidos por características topográficas e hidrográficas, que delimitam um giro ciclônico (denominado de Giro de Weddell - Figura 11) presente na região (CARMACK e FOSTER, 1975a). O Giro de Weddell é o maior giro presente no OA, se extendendo de $50^{\circ} \mathrm{W}$ até entre $20^{\circ}-30^{\circ} \mathrm{E}$ (ORSI et al., 1993). Na superfície ele é alongado e tem uma forma alinhada de NE-SW, enquanto que nas regiões mais profundas ele é dividido em duas células ciclônicas localizadas à leste e oeste de $15^{\circ} \mathrm{W}$ (CARTER et al., 2008). Basicamente, o Giro de Weddell chega a ocupar profundidades maiores que 4000m, atingindo reentrâncias profundas que se extendem para leste próximo à ponta da Península Antártica (Figura 11. A partir daí, a língua norte do giro consegue se sobrepor essas reentrâncias e interagir com a ACC. Com esta interação, o Giro de Weddell favorece a formação da $\mathrm{AABW}$, pois carrega para as regiões polares, massas de água relativamente quentes e salinas, provenientes da Corrente Circumpolar Antártica (ACC) (FOSTER e CARMACK, 1976b; ORSI et al., 1993, FAHRBACH et al., 1994b; CARTER et al., 2008). Vale ressaltar que de 50 a $90 \%$ do total da AABW, que ventila os oceanos mundiais, adquire suas características em Weddell (ABSY et al., 2008; FAHRBACH et al., 1994b; FAHRBACH et al., 1995).

As plataformas continentais ao redor do continente Antártico são em geral estreitas. Exceções são as amplas plataformas encontradas tanto no Mar de Weddell como no Mar de Ross, com uma profundidade em torno de 400m e uma extensão variando entre 600 a 1100km de largura (DEACON, 1982). Estas regiões são caracterizadas por depressões irregulares, canyons submarinos e por plataformas de gelo que se estendem em direção ao mar a partir do continente. A importância desta feição topográfica está relacionada aos processos de formação de águas profundas e de fundo. 


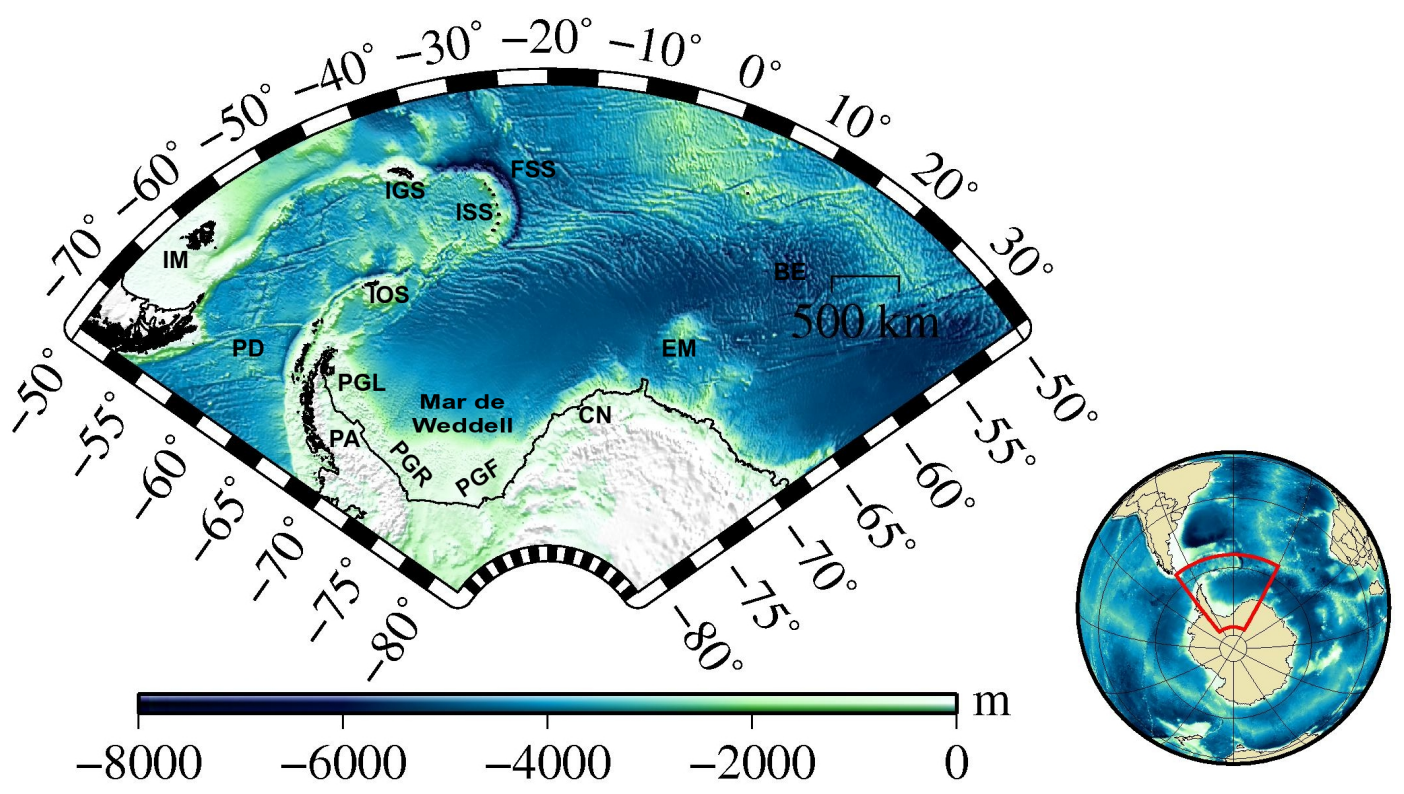

Figura 5: Mapa Topográfico do Mar de Weddell. Legenda: BE - Bacia de Enderby; CN - Cabo Norvegia; EM - Elevação de Maud; FSS - Fossas Sanduíche do Sul; IGS - Ilha Georgia do Sul; IM - Ilhas Malvinas; IOS - Ilhas Orcadas do Sul; ISS - Ilhas Sanduíche do Sul; PA - Península Antártica; PD - Passagem de Drake; PGF - Plataforma de Gelo Filchner; PGL - Plataforma de Gelo Larsen; PGR - Plataforma de Gelo Ronne.

De acordo com Kerr et al. (2009a), a coluna de água do Mar de Weddell pode ser dividida em três principais camadas: i) a superficial, que compreende até os primeiros $200 \mathrm{~m}$ de profundidade; ii) a intermediária, entre 200 e 1500 m; e a iii) profunda, abaixo dos 1500 m. As características das massas de água destas três camadas serão descritas a seguir.

As massas de água superficiais estão próximas do ponto de congelamento e são sazonalmente influenciadas pela variabilidade climática (HUHN et al., 2008). As condições atmosféricas e o gelo marinho são os principais fatores que controlam a temperatura e salinidade destas águas (Figura 6). Nas regiões costeiras do OA, as Águas de Plataforma recentemente ventiladas podem ser diferenciadas pelos seus valores de salinidade. A HSSW e a ISW, com salinidades variando entre 34,56-34,84 e 34,2-34,7, respectivamente, são as principais Águas de Plataforma que contribuem para a formação de massas de água densas na região sudoeste do Mar de 
Weddell (FOSTER e CARMACK, 1976a; ROBERTSON et al., 2002).

As camadas intermediárias e profundas são formadas pela Água Profunda Cálida (WDW), Água Profunda do Mar de Weddell (WSDW), e Água de Fundo do Mar de Weddell (WSBW) (Figura 6). A WDW é outra importante massa de água que contribui com a formação de águas profundas no Mar de Weddell. Segundo Fahrbach et al. (1994a) a porção mais sudeste do Mar de Weddell possui uma pequena contribuição na formação da WDW em virtude de a plataforma continental nesta região ser estreita o suficiente para permitir que esta massa de água alcance as plataformas de gelo, impedindo assim a formação de águas profundas mais densas e salinas. Portanto, acredita-se que estas fontes de águas profundas se localizam muito provavelmente na margem continental da porção ocidental do MW, em virtude desta região ser dominada por uma corrente fortemente barotrópica, presa pelas condições de contorno existentes à noroeste do mar.

Nas margens ocidentais da Bacia de Weddell citadas acima, as águas precursoras da AABW, WSDW e WSBW, são produzidas pela interação entre águas mais quentes de profundidades medianas e superficiais com diferentes águas de plataforma. Especificamente para a formação da WSDW, a HSSW se mistura com a WDW (com $\theta>0^{\circ} \mathrm{C}$, advectada para dentro da Bacia de Weddell da ACC) e a Água de Inverno (WW; uma remanescente da camada de mistura do inverno). Este processo é frequentemente referenciado como o processo de Foster-Carmack (FOSTER e CARMACK, 1976b).

A WSBW é formada pela interação da CDW com a Plataforma de Gelo FilchnerRonne (FRIS). Baseado em observações realizadas na região frontal da FRIS, Foldvik et al. (2004) descreve que plumas de ISW fluem em sentido norte para fora da Depressão de Filchner por meio de diversos caminhos até o fundo da Bacia de Weddell, ou seguindo o talude continental de oeste. Usando dados de correntômetros eles estimaram um fluxo de água mais fria $\left(\theta<-1,9^{\circ} \mathrm{C}\right)$ para fora da depressão de $1,6 \pm 0,5 \mathrm{~Sv}\left(1 \mathrm{~Sv}=10^{6} \mathrm{~m}^{3} / \mathrm{s}\right)$. Devido ao entranhamento da água adjacente, eles deduziram a taxa de formação da WSBW de $4,3 \pm 1,4 \operatorname{Sv}\left(\theta<-0,8^{\circ} \mathrm{C}\right)$.

Segundo Huhn et al. (2008), ainda está sob consideração a capacidade das plataformas de gelo ocidentais ao longo da Península Antártica, particularmente a Plataforma de Gelo Larsen (LIS), em contribuir com a formação da WSBW. Fahrbach et al. (1995) 
reporta a formação da WSBW pela mistura com águas de fundo com um fluxo proveniente da plataforma em frente à LIS. Weppernig et al. (1996) encontrou evidência de que esta água contém frações significantes de ISW, possivelmente originada da LIS. Por fim, Mensch et al. (1998) calculou uma formação total de WSDW e WSBW $\left(\theta<0^{\circ} \mathrm{C}\right)$ de 5 Sv, originadas da porção ocidental do MW.

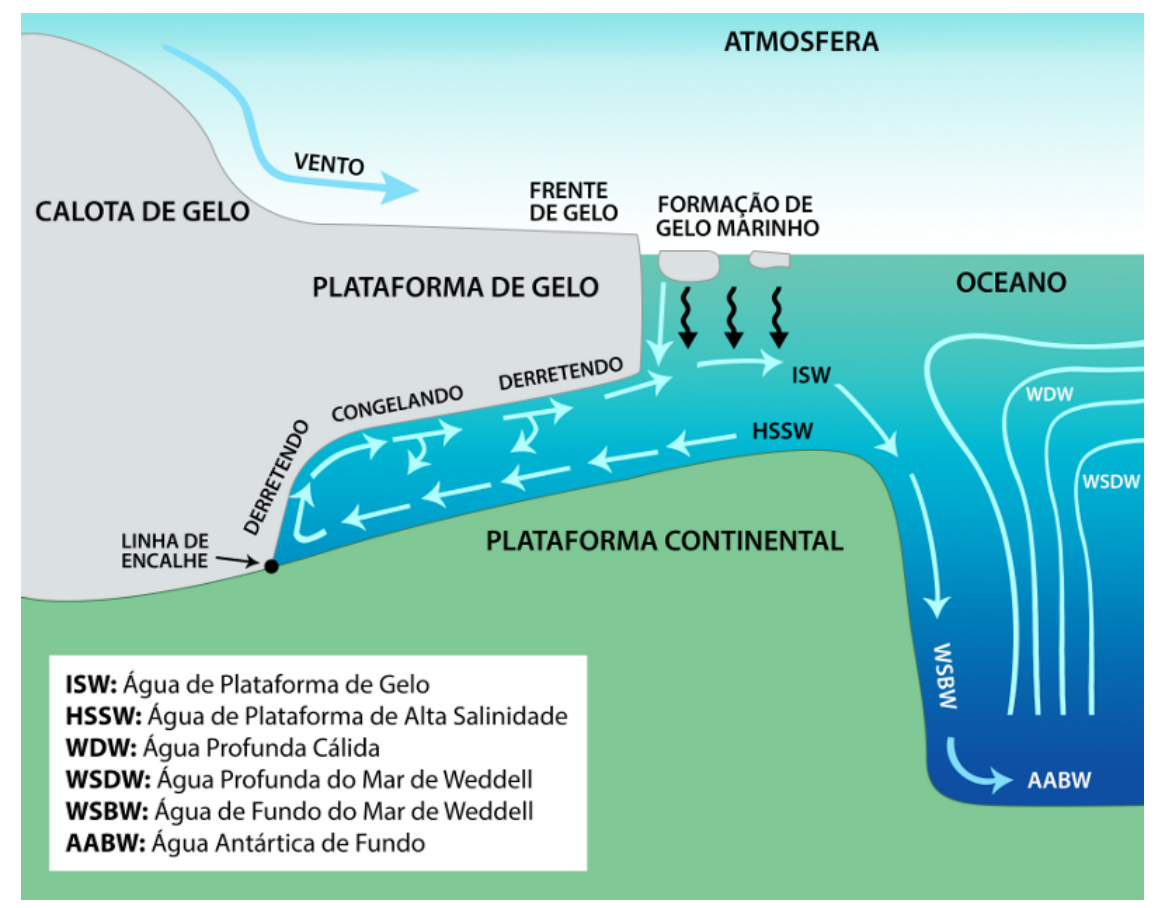

Figura 6: Diagrama esquemático representando a formação, transformação e circulação das massas de água no Mar de Weddell (Modificado de Østerhus (2005)). 


\section{Material e Métodos}

\subsection{Dados}

\subsubsection{Simple Ocean Data Assimilation}

Os dados que foram utilizados neste trabalho fazem parte do conjunto de reanálise SODA (Simple Ocean Data Assimilation), versão 2.1.6. O produto da reanálise utiliza assimilação de dados em um modelo numérico oceânico baseado no Parallel Ocean Program 2.1 (POP) (SMITH e GENT, 2002). Este modelo possui 900 X 600 pontos de grade com uma resolução horizontal média de $0,255^{\circ} \mathrm{X} 0,405^{\circ}$. Sua resolução vertical é de 10 metros nas regiões superficiais, com um total de 40 níveis verticais. O esquema de assimilação é descrito detalhadamente por Carton e Cao (2000); Carton e Cao (2000b). Do total de dados observados de sub-superfície de temperatura e salinidade assimilados pelo modelo, aproximadante dois terços, foram obtidos do banco de dados do $\mathrm{Na}$ tional Oceanographic Data Center, mais precisamente do conjunto World Ocean Database 2001 (WOD2001) (CONKRIGH et al., 2002). Além disso, são assimilados também dados de perfis de temperatura em tempo real do National Oceanographic Data Center (NODC)/National Oceanic and Atmosphere Administration (NOAA), obtidos através de bóias, fundeios e derivadores Argo. Observações in situ do conjunto Comprehensive Ocean-Atmosphere Data Set (COADS) e estimativas do satélite AVHRR NOAA/National Aeronautics and Space Administration (NASA) também fazem parte do banco de dados de superfície (CARTON e CAO, 2000; CARTON e CAO, 2000b; CARTON e GIESE, 2008; DIAZ et al., 2002; VASQUEZ et al., 1998).

Os dados desta última versão do SODA encontram-se disponíveis para acesso à comunidade científica no endereço eletrônico soda . tamu . edu. Eles estão na forma de médias mensais, cobrindo um período de 137 anos entre os anos de 1871 e 2008, mapeados em uma grade uniforme de $0,5^{\circ}$ x $0,5^{\circ}$ em 40 níveis de profundidade. A avaliação deste conjunto de dados e a comparação com observações independentes podem ser encontradas em (CARTON e GIESE, 2006; CARTON e GIESE, 2008; FERRERO e WAINER, 2008). 
Estes dados são disponibilizados no formato $\operatorname{NetCDF(Network~Common~Data~}$ Form). Foi realizado um pré-processamento para o cálculo das médias, bem como para a seleção das variáveis de interesse e definição dos campos e seções a serem analisados. Este pré-processamento teve início com a definição e corte dos dados para a área total dos Mares de Ross (MR) e Weddell (MW). Após esta definição da área, foram escolhidas duas radiais tanto para o MR quanto para o MR que melhor representariam a variabilidade das massas de água dos mares. Os limites delimitando ambos os mares e as radiais escolhidas serão descritas nas seções 4.3.1 e 4.3.2 deste trabalho. Toda a separação dos campos e seções foi realizada com o auxílio do aplicativo Ferret (NOAA).

Médias anuais e, por consequencia, médias decadais foram calculadas (Equação 1) utilizando o Climate Data Operators 1.4.1 (CDO), seguido pela análise visual com o NetCDF Data Viewer 1.93g (NCVIEW). Além das médias decadais foram também calculadas médias para todo o período (1871 a 2008), tanto para o MR quanto para o MW, a fim de se determinar a distribuição climatológica média dessas massas de água. Após uma análise preliminar das distribuições decadais, optou-se por realizar cálculos de distribuições médias para três períodos de 25 anos (1925 a 1949; 1950 a 1974 e 1975 a 1999).

$$
\bar{X}=\sum_{i=1}^{n} \frac{X_{i}}{n}=\frac{i=1}{n} \sum_{i=1}^{n} X_{i}
$$




\subsection{Análise Multiparamétrica Ótima (AMO)}

A técnica escolhida para análise da variabilidade das massas de água foi introduzida por Tomczak (1981) e é denominada de Análise Multiparamétrica Ótima (AMO). Sua proposta inicial foi de expandir a análise clássica de triângulos de mistura entre massas de água através do diagrama TS. Posteriormente, foram realizadas diversas alterações no método proposto com a finalidade de trazer melhorias, até que Tomczak e Large (1989) introduziram o termo Ánalise Multiparamétrica Ótima (Optimum Multiparameter Analysis OMP). O método consiste, basicamente, na utilização de parâmetros conservativos, como temperatura e salinidade, e diversos parâmetros não-conservativos, como oxigênio dissolvido e nutrientes, como uma solução para um sistema de equações lineares de mistura (Equação 3). Além disso, outros parâmetros consideraros conservativos, tais como vorticidade potencial, CFC e isótopos de $\mathrm{O}_{2}$ também podem ser utilizados como traçadores de massas de água (TOMCZAK e LARGE, 1989; TOMCZAK et al., 1994; TOMCZAK, 1999a).

Como pode ser visto em Tomczak e Large (1989), Hinrichsen e Tomczak (1993) e em You e Tomczak (1993), a AMO tem sido aplicada com sucesso em situações de mistura e circulação oceânica regional, onde todas as características hidrográficas podem ser consideradas conservativas. Mas, para que este método pudesse ser aplicado em grandes escalas oceânicas, onde o oxigênio e nutrientes não podem ser considerados como propriedades conservativas, foram incluídas, por Karstensen e Tomczak (1997) e Karstensen e Tomczak (1998), as razões de Redfield para a correção dos termos não-conservativos (REDFIELD et al., 1963).

A AMO baseia-se na suposição de que os processos de mistura que envolvem as massas de água são processos lineares que afetam todos os parâmetros igualmente. Desta forma, cada amostra apresenta características físicas e químicas que são, na verdade, o resultado da mistura entre os vários tipos de água de diferentes fontes (Source Water Type - SWT; (BUDILLON et al., 2003)).

De acordo com Tomczak (1999a), podemos definir uma massa de água como um volume de água que sofre influência atmosférica durante um determinado intervalo de tempo, sendo originada em uma região específica do oceano, possuindo, portanto, as 
características de formação comum. Segundo Poole e Tomczak (1999), a análise AMO tenta determinar a contribuição na amostra de um tipo de agua pré-definido, que representa valores dos parâmetros de uma massa de água original sem mistura. Esta análise estima o melhor conjunto de contribuições entre todas os tipos de água para cada amostra, e permite que as distribuições espacial e estrutural das massas de água possam ser avaliadas. Existem apenas duas restrições físicas para o emprego do método: a primeira é que a contribuição de todas os tipos de água tem que ser igual a 100\%, ou seja, considera-se a manutenção da continuidade e a conservação da massa; a segunda é que esta contribuição não pode ser negativa.

\subsection{Descrição do método}

A base do método da AMO pode ser resumida na expressão abaixo:

$$
G x=B+R
$$

Nesta equação, os parâmetros dos tipos de água são representados pela matriz $G$; já a contribuição dos tipos de água é representada pelo vetor $x$, que nada mais é do que o resultado da AMO; as características observadas são representadas pelo vetor $B$; e $R$ é o vetor que representa os resíduos. Por exemplo, se tomarmos como exemplo uma região da Plataforma Continental Brasileira, onde podem ser observadas três principais águas tipos, e nesta região foi obtido um conjunto de dados observacionais correspondentes à propriedades de massa de água, tais como temperatura, salinidade, oxigênio, fostafo, nitrato e silicato, teremos a seguinte notação só que agora em formato matricial: 


$$
\left[\begin{array}{ccccc}
\theta_{1} & \theta_{2} & \theta_{3} & \theta_{4} & 0 \\
S_{1} & S_{2} & S_{3} & S_{4} & 0 \\
O_{1} & O_{2} & O_{3} & O_{4} & -r O / P \\
P_{1} & P_{2} & P_{3} & P_{4} & 1 \\
N_{1} & N_{2} & N_{3} & N_{4} & r N / P \\
S i_{1} & S i_{2} & S i_{3} & S i_{4} & r S i / P \\
1 & 1 & 1 & 1 & 0
\end{array}\right]\left[\begin{array}{c}
x_{1} \\
x_{2} \\
x_{3} \\
x_{4} \\
\Delta P
\end{array}\right]=\left[\begin{array}{c}
\theta_{\text {Obs }} \\
S_{\text {Obs }} \\
O_{O b s} \\
P_{\text {Obs }} \\
N_{\text {Obs }} \\
S i_{\text {Obs }} \\
1
\end{array}\right]+\left[\begin{array}{c}
R_{\theta} \\
R_{S} \\
R_{O} \\
R_{P} \\
R_{N} \\
R_{S i} \\
R_{C M a s s}
\end{array}\right]
$$

Na Equação 3 os termos $-r O / P, r N / P, r S i / P$ indicam as relações de Redfield, respectivamente, entre oxigênio, nitrato e silicato versus fosfato, e $\Delta \mathrm{P}$ corresponde a mudança de concentração do fostato devido à reatividade biogeoquímica. Também é interessante pontuar que os valores com os índices $\theta_{i}, S_{i}, O_{i}, P_{i}, N_{i}$ e $S i_{i}(i=1, \ldots 4)$ representam os parâmetros pré-determinados conhecidos dos, por exemplo, quatro tipos de água. Além disso, podem ser observados na última linha da matriz $G$ os valores de conservação de massa.

Alguns parâmetros da Equação 3 são difíceis de medir e possuem uma acurácia analítica ou instrumental muito baixa; outros podem variar mais com o tempo e espaço do que outros e podem, além disso, estar associados com uma alta variabilidade ambiental. Portanto, para considerar estas diferenças entre os parâmetros, os mesmos devem possuir pesos diferentes.

Tomczak e Large (1989) obtiveram os pesos relatando a variância de cada parâmetro na matriz $G\left(\sigma_{i}^{2}\right)$ com a medida de um fator externo à matriz $\mathrm{G}$ : a maior variância obtida na região fonte $\left(d_{i(\max )}\right)$. Ou seja, para cada região fonte foi calculada a maior variância para cada parâmetro (i) devido à variabilidade temporal e ambiental, obtendo, portanto a matriz diagonal $W$ contendo os pesos, dada por:

$$
W_{i}=\frac{\sigma_{i}^{2}}{\delta_{i(\max )}}
$$

Para este trabalho, os pesos utilizados tanto para o MR e MW encontram-se nas 
Tabelas 1]e 2, respectivamente.

A AMO assume que as informações obtidas para cada parâmetro são de mesma qualidade, entretanto, isto raramente é obtido em oceanografia. Desta forma a AMO soluciona a Equação 3 através do método do quadrado de resíduos, base do método dos mínimos quadrados, aplicando uma versão normalizada de $G$ por meio da introdução da matriz diagonal $W$, chegando na equação abaixo:

$$
R^{T} R=(G x-B)^{T} W^{T} W(G x-B)=\sum_{i=1}^{m} W_{i}^{2}\left(\sum_{i=1}^{n} G_{i} x_{j}-B_{i}\right)^{2}
$$

Assim, tendo o valor deste erro ao quadrado $\left(R^{T} R\right)$ é possível determinar uma solução para o vetor $x$ que pode ser positivo ou negativo. Sabendo que a AMO não aceita contribuições negativas dos tipos de água fonte predefinidos, é então necessária uma restrição nos percentuais de valores negativos.

A razão de Redfield foi incorporada na AMO para considerar o comportamento não conservativo do oxigênio e dos nutrientes. Esta razão foi introduzida por Redfield et al. (1963) e é relativa ao consumo de oxigênio, na remineralização do fostato e nitrato durante a oxidação de nitritos. Uma vez que estes parâmetros não foram utilizados neste trabalho, também não foi necessária a utilização destes cálculos para a análise da distribuição e variabilidade das massas de água.

Porém, fez-se necessária a utilização da conservação de massa, parâmetro este que a AMO também leva em cosideração. Como a distribuição dos pesos também inclui a conservação de massa, pode-se impor ainda mais os valores dela, aumentando o peso da mesma em relação aos demais parâmetros. Mas, vale ressaltar que a maioria dos estudos, incluindo este presente trabalho, que utilizam a AMO, deixam o peso da conservação de massa igual ao peso da temperatura, que, por sua vez, possui o maior peso da análise (YOU e TOMCZAK, 1993; POOLE e TOMCZAK, 1999; KARSTENSEN e TOMCZAK, 1998). 


\subsubsection{Determinação dos Tipos de Água para o Mar de Ross}

A área do MR foi definida tendo suas latitudes variando de $75^{\circ} \mathrm{S}$ (limite máximo para os dados da renálise) a $55^{\circ} \mathrm{S}$; e longitudes compreendidas entre $160^{\circ} \mathrm{E}$ e $130^{\circ} \mathrm{W}$.

Foram escolhidas duas radiais (R1 e R2 - Figura 7) para uma melhor análise da distribuição de três massas de água, Água Profunda Circumpolar Superior (UCDW), Água Profunda Circumpolar Inferior (LCDW) e Água de Plataforma de Baixa Salinidade (LSSW), através dos dados de salinidade e temperatura. A radial R1 possui orientação meridional, $172,5^{\circ} \mathrm{E}$, e se extende de $55^{\circ}$ a $75^{\circ} \mathrm{S}$. A escolha desta radial se deu, principalmente, por ela atravessar desde a plataforma continental até as bacias mais profundas, abrangendo tanto regiões de escoamento como de formação das massas de água. Já a radial R2, por sua vez, apresenta orientação zonal $\left(73^{\circ} \mathrm{S}\right)$ entre $160^{\circ} \mathrm{E}$ e $130^{\circ} \mathrm{W}$. Esta radial foi escolhida com o intuito de se observar águas capturadas da ACC que circulam sob a plataforma de gelo.

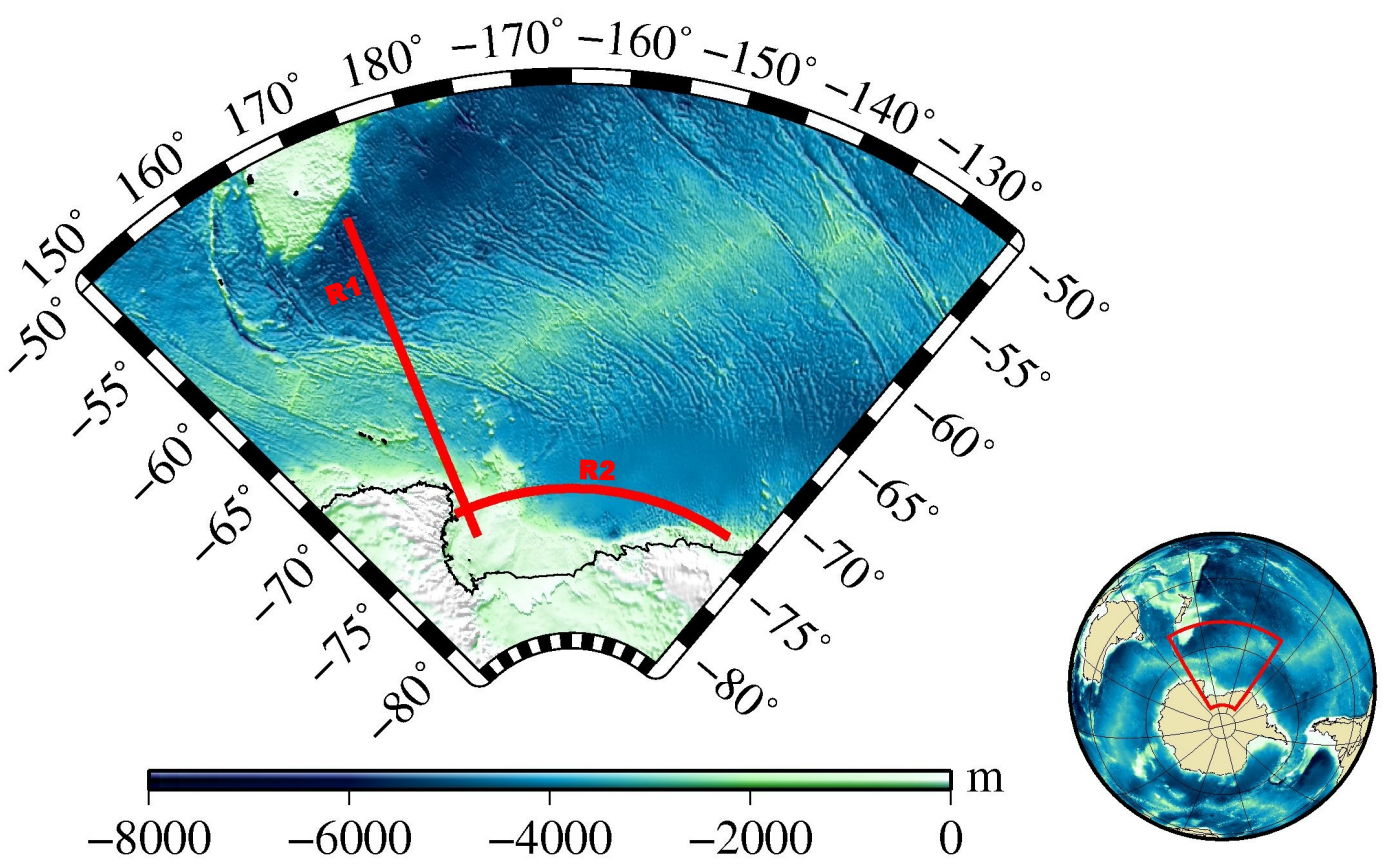

Figura 7: Mapa do Mar de Ross e suas respectivas radiais, R1 e R2.

O primeiro passo foi observar o comportamento dos pares T e S no diagrama TS espalhado (Ver Figura 15), afim de entender a mistura entre a UCDW, LCDW e LSSW. Comparando com trabalhos de Bergamasco et al. (2003); Klinck et al. (2004); Muench 
et al. (2009), Orsi e Wiederwohl (2009), Smith et al. (1999), Tonelli (2009), foi possível determinar a região correspondente de cada massa de água no diagrama. Além disso, para análise inicial da variabilidade das massas de água, foram elaborados dois diagramas TS específicos; um contendo dados de 3 períodos (1925-1949, 1950-1974 e 1975-1999); Figura 16a) e um segundo contendo o registro verticalmente contínuo de 7 décadas (1880, 1900, 1920, 1940, 1960, 1980 e 2000; Figura 16b).

A Tabela 1 apresenta os tipos de água escolhidos e seus respectivos pesos utilizados neste trabalho.

Tabela 1: Tipos de Água e Pesos para o Mar de Ross

\begin{tabular}{ccccc}
\hline & UCDW & LCDW & LSSW & Pesos \\
\hline $\boldsymbol{\theta}$ & 1,4 & 0,5 & $-1,0$ & 10 \\
$\mathbf{S}$ & 34,71 & 34,72 & 34,185 & 5 \\
VP & - & - & - & 0,001 \\
C. Massa & - & - & - & 10 \\
\hline
\end{tabular}

Antes da aplicação da AMO, duas restrições físicas foram impostas para as análises: primeiro, a conservação de massa, que assume que a contribuição de todas as massas de água tem que ser igual a 100\%; e segundo, que a contribuição de cada massa de água em particular não pode ser negativa. Portanto, uma vez que o objetivo do estudo é avaliar não só a representação, mas também a variabilidade das massas de água segundo a reanálise, a AMO foi aplicada primeiramente para o período inteiro dos dados e, posteriormente para três períodos de 25 anos distintos, compreendidos entre 1925 e 1949, 1950 e 1974 e 1975 e 1999, gerando a distribuição das massas de água.

Com o objetivo de aprimorar os resultados das análises de massas de água obtidos e, assim, melhor descrever regionalmente o MR, foram calculadas e plotadas ainda: médias de temperatura e salinidade para cada radial, bem como as anomalias destes parâmetros para os mesmos períodos de 25 anos descritos acima.

Para o cálculo da anomalia, os dados de saída da AMO foram interpolados otimamente em uma grade regular de longitude/latitude e pressão. As diferenças entre a 
contribuição da massa de água de cada período e a contribuição da média climatológica (1871-2008) para a mesma massa de água foram computadas em cada ponto da grade para assim calcular as anomalias das massas de água para cada respectivo período. As anomalias foram então normalizadas com relação ao desvio padrão do campo médio, e só foram calculadas quando o percentual de contribuição de cada massa de água para a mistura fosse maior ou igual a $30 \%$.

Todos os resultados das análises e distribuições poderão ser visualizados na seção 5 deste trabalho. 


\subsubsection{Determinação dos Tipos de Água para o Mar de Weddell}

Assim como para o MR, a área do MW foi definida tendo suas latitudes variando de $75^{\circ} \mathrm{S}$ (limite máximo para os dados da renálise) a $58^{\circ} \mathrm{S}$; e longitudes compreendidas entre $70^{\circ} \mathrm{W}$ e $35^{\circ} \mathrm{E}$.

Foram escolhidas duas radiais (W1 e W2 - Figura 8) para uma melhor análise da distribuição de três massas de água, Água Profunda Cálida (WDW), Água Profunda do Mar de Weddell (WSDW) e Água de Fundo do Mar de Weddell (WSBW), através dos dados de salinidade e temperatura. A radial W2 possui orientação meridional, e se extende de $63^{\circ}$ a $71^{\circ} \mathrm{S}$. A escolha desta radial se deu, principalmente, por ela atravessar desde a plataforma continental até as bacias mais profundas, abrangendo tanto regiões de escoamento como de formação das massas de água. Já a radial W1, por sua vez, apresenta orientação zonal $\left(65^{\circ} \mathrm{S}\right)$ entre $60^{\circ} \mathrm{W}$ e $15^{\circ} \mathrm{W}$. Esta radial foi escolhida com o intuito de poder se observar toda a região de entrada e saída de massas de água, pegando boa parte do Giro de Weddell.

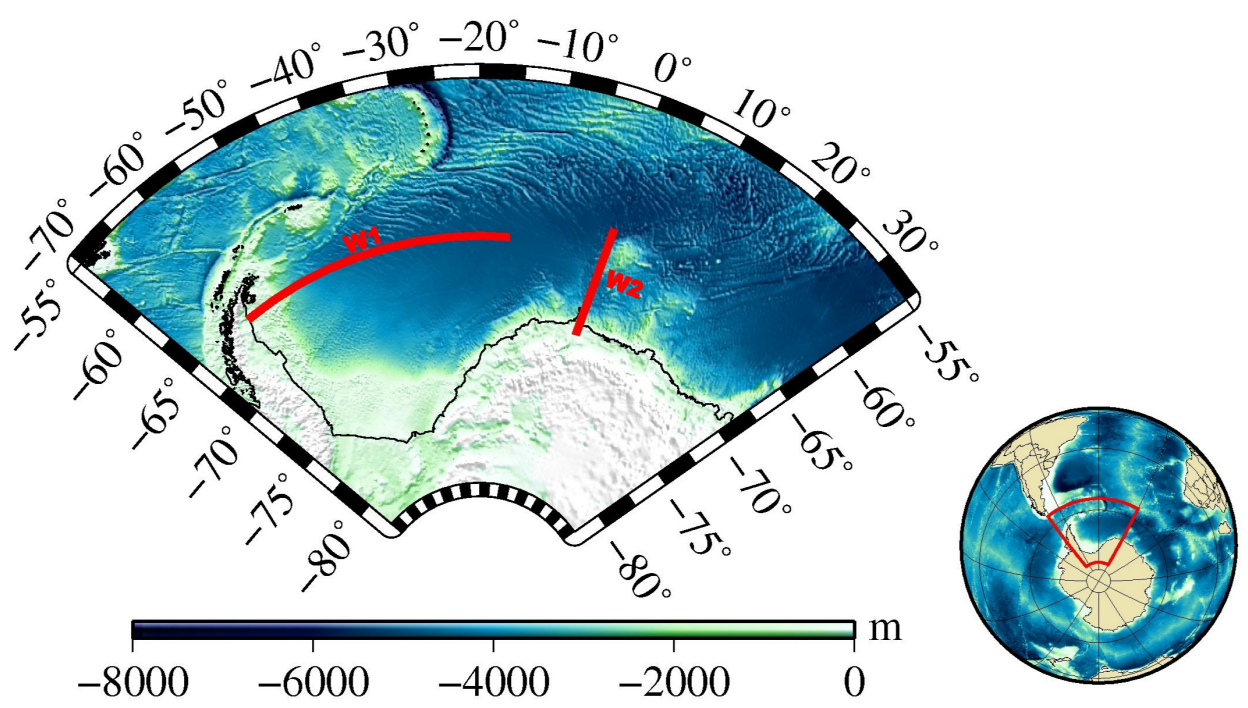

Figura 8: Mapa do Mar de Weddell e suas respectivas radiais, W1 e W2.

O primeiro passo foi observar o comportamento dos pares T e S no diagrama TS espalhado (Ver Figura 39), afim de entender a mistura entre a WDW, WSDW e WSBW. Comparando com trabalhos de Absy et al. (2008); Huhn et al. (2008); Kerr et al. (2009a); Kerr et al. (2009b); Kerr et al. (2012a); Kerr et al. (2012b), foi possível determinar a 
região correspondente de cada massa de água no diagrama. Além disso, para análise inicial da variabilidade das massas de água, foram elaborados dois diagramas TS específicos; um contendo dados de 3 períodos (1925-1949, 1950-1974 e 1975-1999); Figura 40a) e um segundo contendo o registro verticalmente contínuo de 7 décadas $(1880,1900,1920$, 1940, 1960, 1980 e 2000; Figura 40p).

A Tabela 2 apresenta os tipos de água escolhidos e seus respectivos pesos utilizados neste trabalho.

Tabela 2: Tipos de Água e Pesos o Mar de Weddell

\begin{tabular}{ccccc}
\hline & WDW & WSDW & WSBW & Pesos \\
\hline $\boldsymbol{\theta}$ & 0,45 & $-0,25$ & $-0,7$ & 11,5 \\
$\mathbf{S}$ & 34,68 & 34,66 & 34,64 & 11,5 \\
VP & - & - & - & 0,001 \\
C. Massa & - & - & - & 11,9 \\
\hline
\end{tabular}

Assim como na análise do MR, antes da utilização da AMO, duas restrições físicas foram impostas para as análises no MW: primeiro, a conservação de massa, que assume que a contribuição de todas as massas de água tem que ser igual a 100\%; e segundo, que a contribuição de cada massa de água em particular não pode ser negativa. Portanto, uma vez que o objetivo do estudo é avaliar não só a representação, mas também a variabilidade das massas de água segundo a reanálise, a AMO foi aplicada primeiramente para o período inteiro dos dados e, posteriormente para três períodos de 25 anos distintos, compreendidos entre 1925 e 1949, 1950 e 1974 e 1975 e 1999, gerando a distribuição das massas de água.

Com o objetivo de aprimorar os resultados das análises de massas de água obtidos e, assim, melhor descrever regionalmente o MW, foram calculadas e plotadas ainda: médias de temperatura e salinidade para cada radial, bem como as anomalias destes parâmetros para os mesmos períodos de 25 anos descritos acima.

Para o cálculo da anomalia, os dados de saída da AMO foram interpolados otimamente em uma grade regular de longitude/latitude e pressão. As diferenças entre a 
contribuição da massa de água de cada período e a contribuição da média climatológica (1871-2008) para a mesma massa de água foram computadas em cada ponto da grade para assim calcular as anomalias das massas de água para cada respectivo período. As anomalias foram então normalizadas com relação ao desvio padrão do campo médio, e só foram calculadas quando o percentual de contribuição de cada massa de água para a mistura fosse maior ou igual a $30 \%$.

Todos os resultados das análises e distribuições poderão ser visualizados na seção 5 deste trabalho. 


\section{Resultados e Discussão}

\subsection{Mar de Ross}

\subsubsection{Seções de Temperatura}

A Figura 9a exibe a seção vertical de temperatura da radial R1. A plataforma continental interior é marcada por um núcleo de águas mais frias (temperaturas inferiores à $-1^{\circ} \mathrm{C}$ ) penetrando pela porção mais ao Sul da seção, atingindo os $500 \mathrm{~m}$ de profundidade entre as latitudes 75 à $72^{\circ} \mathrm{S}$. Este núcleo tende a permanecer nas camadas mais superficiais (até $200 \mathrm{~m}$ ) ocupando até a latitude de $70^{\circ} \mathrm{S}$ e a partir daí até a latitude de $63^{\circ} \mathrm{S}$, ocupando apenas os 100 primeiros metros da coluna d'água. Vale ressaltar que este núcleo, comparado com o primeiro destacado acima, possui temperaturas um pouco mais elevadas oscilando entre $-0,5$ e $0^{\circ} \mathrm{C}$.

Este mesmo núcleo de águas mais frias descrito acima também pode ser observado na Figura 9p, confirmando a presença de águas frias sobre a plataforma (porção mais oeste da seção). Diferentemente da seção R1 ( Figura 9a), este núcleo ocupa a região superficial (até 100m) da seção inteira. Ambos núcleos de águas frias observados tanto na radial R1 como na radial R2 são responsáveis diretamente pela formação da LSSW, caracterizada pela presença de águas mais frias e salinas (ASSMANN et al., 2003; BUDILLON et al., 2003; SMETHIE e JACOBS, 2005; TONELLI, 2009).

Também é possível notar o aprisionamento de um núcleo de águas mais quentes (temperaturas superiores à $0^{\circ} \mathrm{C}$ ) entre dois núcleos de águas mais frias, permanecendo até a profundidade de $500 \mathrm{~m}$ na altura da longitude de $180^{\circ} \mathrm{W}$. É notável também a entrada de de águas mais quentes (temperaturas superiores à $1^{\circ} \mathrm{C}$ ) subsuperficiais, provenientes da porção Oeste do MR, confirmando a presença da CDW (UCDW e LCDW) nas seções e corroborando com trabalhos pretéritos realizados na região por Carmack (1977); Orsi e Wiederwohl (2009); Pardo et al. (2012); Tonelli (2009); Whitworth e Nowlin (1987). Além disso, é possível a identificação de um gradiente bem definido a partir dos 1500m, com as águas diminuindo sua temperatura à medida que se aproximam do fundo.

As anomalias de temperatura referentes à climatologia média para a radial R1 
mostram que durante o período de 1950 a 1999 (Figuras 10p e 10p) nas águas superficiais (até 500m) os padrões de anomalias são bastante semelhantes, apresentando valores positivos na porção mais ao Sul e Norte e negativos em toda a região central, cobrindo desde a latitude de 70 até $62^{\circ} \mathrm{S}$. Já para o primeiro período analisado, compreendido entre os anos de 1925 e 1949 (Figura [10a) o padrão se inverte, apresentando anomalias negativas nas extremidades, com valores atingindo a - $-0,6$ e anomalias positivas na região central, com valores oscilando entre 0,1 e 0,6. A partir destas observações, pode-ser concluir que realmente houve uma tendência de aquecimento das águas do ano de 1925 para o ano de 1999, pois suas anomalias positivas só tendem a aumentar até o período compreendido entre 1975-1999 (Figura 10k), confirmando também o que é apresentado pela Figura 10d, com aumentos de $\mathrm{T}^{\circ} \mathrm{C}$ observados em toda a coluna d'água no período analisado (1925-1999).

Analisando especificamente a Figura $10 \mathrm{~d}$, que compreende anomalias de $\mathrm{T}^{\circ} \mathrm{C}$ para todo o período, é possível observar o mesmo padrão encontrado entre 1950-1999, porém, em menor intensidade, em virtude de a média geral incluir também o primeiro período, que por sua vez apresenta tendências opostas, assim como descrito acima. Vale destacar um núcleo de águas com anomalias positivas penetrando abaixo dos 1000m pela região norte, núcleo este somente observado neste período analisado.

É possível observar o mesmo padrão de inversão de anomalias na seção R2 (Figura 11). Para os dois últimos períodos analisados e para a anomalia geral (1925-1999), entre $180^{\circ}$ e $130^{\circ} \mathrm{W}$ são apenas observadas anomalias negativas. Já no primeiro período, toda a região da camada superficial compreendida entre $175^{\circ} \mathrm{E}$ até o final da seção é bem demarcada por anomalias positivas, chegando a alcançar valores na ordem de 0,3 . Os resultados da anomalia geral (Figura $11 \mathrm{~d}$ ) corroboram com os resultados obtidos na R1, confirmando a ocorrência de um aquecimento das águas entre os anos de 1925 e 1999 e, mais espeficicamente, da porção oriental da Plataforma de Gelo do MR. 
(a)

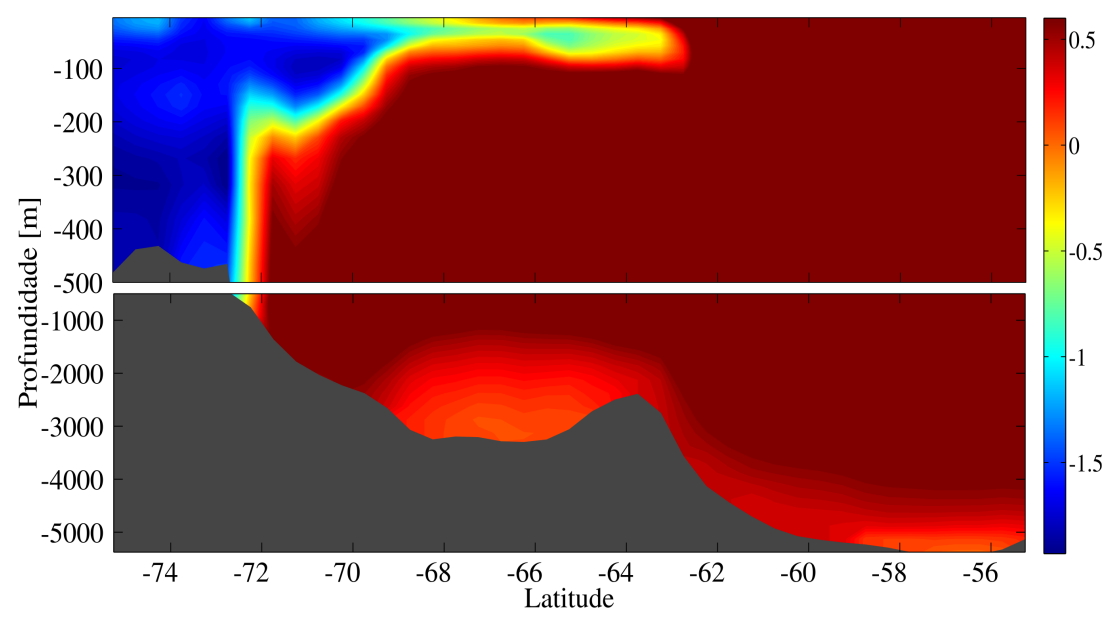

(b)

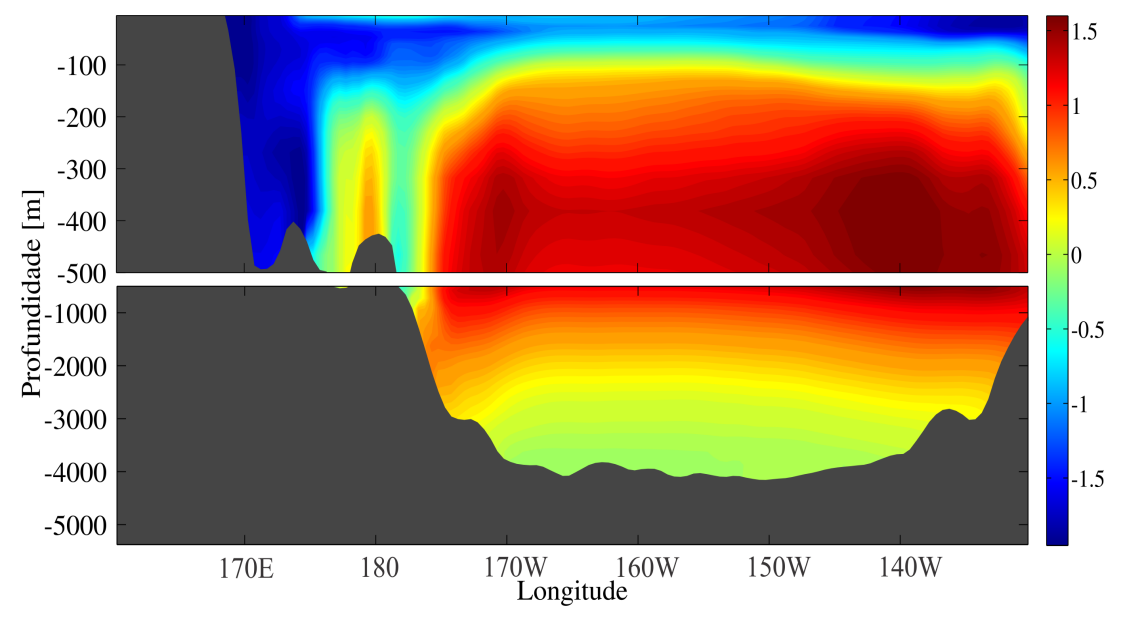

Figura 9: (a) Média climatológica $(1871-2008)$ da temperatura $\left({ }^{\circ} \mathrm{C}\right)$ na radial $\mathrm{R} 1$; (b) Média climatológica (1871-2008) da temperatura $\left({ }^{\circ} \mathrm{C}\right)$ na radial R2 
(a)

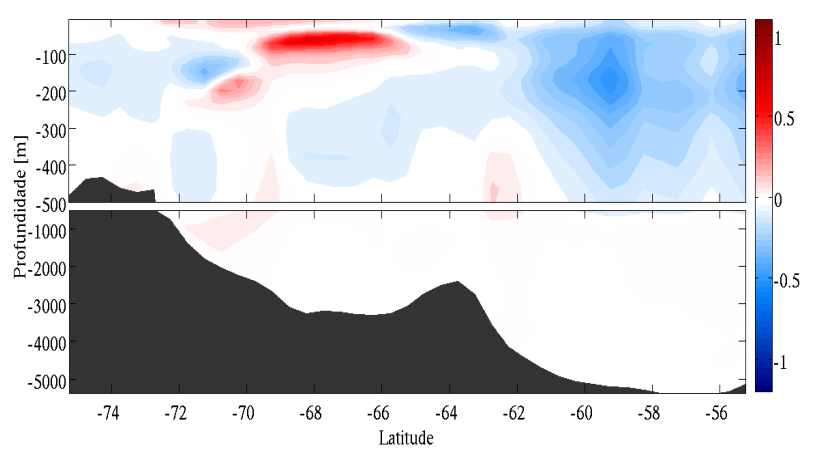

(b)

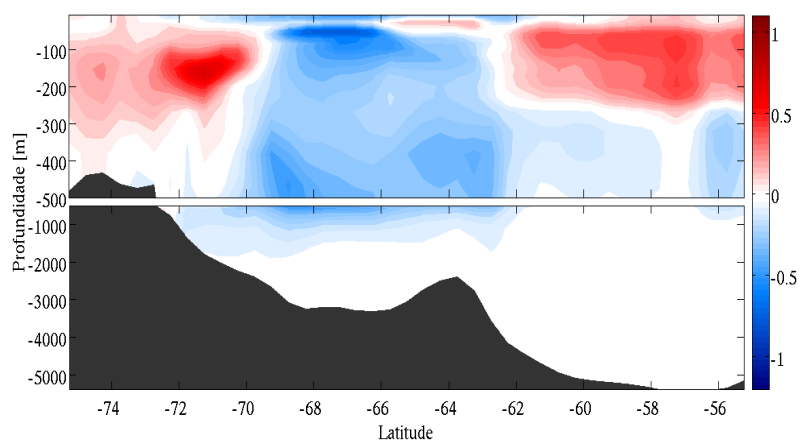

(c)

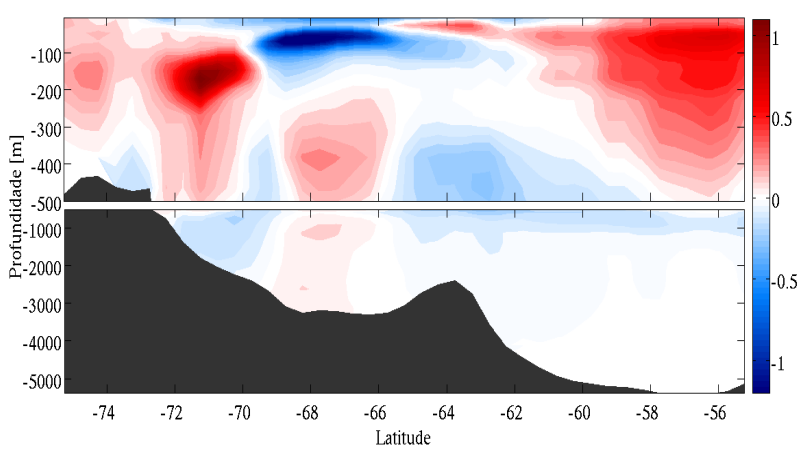

(d)

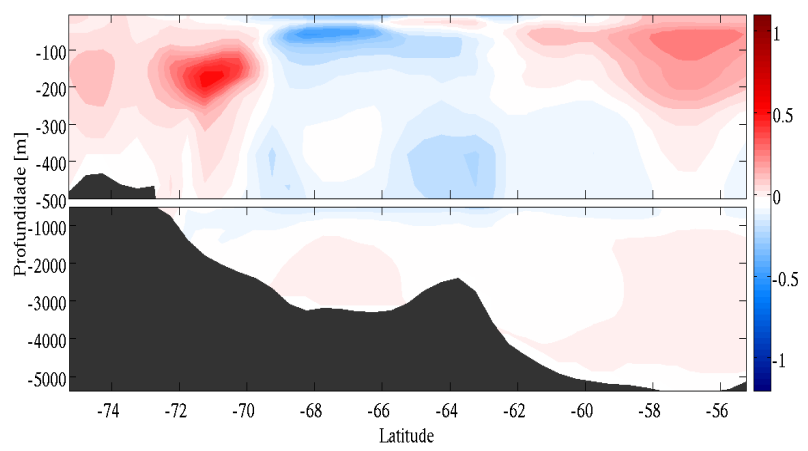

Figura 10: (a) Anomalia de temperatura $\left({ }^{\circ} \mathrm{C}\right)$ na $\mathrm{R} 1$ relativa à média climatológica (18712008) para o período entre 1925 e 1949; (b) 1950-1974; (c) 1975-1999; (d) 1925-1999. 
(a)

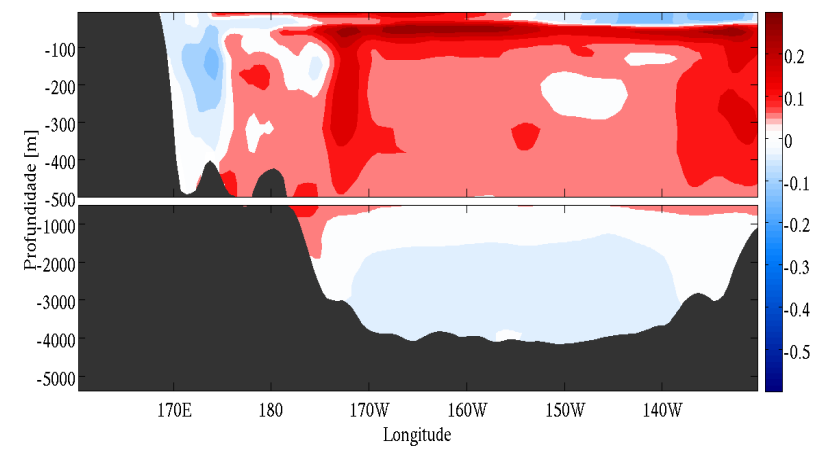

(b)

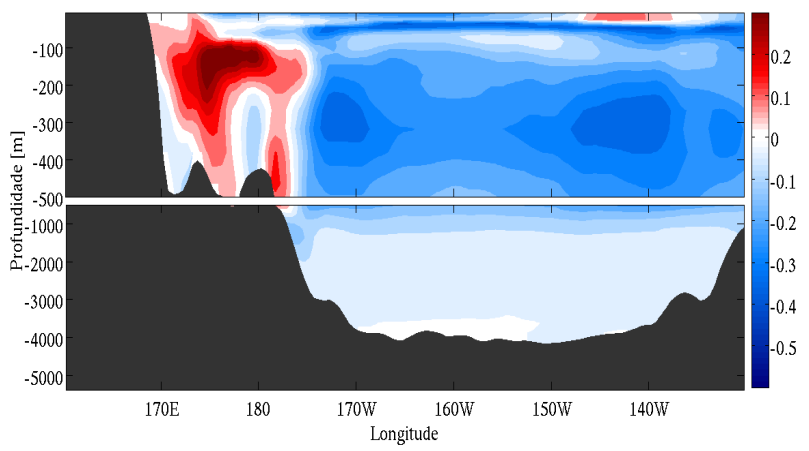

(c)

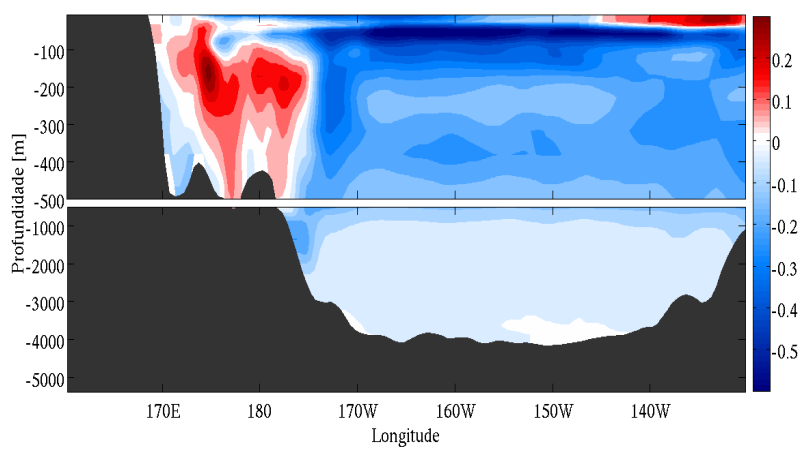

(d)

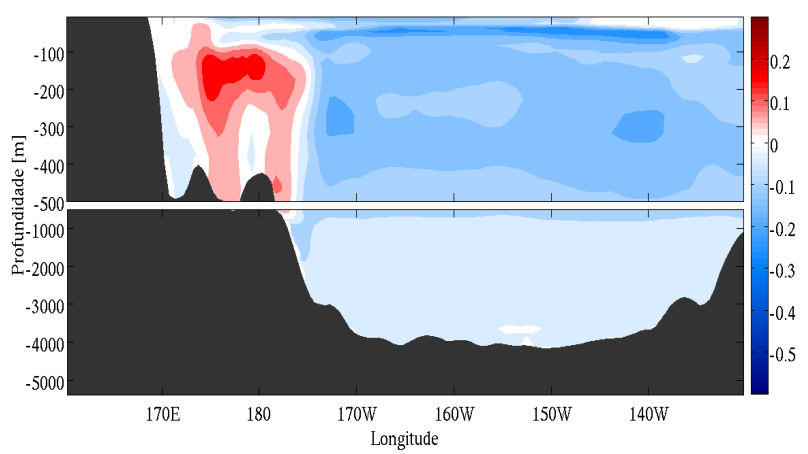

Figura 11: (a) Anomalia de temperatura $\left({ }^{\circ} \mathrm{C}\right)$ na $\mathrm{R} 2$ relativa à média climatológica (18712008) para o período entre 1925 e 1949; (b) 1950-1974; (c) 1975-1999; (d) 1925-1999. 


\subsubsection{Seções de Salinidade}

As seções de salinidade média (Figuras 12 a e $12 \mathrm{~b}$ ) exibem um padrão de estratificação, com águas mais salinas em regiões mais profundas e águas menos salinas ao largo em superfície. Comparando os dois perfis das duas radiais, é possível notar que águas de maiores salinidades da R1 (Figura $12 \mathrm{~g}$ ) atingem menores profundidades (100m) se comparadas às águas de maiores salinidades da R2. Estes altos valores de salinidade da R1 em regiões mais superficiais podem ser observados entre as latitudes de 69 e $66^{\circ} \mathrm{S}$. Vale pontuar duas importantes características observadas na Figura $12 \mathrm{~b}$ : uma região de salinidades bem reduzidas próxima a plataforma Leste, indicando a formação de LSSW no local (ORSI e WIEDERWOHL, 2009); e a topografia influenciando fortemente a distribuição da salinidade em toda a radial.

Com relação aos campos de anomalias de salinidade na radial R1 (Figura 13) é possível observar núcleos de valores negativos em ambos os períodos presentes em toda a coluna d' água, valores estes atingindo um mínimo de $-0.25 \%$. O segundo e terceiro período analisados (Figuras 13b e 13k) apresentam um padrão de anomalias bastante similares, com núcleos positivos penetrando tanto pela marginal mais à Sul da seção quanto pela marginal mais à Norte, ambos em camadas superficiais, atingindo uma profundidade de até 500m. Este padrão não é observado no primeiro período estudado (Figura [13a), que diferentemente dos outros dois, apresenta apenas um único e pequeno núcleo de anomalias positivas em camadas superficiais (até 500m). O quarto e último período analisado apresenta apenas anomalias negativas em toda a coluna d'água, com valores acima de 0,15\%, levando à ocorrência de uma diminuição de salinidade com o passar dos anos nesta seção.

Esta mesma similaridade nos padrões de distribuição de anomalias entre os três últimos períodos é também bem evidenciada na radial R2 (Figuras 14b, 14k e 14d), porém núcleos positivos são observados somente no setor mais à Leste da seção, ocorrendo com maior intensidade entre os anos de 1950-1999 (Figuras 14b e 14c) e menor frequencia no período entre 1925 e 1999, confirmando a tendência de diminuição de salinidade também observada na R1 (Figura 14d). Por sua vez, o primeiro período analisado (Figura 14a) apresenta uma fina camada com anomalias positivas, ocupando somente 
uma camada bem superficial, não atingindo mais que 100m de profundidade, percorrendo toda a porção Oeste da seção. 
(a)

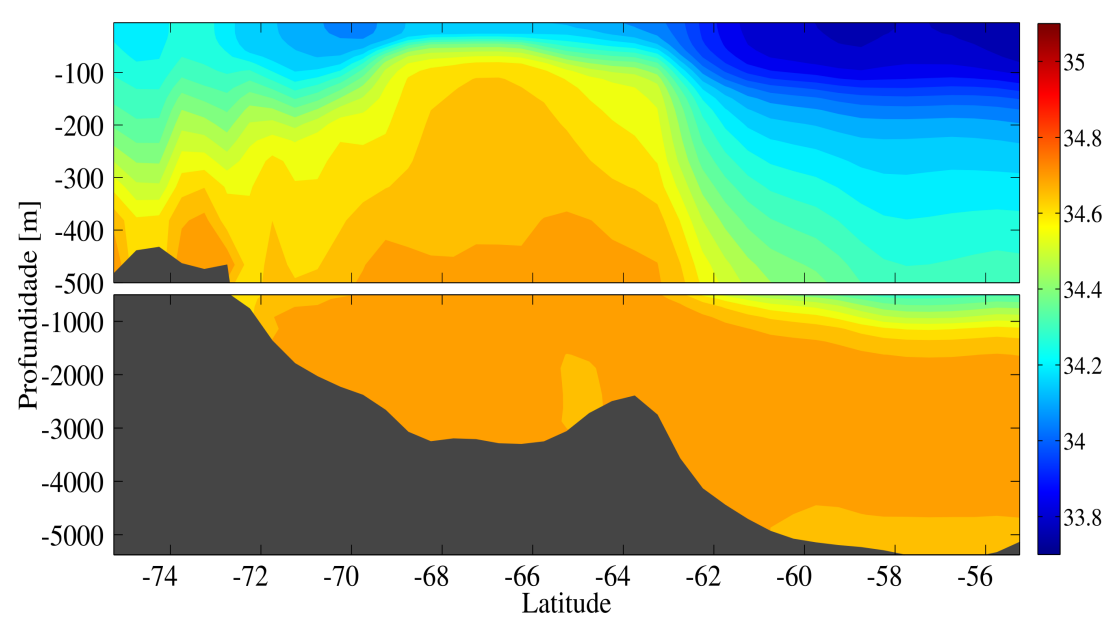

(b)

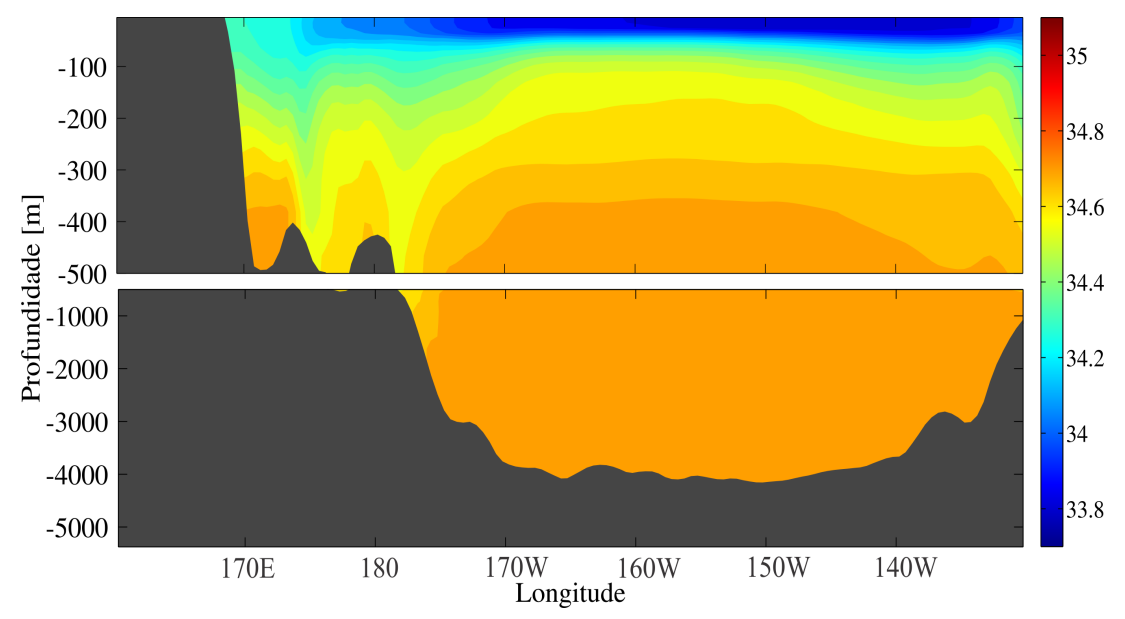

Figura 12: (a) Média climatológica (1871-2008) da salinidade na radial R1; (b) Média climatológica (1871-2008) da salinidade na radial R2 
(a)

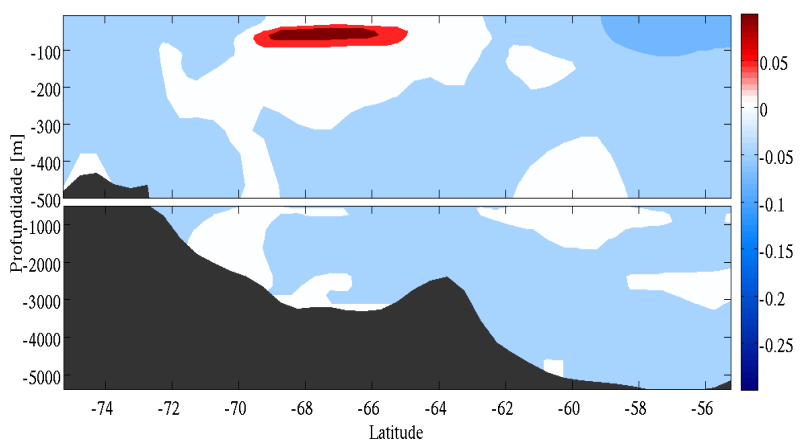

(b)

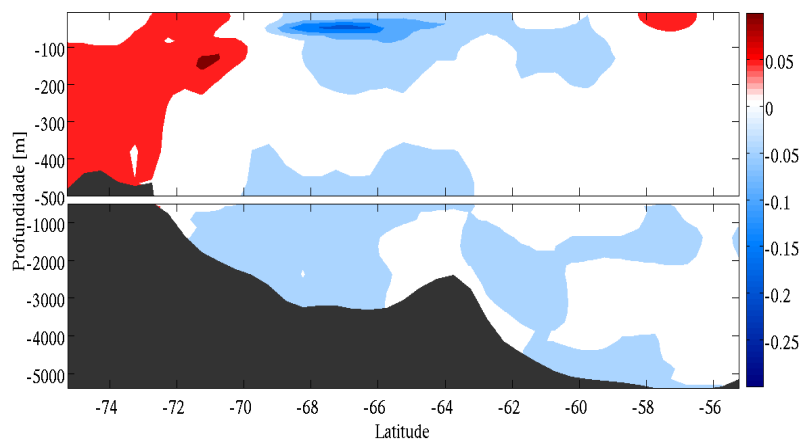

(c)

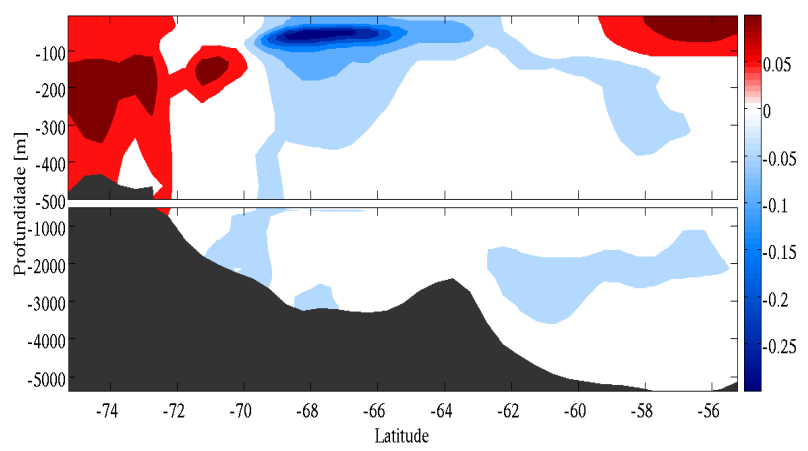

(d)

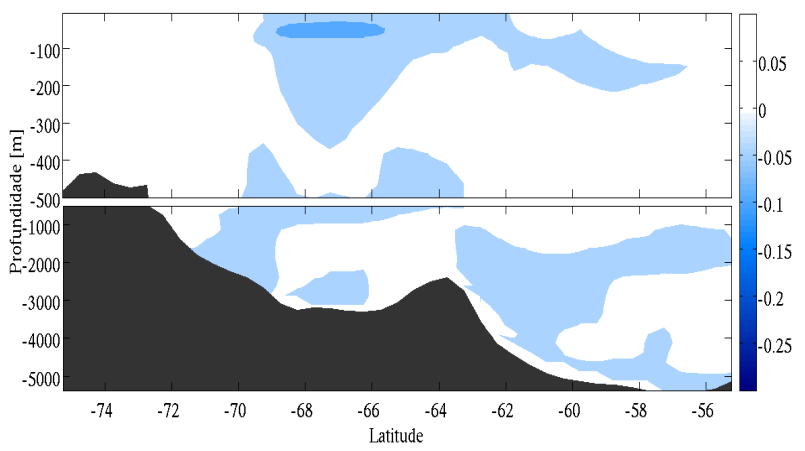

Figura 13: (a) Anomalia de salinidade na R1 relativa à média climatológica (1871-2008) para o período entre 1925 e 1949; (b) 1950-1974; (c) 1975-1999; (d) 1925-1999. 
(a)

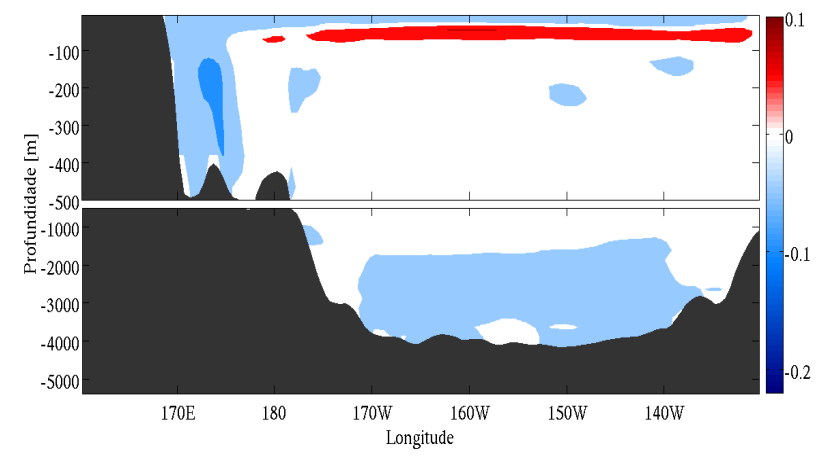

(b)

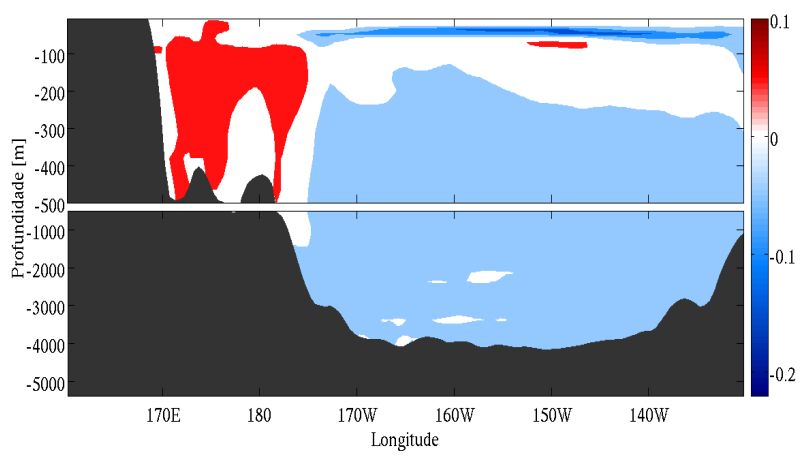

(c)

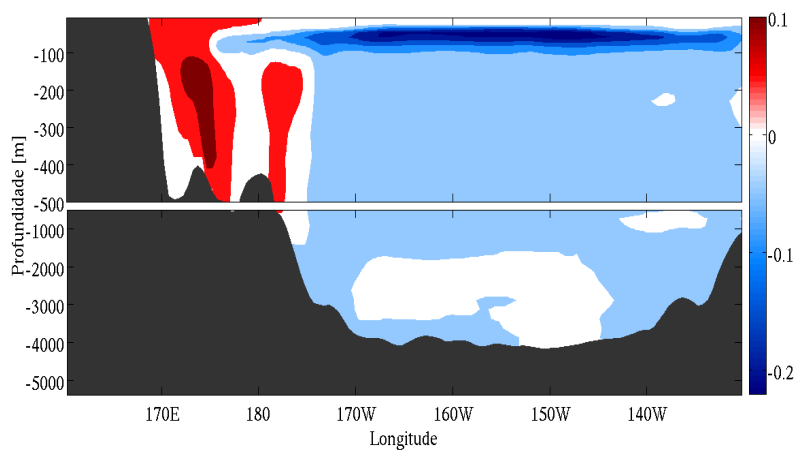

(d)

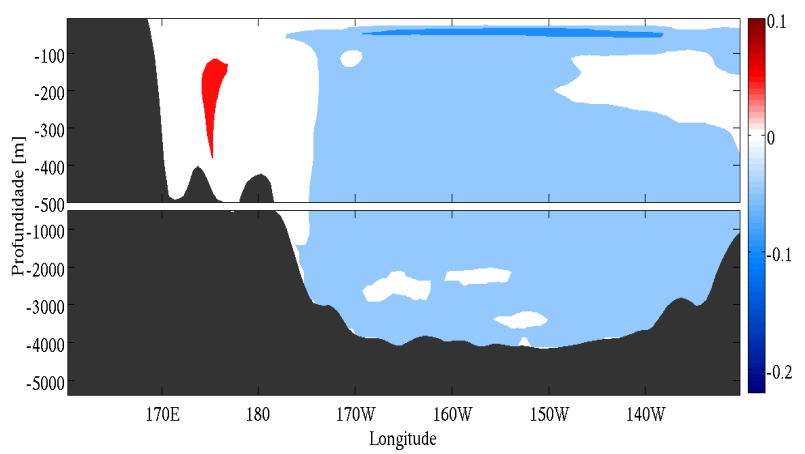

Figura 14: (a) Anomalia de salinidade na R2 relativa à média climatológica (1871-2008) para o período entre 1925 e 1949; (b) 1950-1974; (c) 1975-1999; (d) 1925-1999. 


\subsubsection{Diagramas TS}

O diagrama de temperatura e salinidade (TS) foi construído a partir dos dados da reanálise SODA para a média climatológica entre os anos de 1871 e 2008 do MR, e é apresentadona Figura 15. Primeiramente o diagrama foi comparado à outros de estudos observacionais realizados para mesma região, tais como Bergamasco et al. (2003); Klinck et al. (2004); Muench et al. (2009); Orsi e Wiederwohl (2009); Smith et al. (1999); Tonelli (2009), A partir daí, foram identificadas três principais massas de água, UCDW, LCDW e LSSW, cujos índices termohalinos (Tabela 11) foram considerados na investigação da $\mathrm{AMO}$. Temperaturas de 0,5 à $2^{\circ} \mathrm{C}$ e salinidades de 34,7 encontradas em valores de $\sigma_{0}$ maiores que 27,75 representam a Água Profunda Circumpolar (CDW), que pode ser subdividida em duas variedades, Água Profunda Circumpolar Superior (UCDW) e Água Profunda Circumpolar Inferior (LCDW), o que reflete em diferentes propriedades adquiridas de diferente regiões de formação (SMITH et al., 1999). A região com menor temperatura associada aos baixos valores de salinidade confirma a presença da LSSW, precursora da AASW (ASSMANN et al., 2003). Vale ressaltar que as três águas encontradas neste TS atuam na formação das águas exportadas pelo continente antártico (AASW e AABW).

A Figura 16 exibe o diagrama TS gerado com dados de 3 períodos obtidos a partir da reanálise (1925-1949, 1950-1974 e 1975-1999). Como uma primeira aproximação sobre a variabilidade das massas de água representadas, nota-se que a região ocupada pela LSSW sofreu uma diminuição de temperatura durante o período compreendido entre 1925 e 1949. Neste mesmo período foram observados valores máximos na região da UCDW, atingindo valores de temperatura e salinidade superiores à $1,5^{\circ} \mathrm{C}$ e 34,73 , respectivamente. Já a região ocupada pela LCDW atingiu seus valores máximos de salinidade no período entre os anos de 1975 e 1999.

O diagrama verticalmente contínuo da Figura 16 mostra que a região ocupada pela LSSW sofreu uma diminuição de temperatura durante a década de 2000 , de $0,1^{\circ} \mathrm{C}$ seguida por um aumento de temperatura de $0,8^{\circ} \mathrm{C}$. Já durante a década de 1900 foi observado uma diminuição de $0,2^{\circ} \mathrm{C}$, seguido por um aumento de também $0,8^{\circ} \mathrm{C}$. Vale ressaltar que para esta região os menores valores de temperatura foram ocupados pela década de 
2000, seguidos pelas décadas de 1980, 1960, 1880, 1940, 1920 e 1900 ocupando a região com maiores os valores. Já para a região da CDW, as maiores salinidades foram observadas na década de 1980, e as menores na década de 1960, podendo-se observar então um aumento total de salinidade na ordem de 0,2 . 


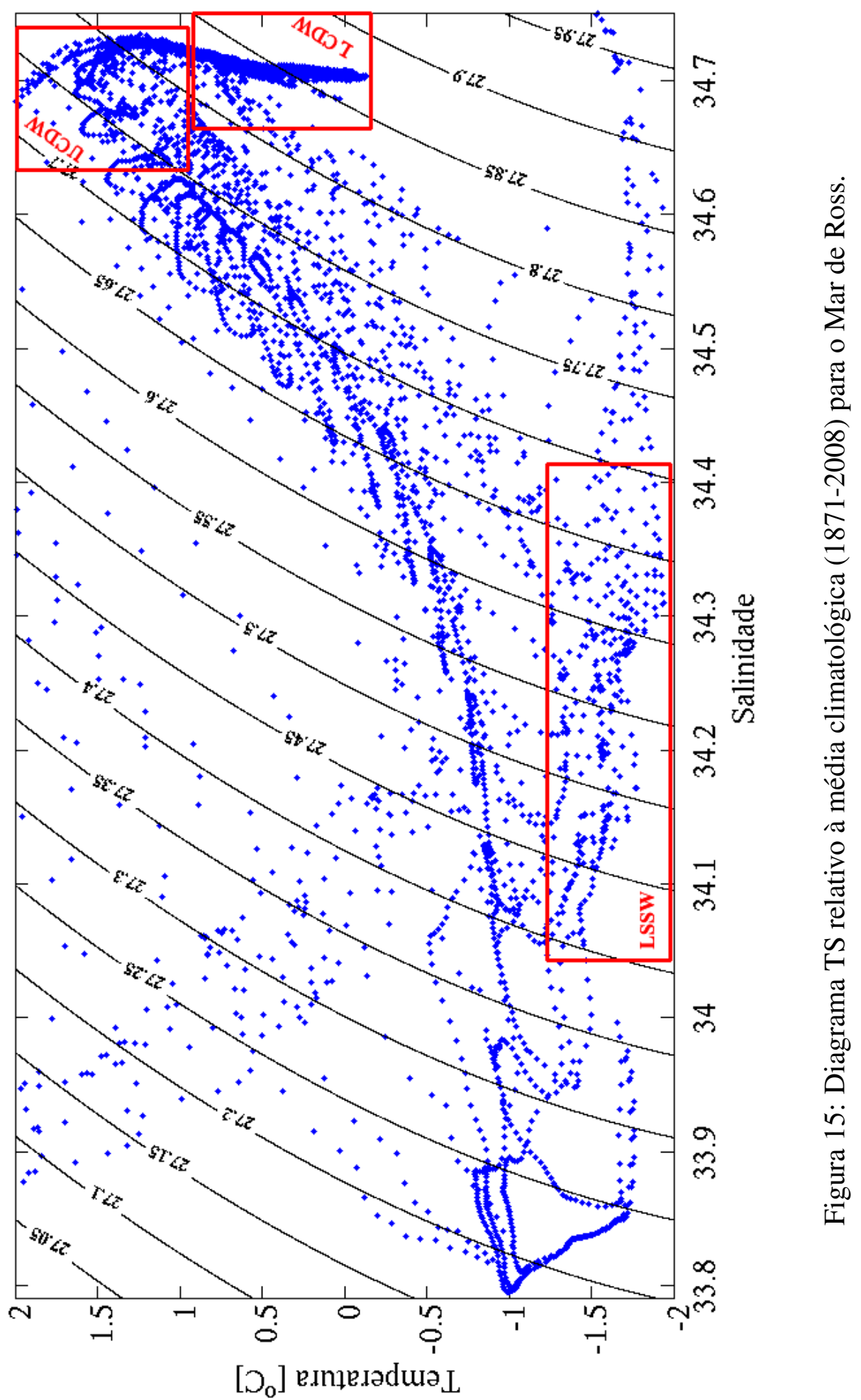


(a)

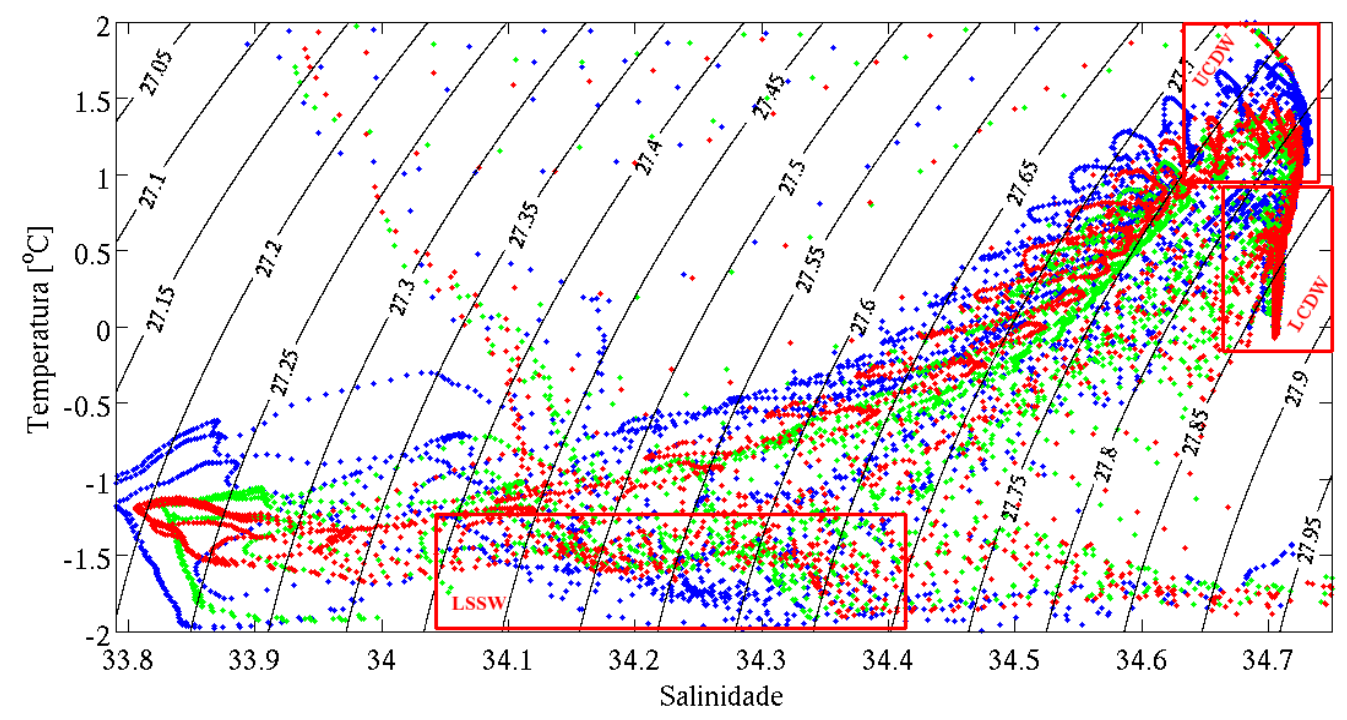

(b)

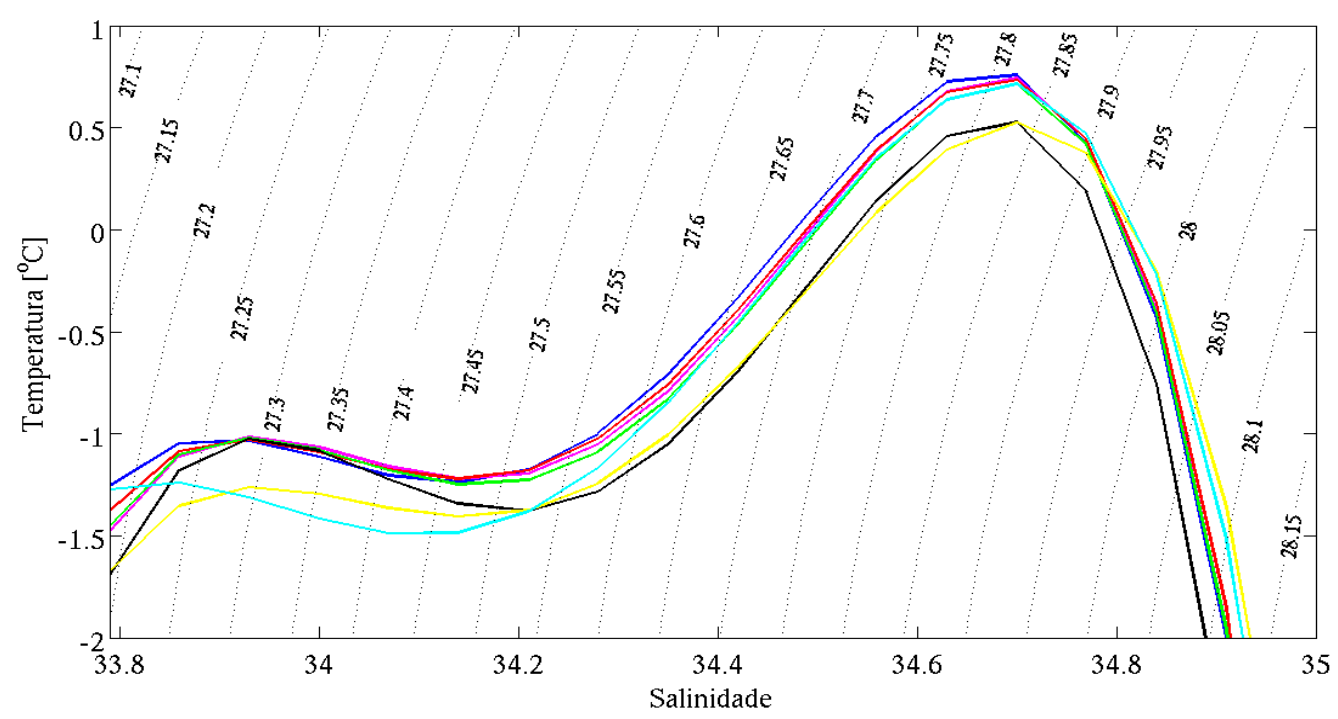

Figura 16: Diagrama TS para os três períodos: 1925-1949 (azul), 1950-1974 (verde) e 1975-1999 (vermelho); (b) Diagrama TS contínuo para 7 décadas: 1880 (azul), 1900 (rosa), 1920 (vermelho), 1940 (verde), 1960 (preto), 1980 (amarelo) e 2000 (azul claro). 


\subsubsection{Distribuição das Massas de Água}

Ainda existem incertezas com relação ao local principal de transformação de massas de água no Mar de Ross. As quantidades exatas e suas respectivas localizações onde as camadas superiores de água são modificadas e eventualmente transformadas em águas densas não são claramente conhecidas (ORSI e WIEDERWOHL, 2009). Por isso, como tentativa de melhor entender a distribuição e variabilidade das massas de água no MR, foram elaboradas diagramas de distribuição e suas respectivas anomalias que serão apresentados a seguir.

Primeiramente foram elaborados diagramas de distribuição média da Água Profunda Circumpolar Superior (UCDW), da Água Profunda Circumpolar Inferior (LCDW) e da Água de Plataforma de Baixa Salinidade (LSSW) para a radial R2 (Figura 17). Optou-se por apresentar somente as distribuiçõoes médias para esta radial, em virtude de ela representar melhor a localização e distribuição destas massas de água no Mar de Ross, se comparado com a radial $\mathrm{R} 1$.

Analisando especificamente as Figuras 17a e 17p já é possível identificar a entrada e penetração tanto da UCDW como da LCDW pela porção Oeste do MR. Esta entrada se dá em virtude do fluxo ciclônico do Giro de Ross, que trás as águas da ACC por uma língua proveniente do Leste (ORSI e WIEDERWOHL, 2009).

Dinniman e Klinck (2004) discutiram as dinâmicas do movimento da CDW, mas para a região à oeste da Península Antártica. Os resultados obtidos por eles indicaram que o movimento da CDW até a Península ocorre quando o fluxo da ACC ao longo da borda da plataforma exterior é desviado para as regiões de mar aberto em virtude da topografia que é variável, o que pode ser observado visivelmente nas Figuras 17p, 23 e 25. Deste modo, é possível concluir que a introdução da CDW na plataforma requer a presença tanto da ACC como também da topografia variável, além de é claro da presença e intensidade do Giro de Ross. 
(a)

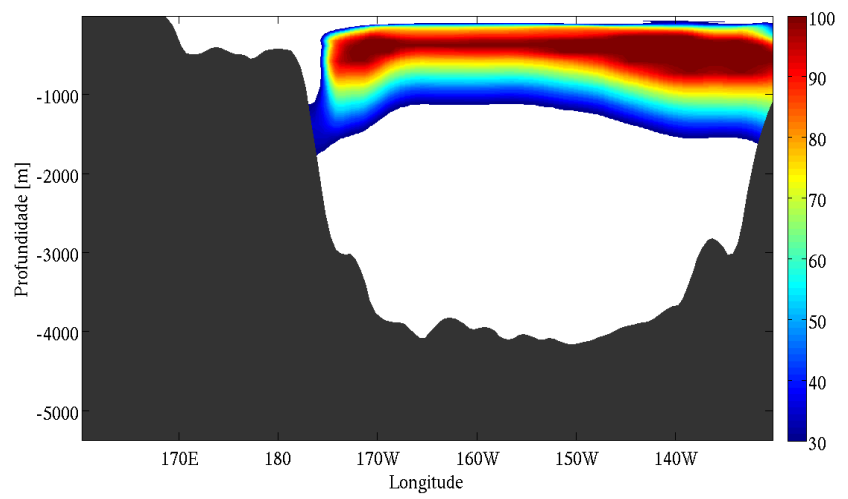

(b)

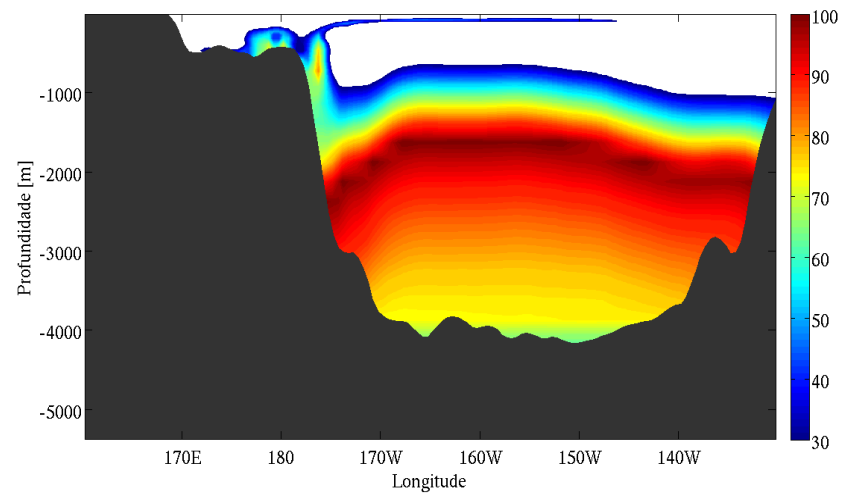

(c)

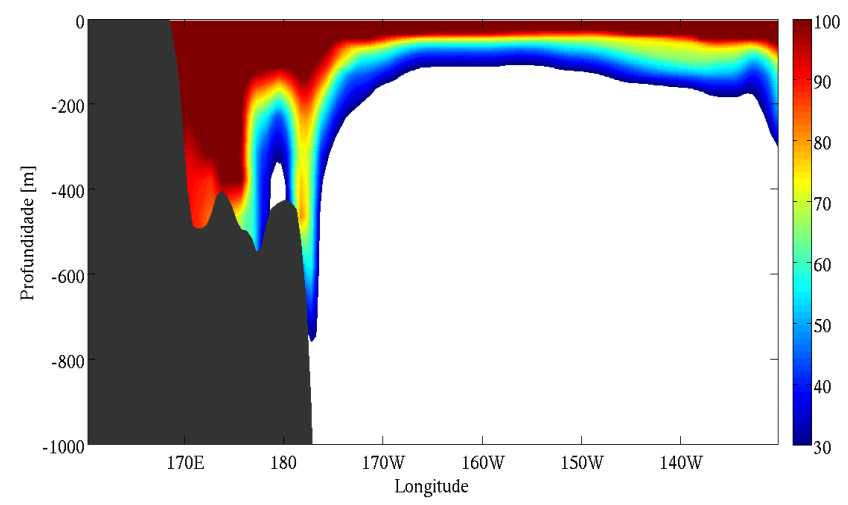

Figura 17: (a) Distribuição média (\%) da UCDW na radial R2 para todo o período entre 1870 e 2008; (b) Distribuição média (\%) da LCDW na radial R2 para o mesmo período; (c) Distribuição média (\%) da LSSW na radial R2 para o mesmo período. 


\subsubsection{Distribuição da UCDW}

A distribuição da UCDW foi investigada nas 2 radiais do MR (R1 e R2). A Figura 18a apresenta a distribuição da UCDW na radial R1 para o período de 1925 a 1949. Já as Figuras 18b e 18p apresentam a distribuição da UCDW para os anos de 1950 a 1974 e 1975 a 1999, respectivamente. Nas três décadas foi possível observar uma porção mais espessa ao Norte da seção, porção esta associada à Corrente Circumpolar Antártica (ACC). Segundo Sievers e Nowlin (1984), a CDW é a água mais volumosa da ACC, corroborando com os resultados obtidos neste trabalho e apresentados na Figura 22. onde a UCDW é encontrada com contribuições de até $100 \%$ na região da ACC, em todas as profundidades analisadas.

Durante os anos de 1950 a 1974 (Figura 18b), a UCDW apresenta uma diminuição da sua contribuição próximo à plataforma continental, diminuição esta ocasionada muito provavelmente por um enfraquecimento da intensidade da borda Leste do Giro de Ross, trazendo assim, menos água para a plataforma do MR, e, consequentemente, diminuindo a temperatura junto à plataforma; pois de acordo com Jacobs et al. (1985); Locarnini (1994); Tonelli (2009), a CDW é a única massa de água que transporta calor para o interior do MR. Esta diminuição da contribuição da UCDW é confirmada pelo campo de anomalias (Figuras 19p e 19d), onde é possível notar um recuo desta massa de água em latitudes superiores à $64^{\circ} \mathrm{S}$.

Comparando agora o terceiro período (1975-1999) (Figura 18k) com os dois outros já descritos acima, é possível afirmar que sua contribuição torna-se ainda maior nas proximidades da plataforma, com seu núcleo principal atingindo valores maiores que $80 \%$ em $\sim 500 \mathrm{~m}$ de profundidade.

Na radial R2 (Figura 20) a contribuição da UCDW é mais significativa na porção Oeste, onde ocorre a intrusão da massa de água no MR em virtude de esta radial estar muito próxima da região de captura da CDW pelo Giro de Ross, como descrito anteriormente, o que permite que a massa de água ocupe uma camada mais espessa na região mais à Oeste do MR (CARMACK, 1977; TONELLI, 2009; WHITWORTH e NOWLIN, 1987). A variação temporal exibe o mesmo padrão observado na $\mathrm{R} 1$, com uma diminuição na contribuição da UCDW junto à plataforma oeste, no período entre 1950 e 1974 (Figura 
20p), seguida de um aumento durante os anos de 1975 a 1999 (Figura 20c).

Os campos de anomalias da UCDW obtidos para a radial R2 (Figura 21) apresentaram um padrão bem semelhante basicamente encontrado de 1925 à 1999: um contínuo recuo desta massa de água até o ano de 1999. Apenas o primeiro período (Figura 21月) que difere dos restantes, em virtude de este apresentar pulsos de águas com anomalias positivas saindo da Plataforma Continental Oriental do MR.

Estudando especificamente os resultados obtidos na Figura 22, além do que já foi descrito acima, é possível concluir que a maior contribuição da UCDW ocorreu na profundidade de 400m (Figura 22p), região esta realmente dominada pela UCDW, alcançando valores de até $100 \%$ em toda a região Norte e Leste do MR (ORSI e WIEDERWOHL, 2009). Vale destacar que a UCDW não conseguiu atingir as proximidades do Cabo Adare, em virtude desta massa de água ser separada da Água de Superfície Antártica (AASW) pela Frente Antártica de Talude no Cabo Colbeck (Ver Figura 226). A partir daí, quem segue fluindo até o Cabo Adare é a AASW (ORSI e WIEDERWOHL, 2009). 
(a)

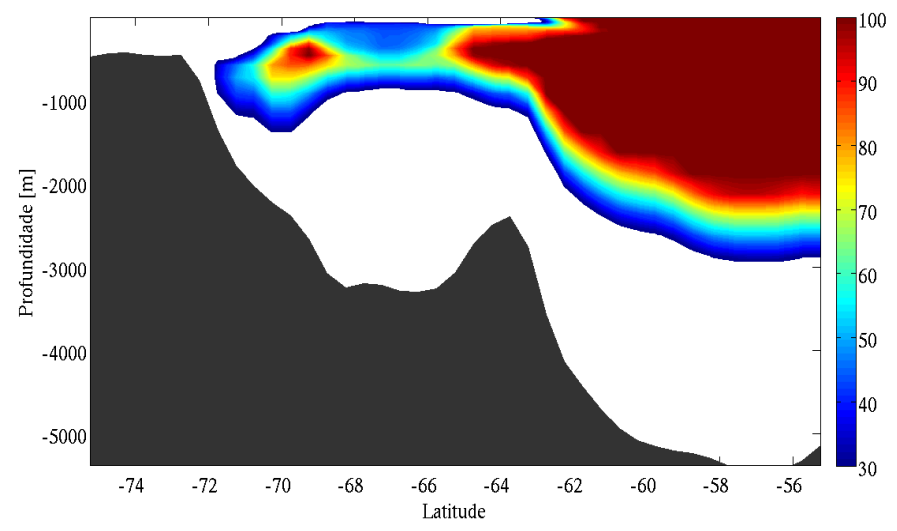

(b)

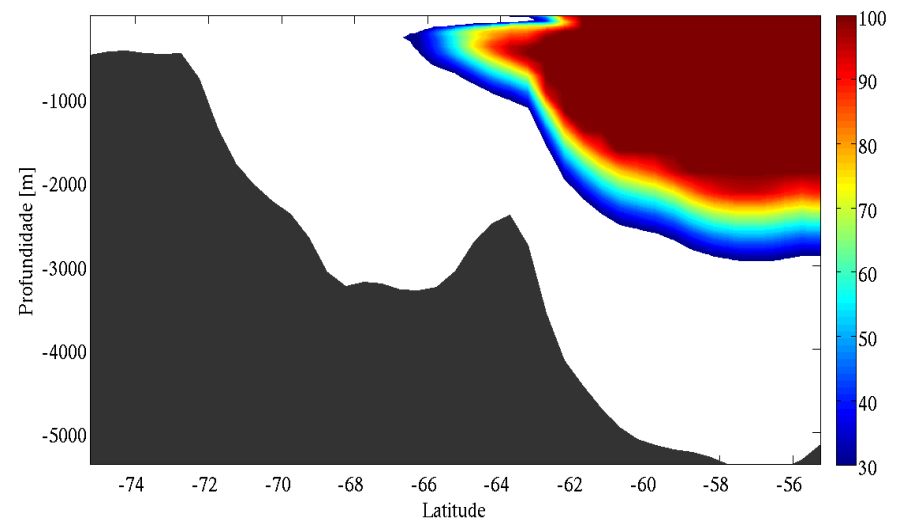

(c)

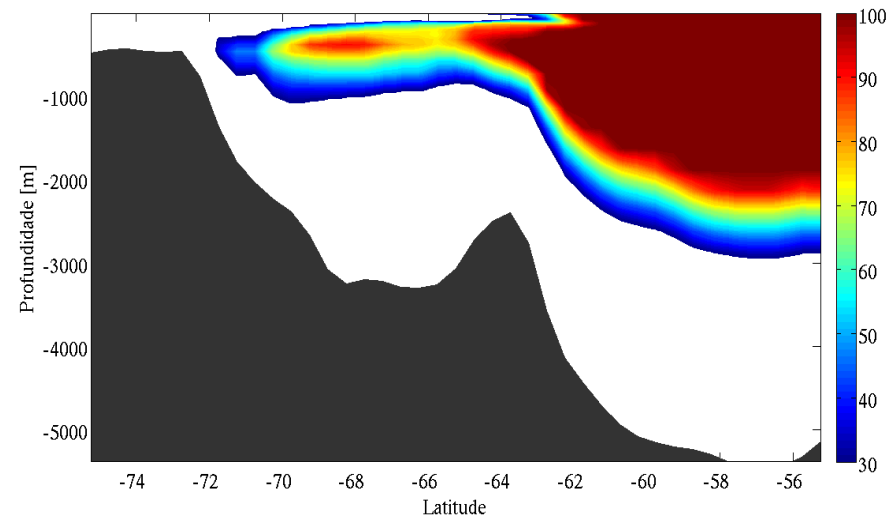

Figura 18: (a) Distribuição (\%) da UCDW na R1 para o período entre 1925 e 1949; (b) 1950-1974; (c) 1975-1999 
(a)

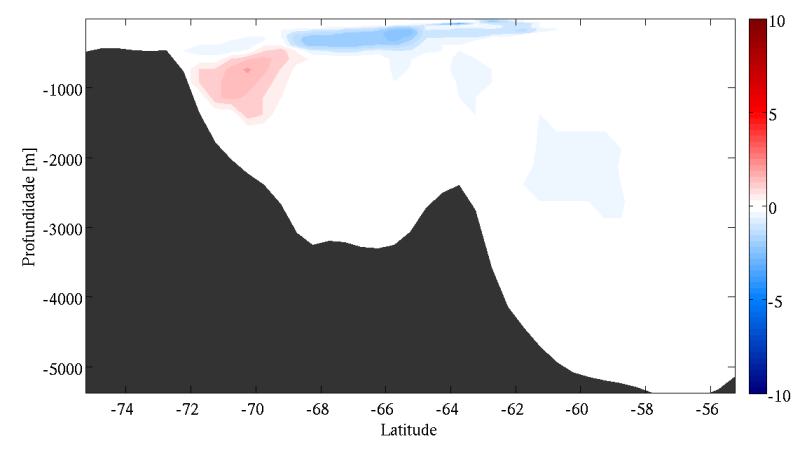

(b)

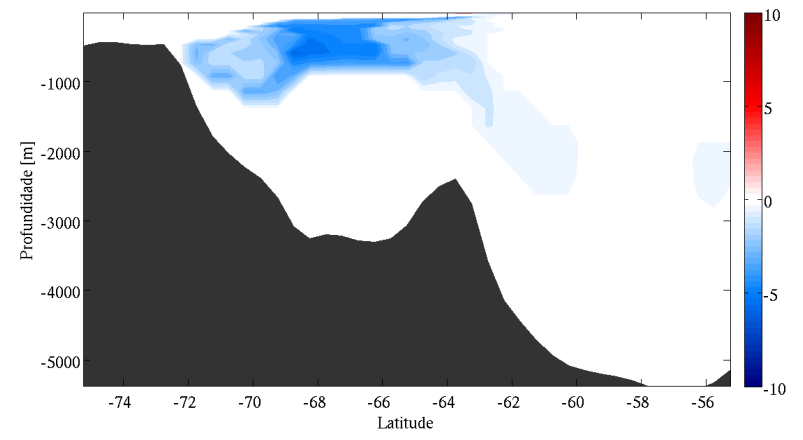

(c)

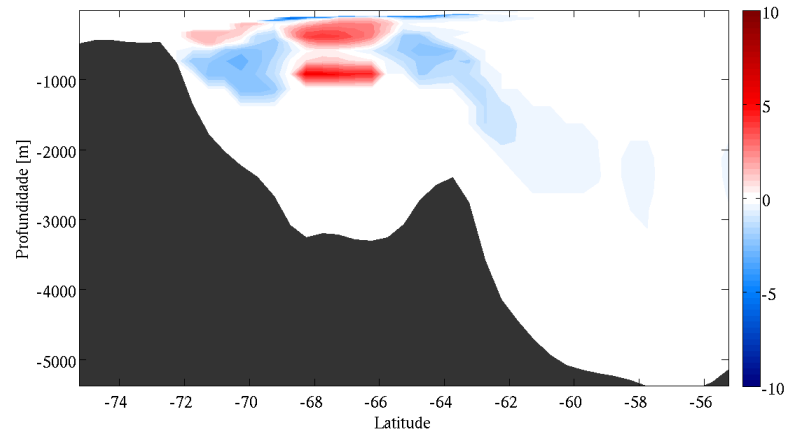

(d)

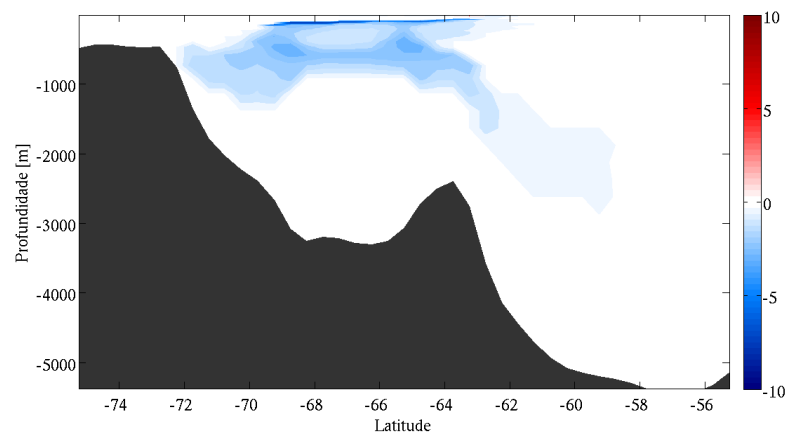

Figura 19: (a) Anomalia da distribuição $(\%)$ da UCDW na R1 relativa à média climatológica (1871-2008) para o período entre 1925 e 1949; (b) 1950-1974; (c) 1975-1999; (d) 1925-1999. 
(a)

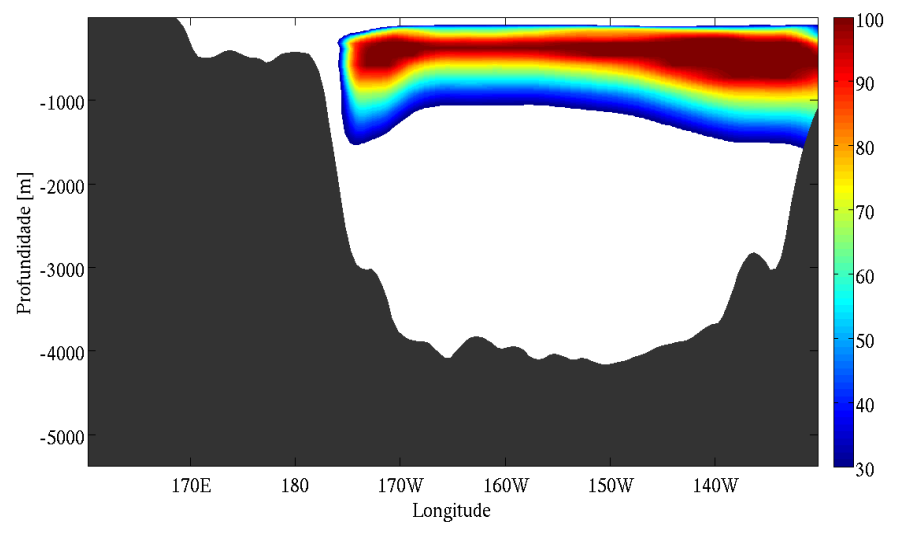

(b)

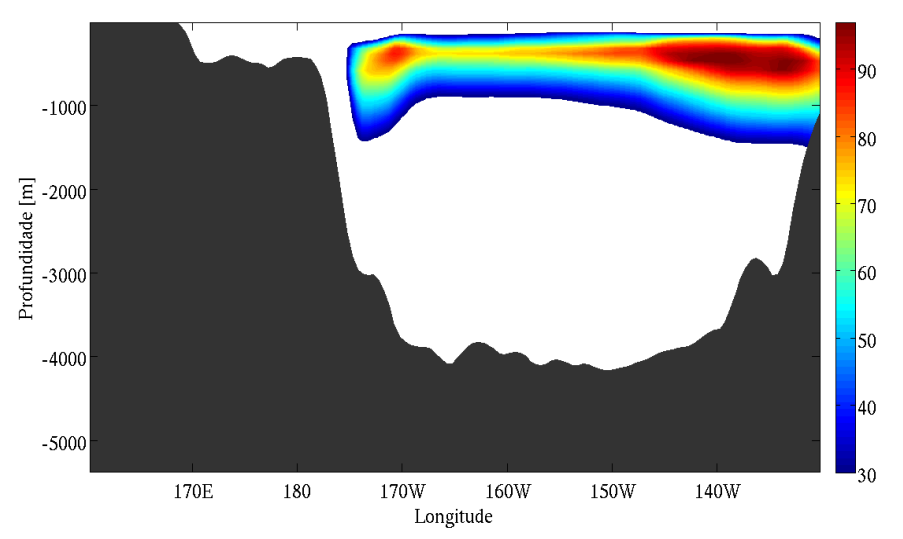

(c)

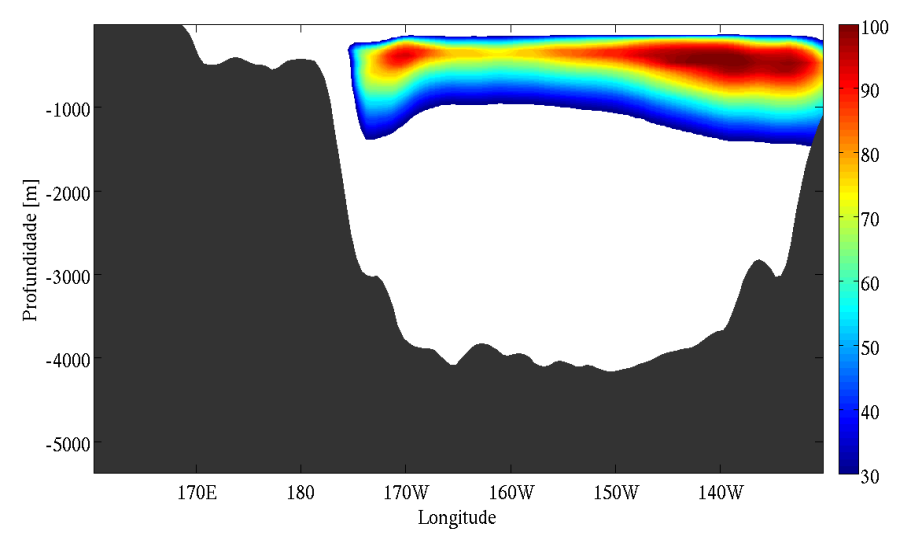

Figura 20: (a) Distribuição (\%) da UCDW na R2 para o período entre 1925 e 1949; (b) 1950-1974; (c) 1975-1999 
(a)

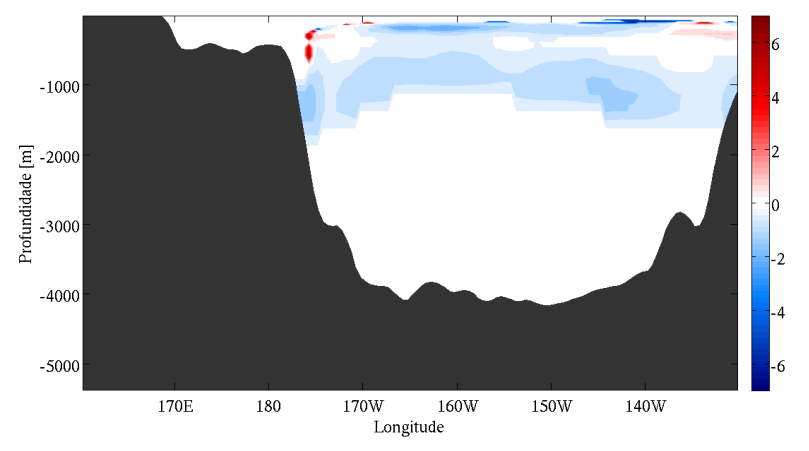

(b)

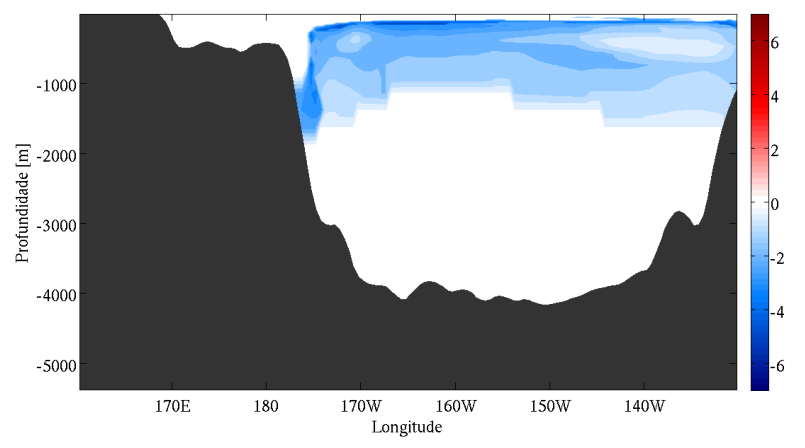

(c)

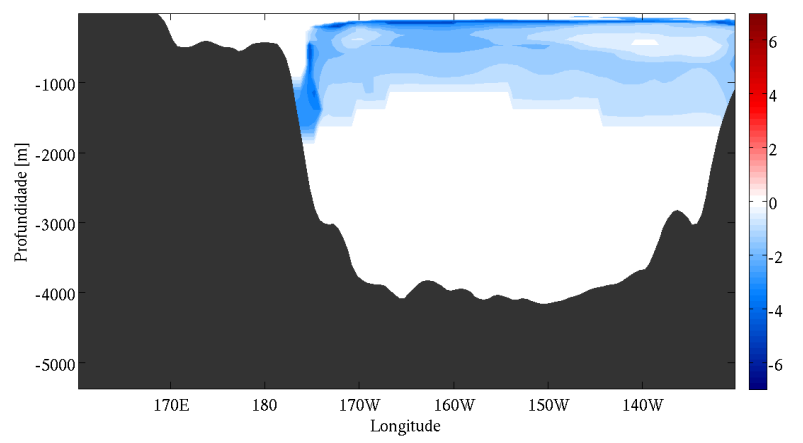

(d)

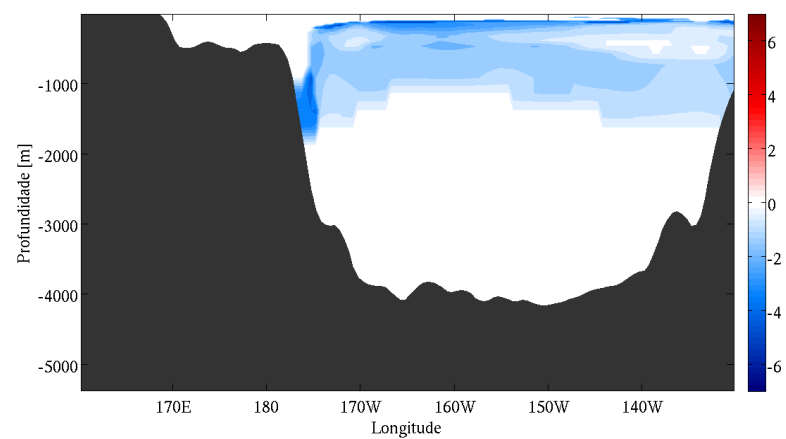

Figura 21: (a) Anomalia da distribuição (\%) da UCDW na R2 relativa à média climatológica (1871-2008) para o período entre (a) 1925 e 1949; (b) 1950-1974; (c) 1975-1999; (d) $1925-1999$. 
(a)

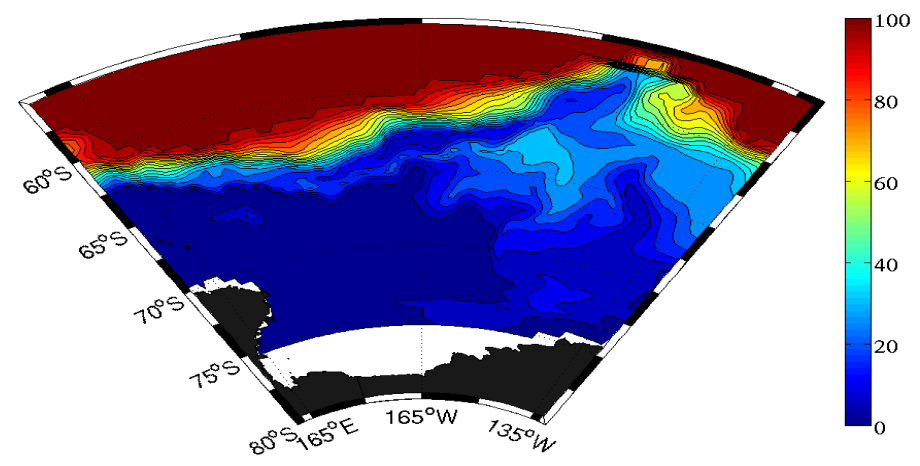

(b)

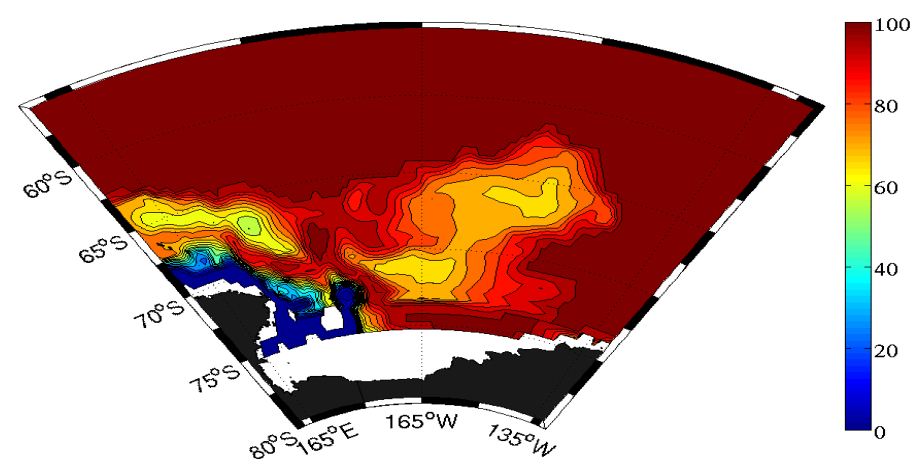

(c)

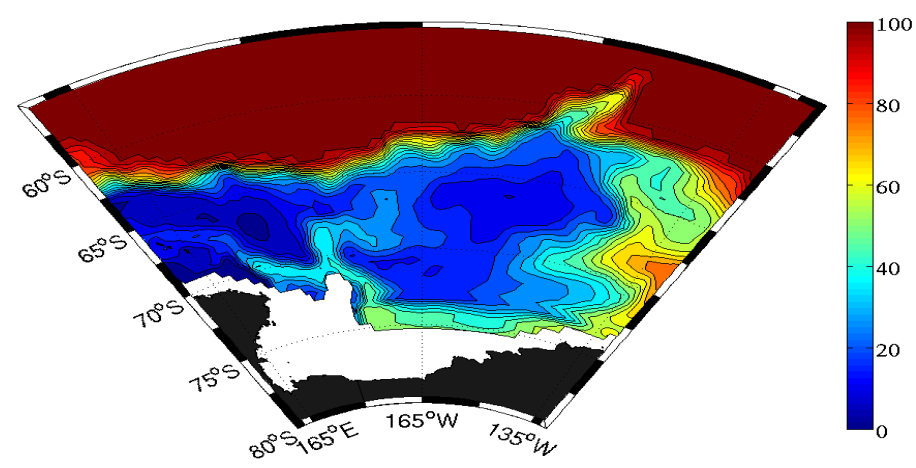

(d)

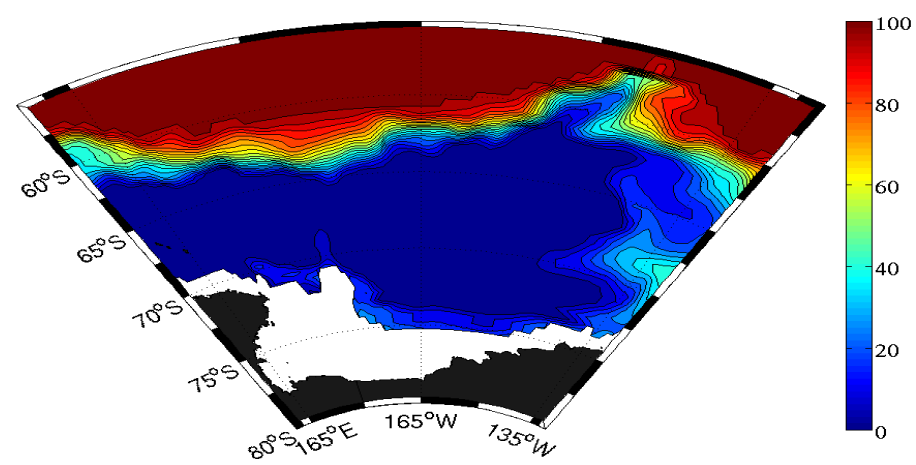

Figura 22: (a) Distribuição (\%) média (1871-2008) da UCDW no Mar de Ross para a profundidade de 60m; (b) 400m; (c) 1000m; (d) 1600m 


\subsubsection{Distribuição da LCDW}

A LCDW é uma forma modificada da UCDW, sendo ela caracterizada por uma salinidade máxima, que é derivada da Água Profunda do Atlântico Norte (NADW) (GORDON, 1967; KLINCK et al., 2004; REID et al., 1977; SMITH et al., 1999; WHITWORTH e NOWLIN, 1987). Como sua contribuição para as propriedades das massas de água do MR ainda não está bem definida, viu-se a necessidade da investigação da distribuição e variabilidade nas duas radiais ( $\mathrm{R} 1$ e R2) aqui representadas nas figuras 23 e 25. Assim com a UCDW, esta massa penetra no MR pela região Norte da área de estudo, e ocupa percentuais expressivos em toda a região das seções a partir dos $1000 \mathrm{~m}$ de profundidade.

Nas Figuras 23a e 23 (radial R1) é possível notar claramente a água chegando até a plataforma de gelo, mas, devido a declividade, ela não consegue atingir profundidades menores que $500 \mathrm{~m}$, batendo e retornando, muito provavelmente, para as posições anteriormente ocupadas por esta massa. Analisando em especial as seções de anomalias apresentas na Figura 24, é possível verificar um avanço da LCDW entre os anos de 1950-1974 e 1925-1999, corroborando com os resultados obtidos acima pela UCDW, pois durante este mesmo período houve um recuo dela. Isto ocorre devido a uma condição básica da dinâmica de fluídos geofísicos: a conservação de massa (PEDLOSKY, 1982). Segundo esta condição, o volume que era anteriormente ocupado pela UCDW deve ser preenchido então por uma outra massa de água, no caso a LCDW (Figuras 24b e 24d).

Observando por sua vez a radial R2 nas Figuras 25a, 25b e 25k, é possível notar claramente o aprisionamento desta massa de água em virtude do corte transversal desta radial. Os maiores percentuais desta massa são encontrados em núcleos centrados na profundidade de $2000 \mathrm{~m}$, e em ambas as três figuras é possível notar a tentativa de superposição da plataforma de gelo pela massa de água, possibilitando a LCDW contribuir mesmo que indiretamente para a plataforma (SMITH et al., 1999). Esta tentativa de superposição é bem evidenciada nas seções de anomalias (Figura 26). Analisando estas seções, é possível afirmar que em todos os quatro períodos houve um recuo nas camadas inferiores (superiores à 2000m) e um avanço desta massa de água nas camadas superiores. Porém, entre os anos de 1925 a 1949 (Figura 26a) este incremento foi bem menor, apresentando concentrações de anomalias positivas bem na região da quebra da 
plataforma Leste, o que significa que, neste período, a tentativa de superposição não foi bem sucedida pois a LCDW não conseguiu retornar para as camadas superficiais de forma significativa.

Analisando espacialmente os resultados obtidos na Figura 27]é bem interessante notar a entrada da LCDW proveniente da ACC pela porção Leste do MR. Esta entrada chega primeiramente em pulsos, como pode ser visto na Figura $27 \mathrm{~A}$, aumentando suas contribuições a medida que vai atingindo regiões mais profundas (Figura $27 \mathrm{~d}$ ). Vale ressaltar que suas contribuições no $\mathrm{MR}$ atingem até a linha de $55^{\circ} \mathrm{S}$, não chegando à regiões mais ao Norte que, por sua vez, são ocupadas pela UCDW nestas profundidades. 
(a)

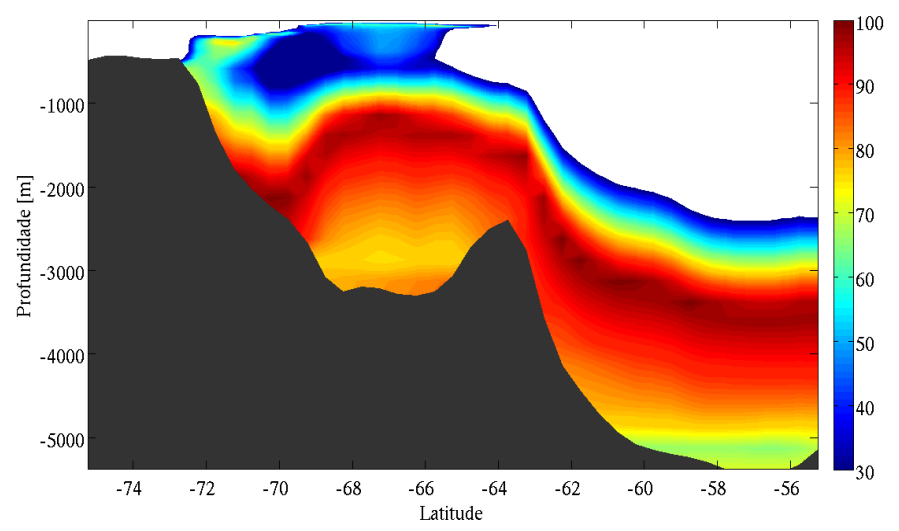

(b)

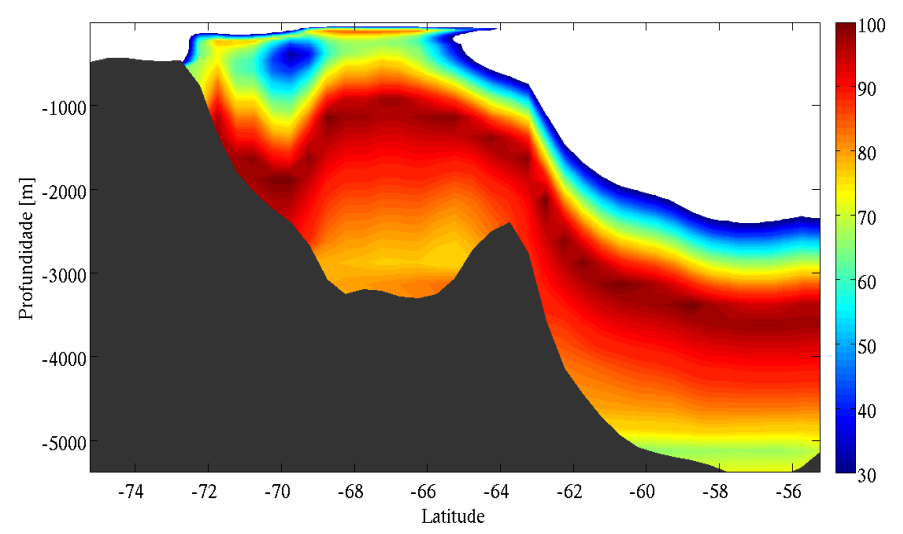

(c)

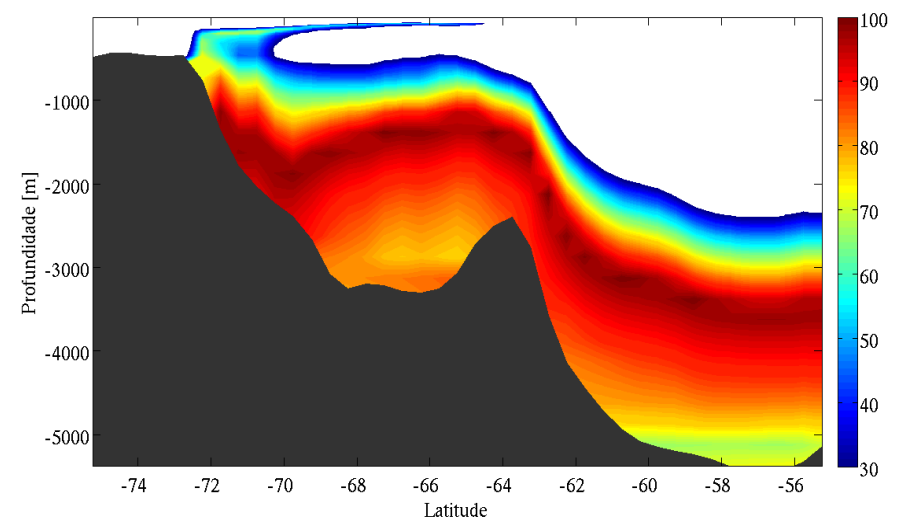

Figura 23: (a) Distribuição (\%) da LCDW na R1 para o período entre 1925 e 1949; (b) 1950-1974; (c) 1975-1999 
(a)

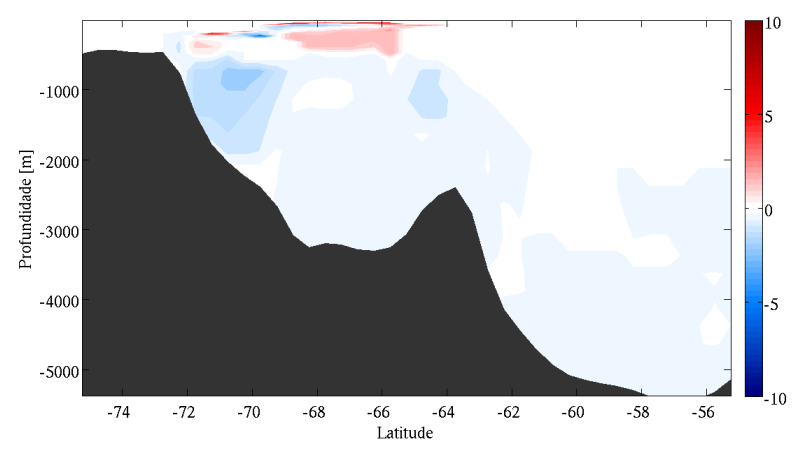

(b)

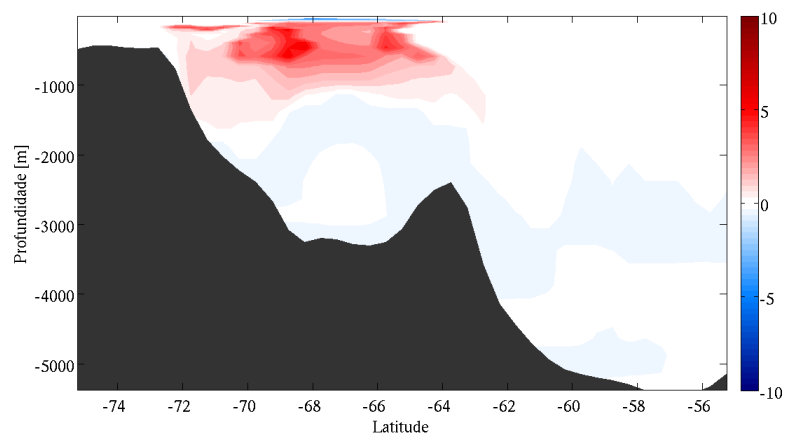

(c)

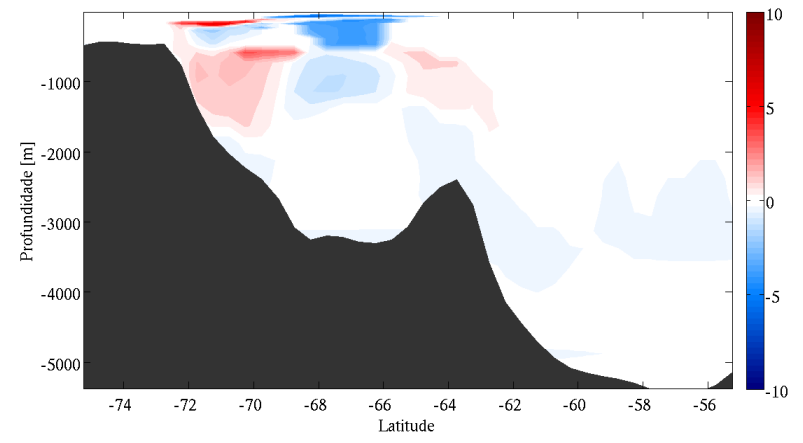

(d)

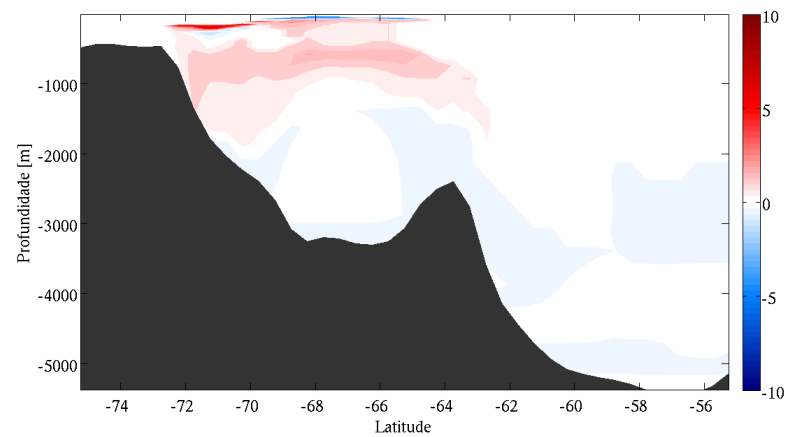

Figura 24: (a) Anomalia da distribuição (\%) da LCDW na R1 relativa à média climatológica (1871-2008) para o período entre 1925 e 1949; (b) 1950-1974; (c) 1975-1999; (d) 1925-1999. 
(a)

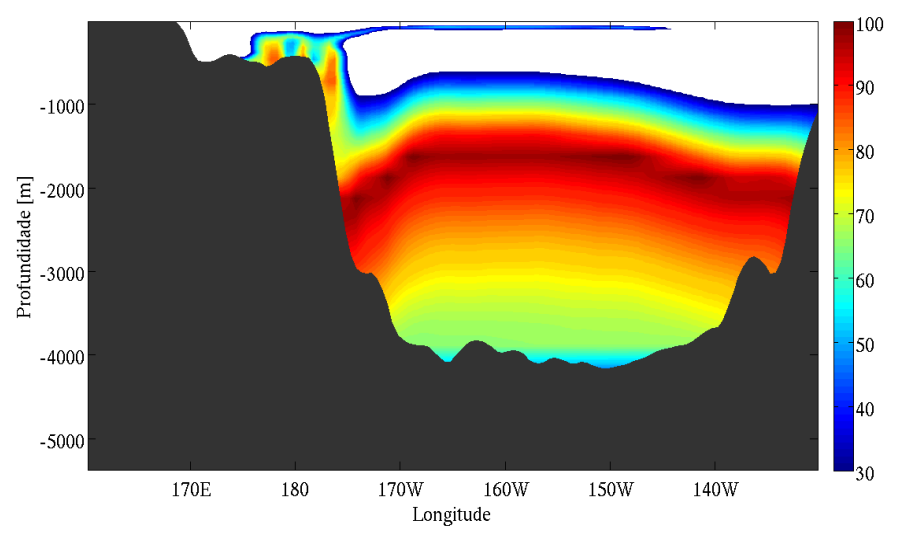

(b)

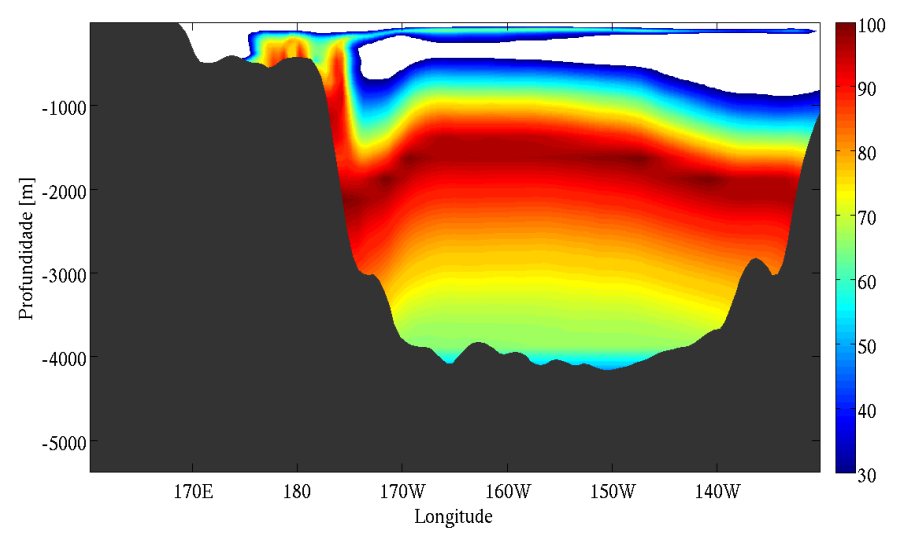

(c)

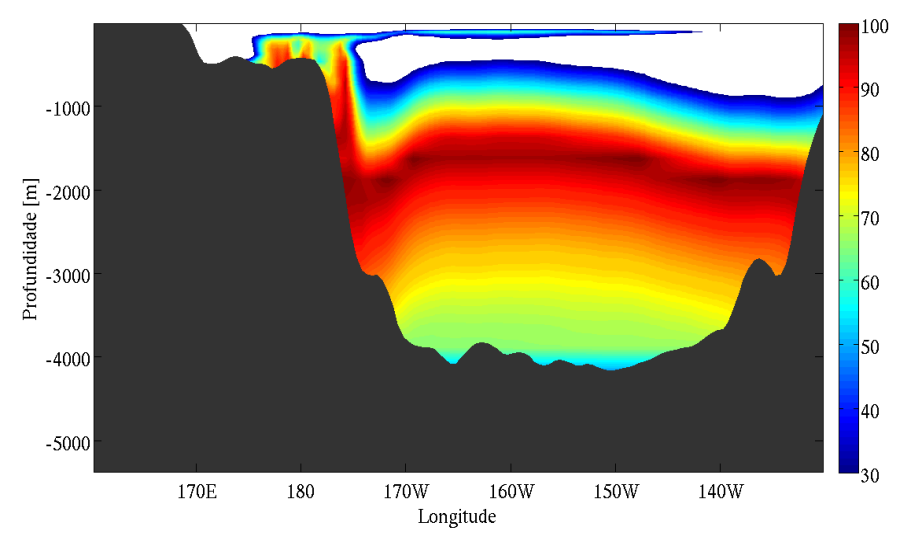

Figura 25: (a) Distribuição (\%) da LCDW na R2 para o período entre 1925 e 1949; (b) 1950-1974; (c) 1975-1999 
(a)

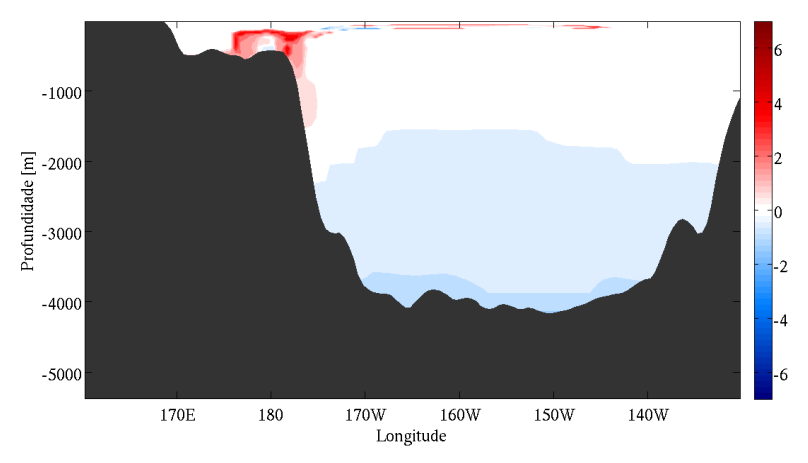

(b)

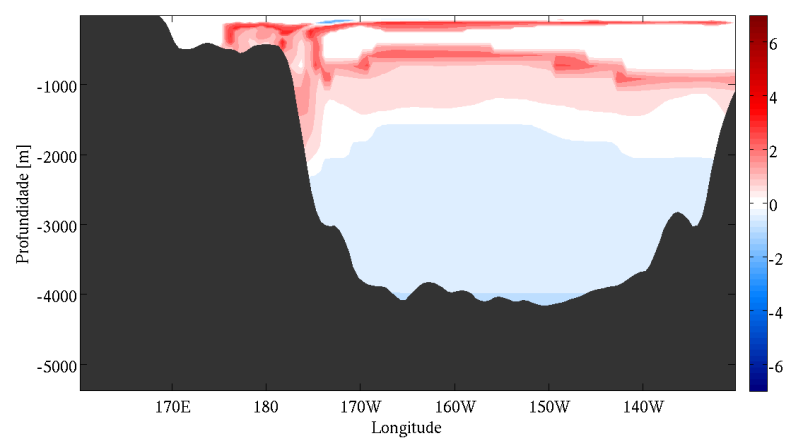

(c)

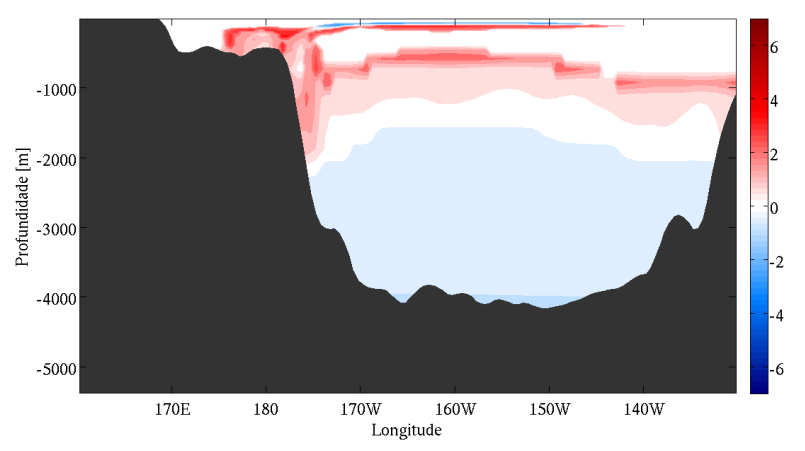

(d)

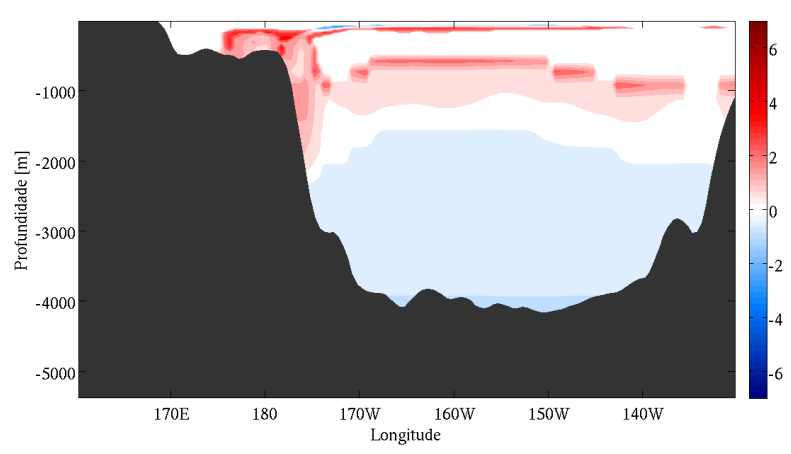

Figura 26: (a) Anomalia da distribuição (\%) da LCDW na R2 relativa à média climatológica (1871-2008) para o período entre 1925 e 1949; (b) 1950-1974; (c) 1975-1999; (d) 1925-1999. 
(a)

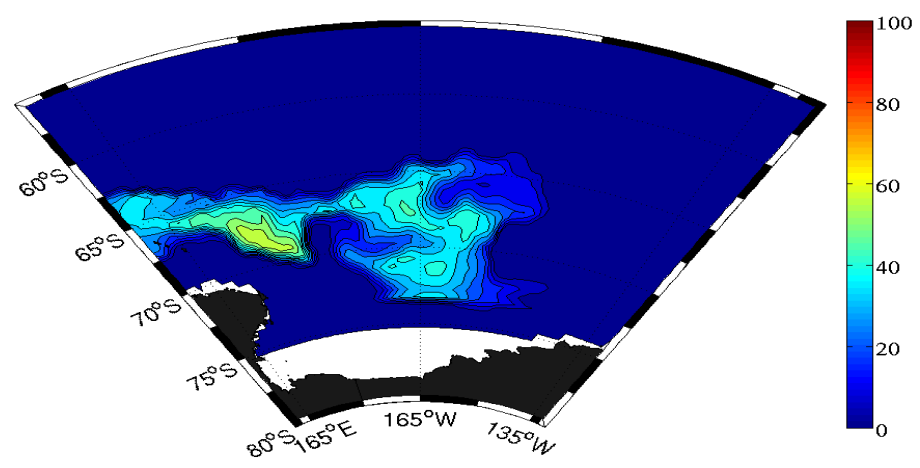

(b)

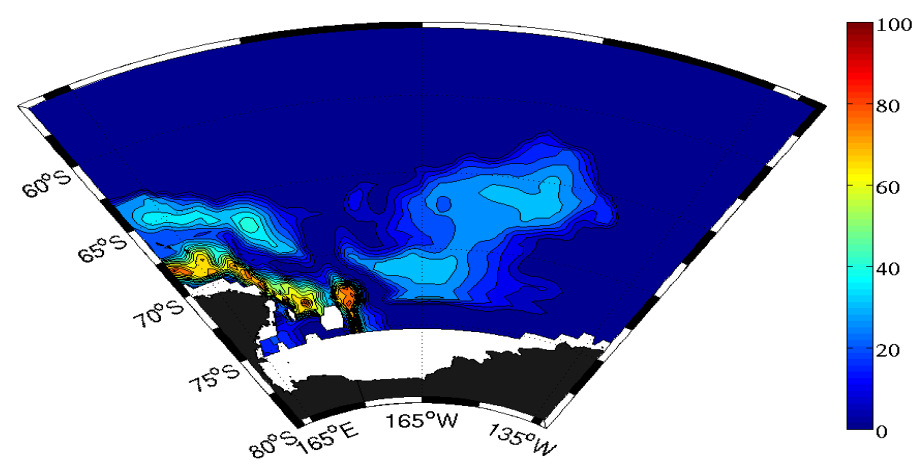

(c)

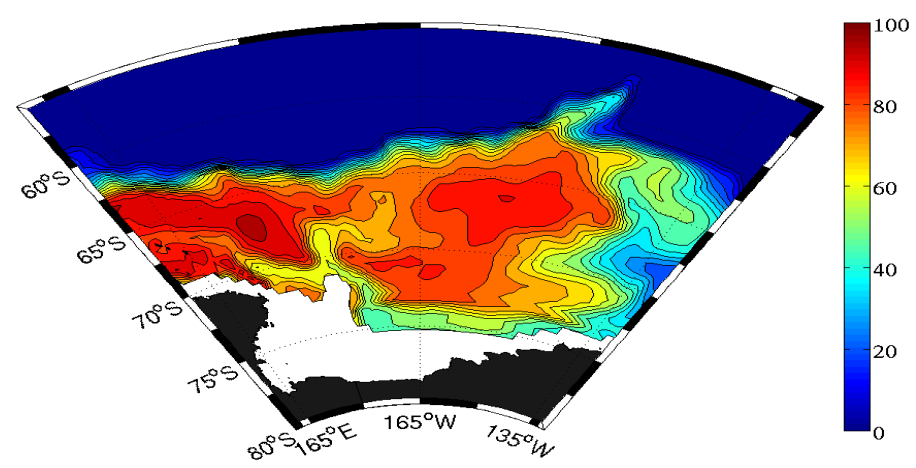

(d)

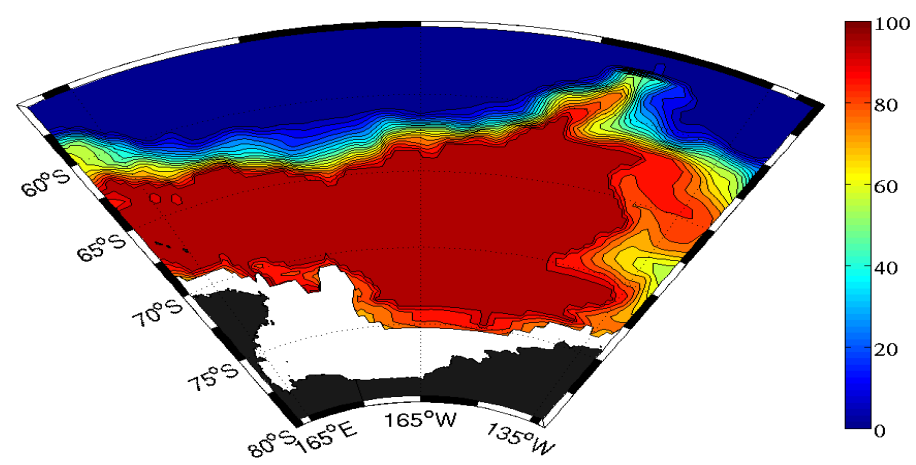

Figura 27: (a) Distribuição (\%) média (1871-2008) da LCDW no Mar de Ross para a profundidade de 60m; (b) 400m; (c) 1000m; (d) 1600m 


\subsubsection{Distribuição da LSSW}

Fazendo avaliação inicial das Figuras 28 e 30 já é possível evidenciar a importância da LSSW sobre a plataforma Leste do MR, onde a presença da água é dominante. Observando em especial a Figura 28 é possível verificar que esta massa atinge profundidades de até $600 \mathrm{~m}$, estendendo-se ao norte da latitude de $62^{\circ} \mathrm{S}$. Esta distribuição obtida em ambas radiais é consistente com trabalhos pretéritos realizados por Budillon $e t$ al. (2003); Smethie e Jacobs (2005); Tonelli (2009); porém, a variação temporal apresentada pela LSSW é muito pequena, valendo-se então da análise das anomalias que são apresentadas na Figura 29. Elas indicam que durante os primeiros 25 anos houve um recuo da LSSW, seguido de um avanço entre os anos de 1950 à 1974 (Figura 29p). Este avanço novamente se deu por conta do recuo da UCDW ocorrido neste mesmo período. A partir daí, vale ressaltar que os valores de anomalias continuaram então bem semelhantes, tanto para o período inteiro (1925-1999) como para os últimos 25 anos analisados (Figuras 29d e 29k, respectivamente).

Assim como a radial R1, a R2 apresenta também uma pequena variação temporal (Figura 30, , atingindo seus maiores valores de profundidade apenas na região da plataforma, justamente em virtude de ela ser formada alí no local. É interessante ainda chamar a atenção pelo fato de que esta massa de água cobre toda a extensão longitudinal da R2.

Levando em conta as seções de anomalia para esta radial (Figura 31), é possível notar um recuo da LSSW em cima da Plataforma Leste de Ross durante os quatro períodos; porém ao longo da seção é possível notar diferenças significativas, indicando que entre os anos de 1925 a 1949 houve predominantemente um afundamento das águas mas, merecendo destaque também, um pequeno núcleo de afloramento da LSSW localizado entre as longitudes de 160 e $140^{\circ} \mathrm{W}$, com anomalias positivas inferiores à $2 \%$.

Essas anomalias positivas encontradas a partir de $1950 \mathrm{em}$ ambas radiais indicam não somente o afloramento desta massa de água, mas também uma intensificação na formação dessa massa de água. Como a característica chave da formação da LSSW é a diminuição da salinidade, ela pode ser obtida como o resultado de uma combinação de diferentes forçantes, as quais incluem o aumento da precipitação, a diminuição da produção de gelo marinho e o aumento do derretimento da Plataforma Leste de 
Gelo Marinho (BUDILLON et al., 2002; JACOBS et al., 2002).

A Figura 32 apresenta os cortes das distribuições espaciais da LSSW. Visualizando a figura referente a $60 \mathrm{~m}$ (Figura $32 \mathrm{a}$ ) é possível notar que as contribuições acima de $90 \%$ se encontram na porção Leste da Plataforma de Ross, indicando que alí seria sua região de formação (ORSI e WIEDERWOHL, 2009). A partir daí ela segue um fluxo para o Oeste, apresentando elevadas contribuições em toda a porção Sul do MR. Já na porção Oeste a água segue em sentido Norte, chegando a alcançar a latitude de $60^{\circ} \mathrm{S}$ e, a partir daí, suas contribuições começam a diminuir até se tornarem nulas.

Na profundidade de 400m (Figura 32p) ainda é encontrado um elevado percentual de LSSW, porém ela fica confinada bem próxima à plataforma leste (BUDILLON et al., 2003), levando todo o restante do MR a apresentar valores nulos ou próximos de 0 . Nas últimas profundidades (Figuras 32 e e 32d) já não é possível a visualização da ocorrência desta massa, em virtude de a espessura da camada de gelo ser maior nestas profundidades. 


$$
\begin{aligned}
& \mathbf{r} \\
& \mathbf{r}
\end{aligned}
$$


(a)

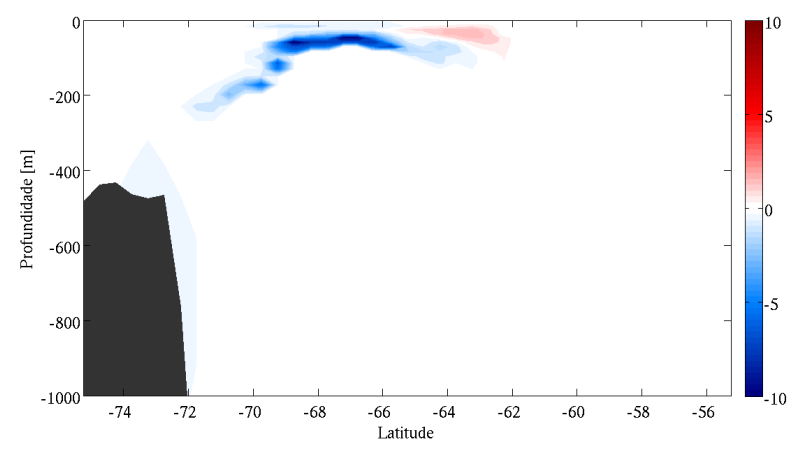

(b)

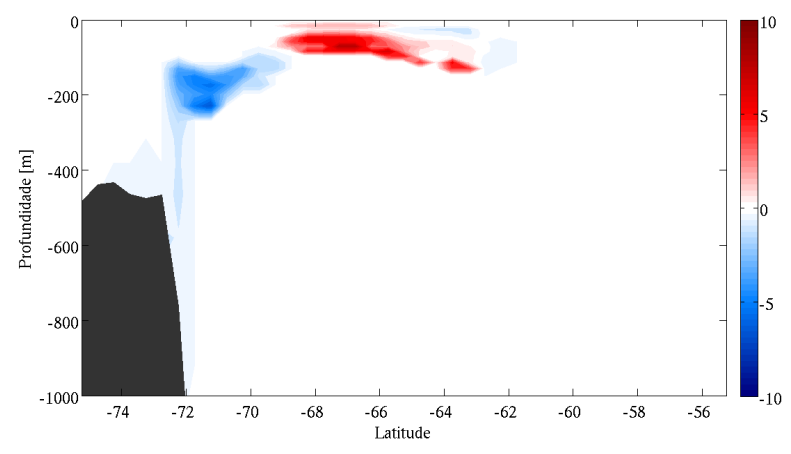

(c)

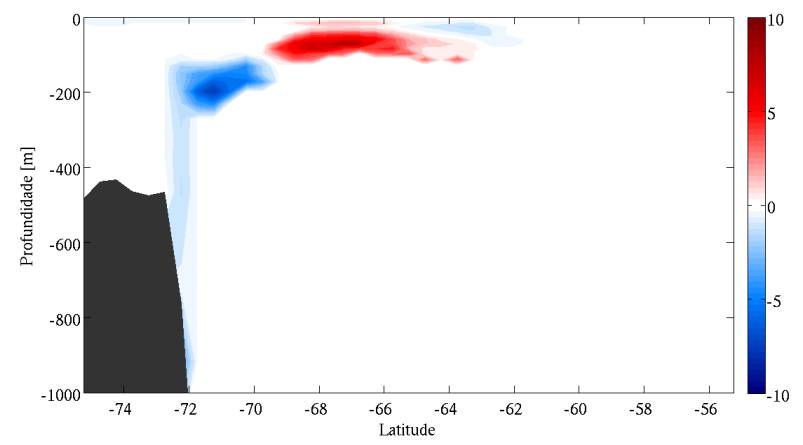

(d)

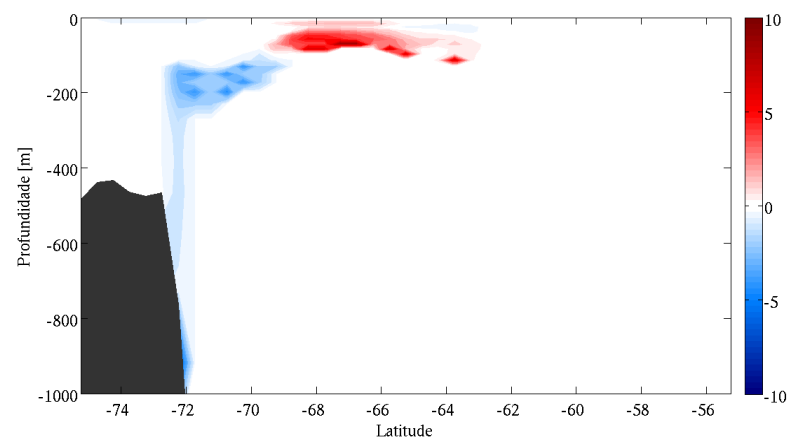

Figura 29: (a) Anomalia da distribuição (\%) da LSSW na R1 relativa à média climatológica (1871-2008) para o período entre 1925 e 1949; (b) 1950-1974; (c) 1975-1999; (d) 1925-1999. 
(a)

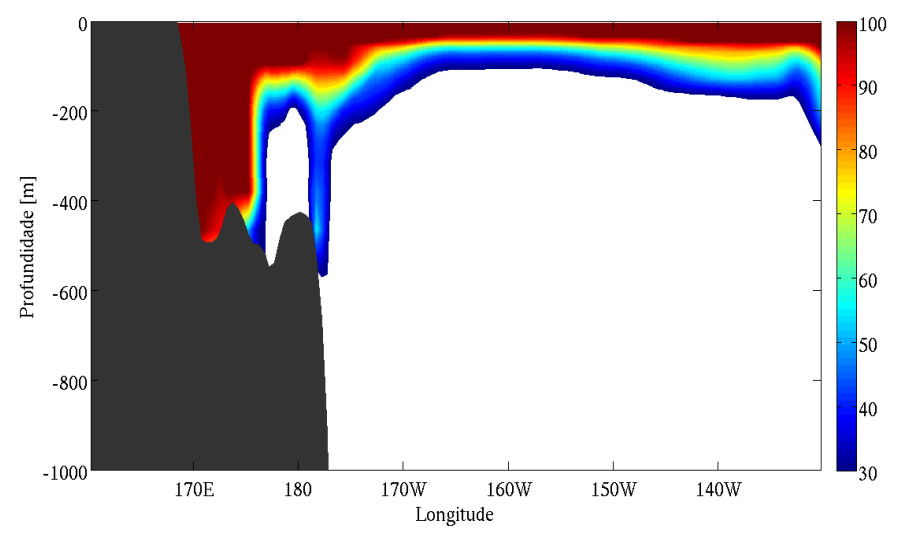

(b)

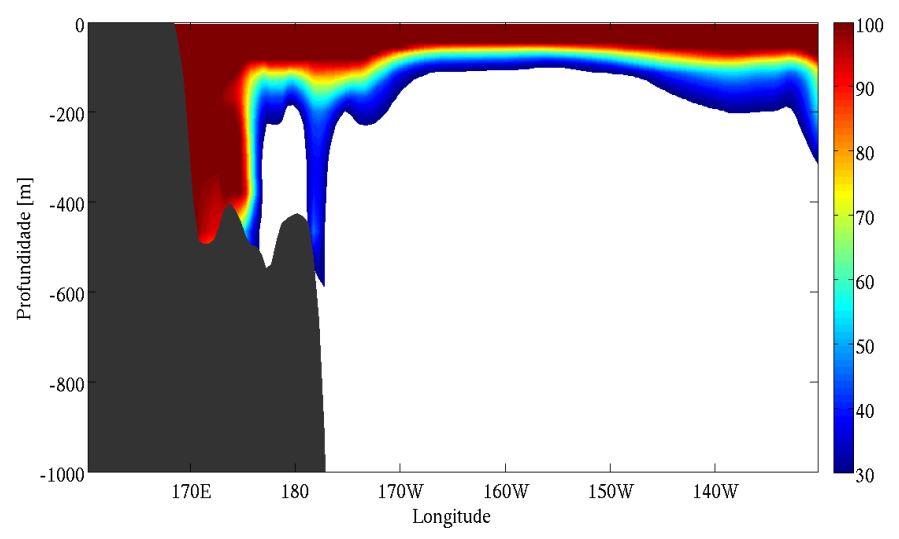

(c)

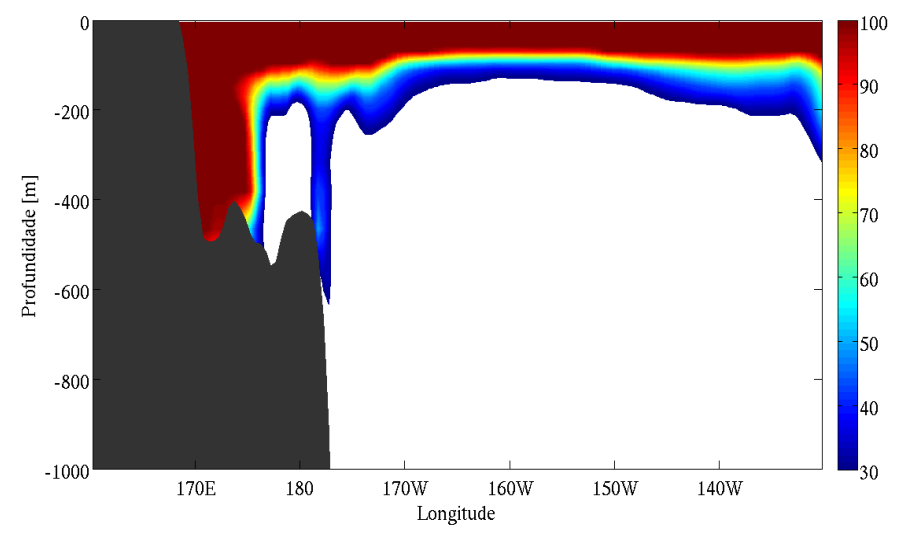

Figura 30: (a) Distribuição (\%) da LSSW na R2 para o período entre 1925 e 1949; (b) 1950-1974; (c) 1975-1999 
(a)

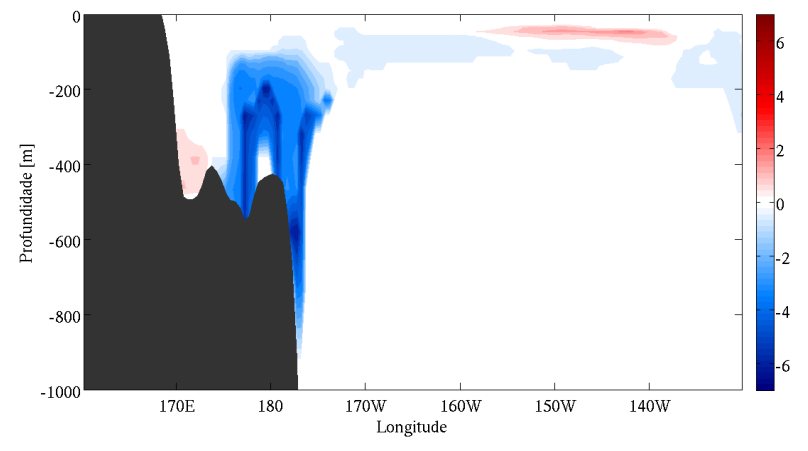

(b)

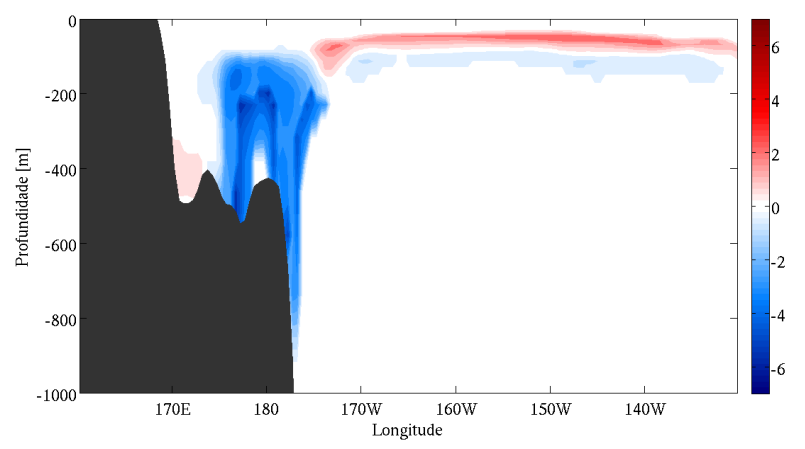

(c)

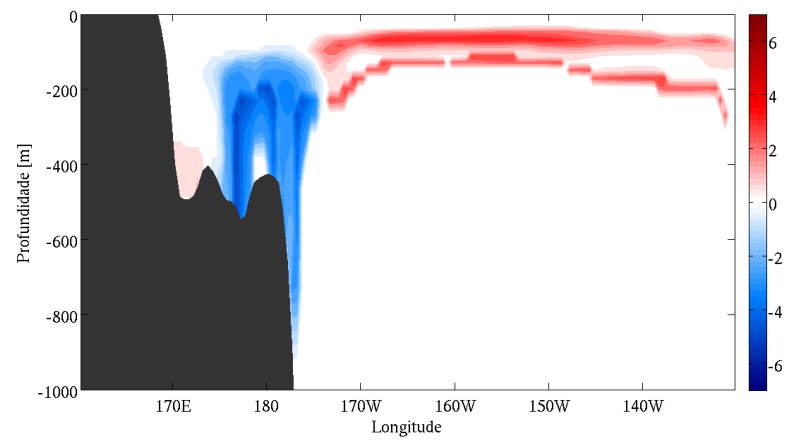

(d)

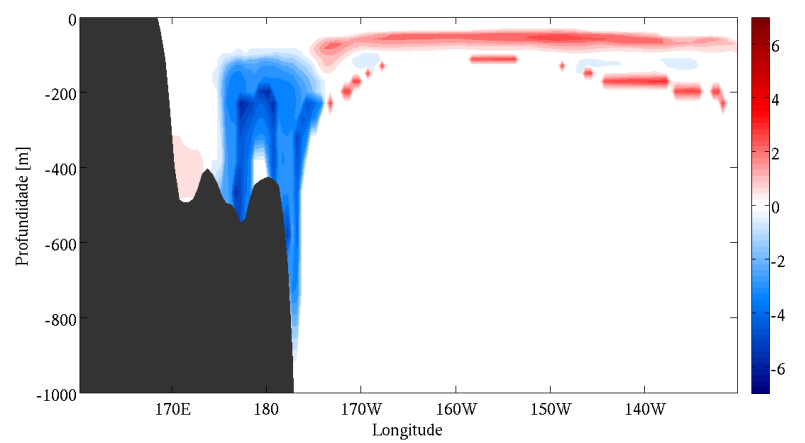

Figura 31: (a) Anomalia da distribuição (\%) da LSSW na R2 relativa à média climatológica (1871-2008) para o período entre 1925 e 1949; (b) 1950-1974; (c) 1975-1999; (d) $1925-1999$. 
(a)

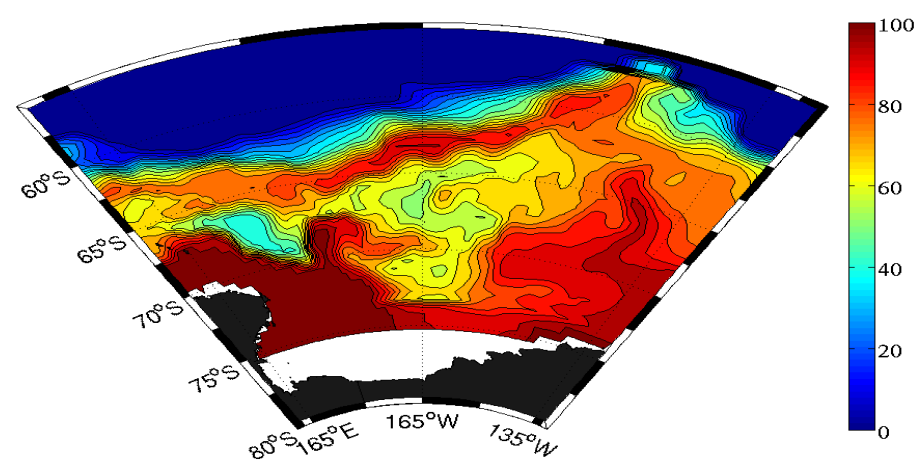

(b)

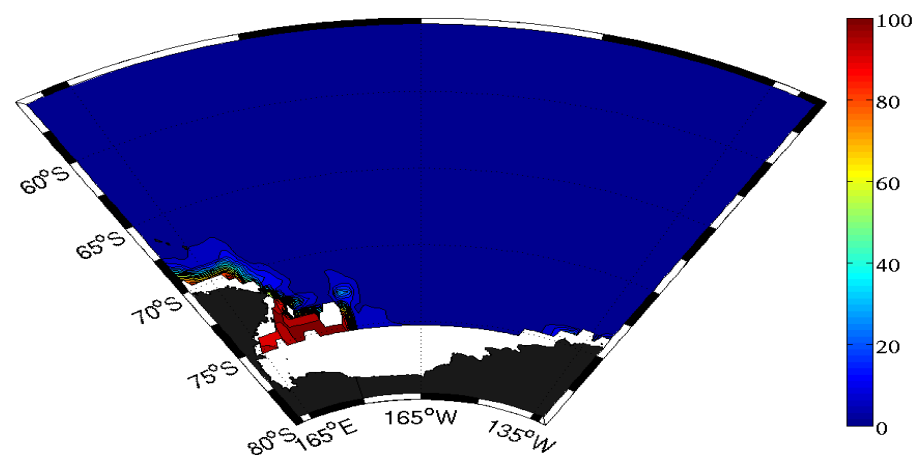

(c)

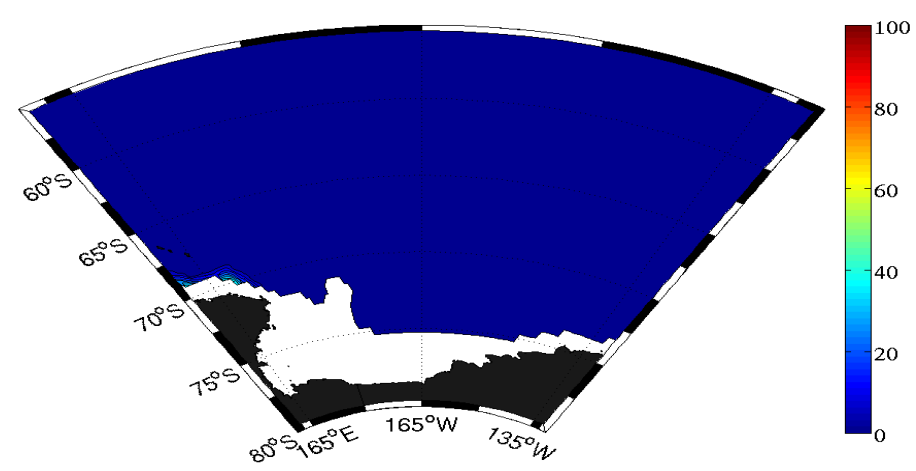

(d)

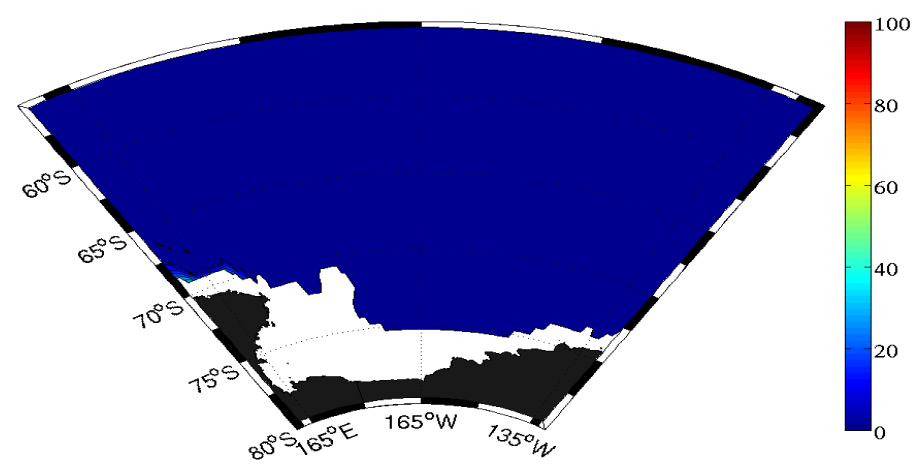

Figura 32: (a) Distribuição (\%) média (1871-2008) da LSSW no Mar de Ross para a profundidade de 60m; (b) 400m; (c) 1000m; (d) 1600m 


\subsection{Mar de Weddell}

\subsubsection{Seções de Temperatura}

As seções de temperatura média em ambas radiais (W1 e W2 - Ver Figuras 33a e 33b) mostram uma língua de águas mais frias, característica da Água de Inverno (WW), com temperaturas abaixo de $-1^{\circ} \mathrm{C}$, se desprendendo da plataforma continental do $\mathrm{MW}$ e percorrendo toda a camada superficial das seções em questão. A partir desta camada superficial em direção ao fundo é possível identificar uma camada com maiores valores de temperatura, podendo atingir até $0,5^{\circ} \mathrm{C}$ na profundidade de $1000 \mathrm{~m}$, diminuindo, assim, gradativamente até o assoalho oceânico.

Assim com observado em Absy et al. (2008), tanto na seção zonal como na seção meridional é possível detectar uma camada superficial de mistura fortemente desenvolvida, se extendendo até uma profundidade média de $200 \mathrm{~m}$. Vale destacar também, que este pesado gradiente vertical observado em ambas seções indica uma picnoclina permanente, que marca a transição entre a fria WW e a mais quente WDW. Além destas massas, a WSDW também é bem definida por $-0,7^{\circ} \leq \theta \leq 0^{\circ} \mathrm{C}$, sobrepondo a gelada WSBW (ABSY et al., 2008). A WSBW aparece logo acima do fundo, como uma camada contínua, espessura média entre 200 e $500 \mathrm{~m}$, águas mais geladas que $-0.7^{\circ} \mathrm{C}$ e salinidades ao redor de 34,65 (Figura 36), corroborando com os intervalos de temperatura e salinidade propostos por Carmack e Foster (1975a) para a WSBW. Por fim, é interessante notar também que não existe uma camada contínua entre esta água fria e profunda do talude e as águas da plataforma, sugerindo que esta água encontrada no talude se tornou isolada devido às suas fontes formadoras se localizarem muito provavelmente no próprio talude (ABSY et al., 2008).

Analisando a Figura 34 e comparando os resultados das anomalias para os quatro períodos analisados da radial W1, é possível notar primeiramente a presença de anomalias negativas para os quatro períodos a partir dos $500 \mathrm{~m}$. No primeiro e terceiro período estudado (Figuras 34a e 34 ) foram encontradas anomalias positivas em toda a região bem superficial, sendo que estas anomalias no último período são mais relevantes, atingindo valores de quase 0,6. Já no segundo período (Figura 34p), apenas um núcleo positivo é observado, também em profundidades não maiores que 100m e surgindo apenas na porção 
mais à Leste da seção, atingindo até a longitude de $23^{\circ} \mathrm{W}$. Foram observados valores de anomalias muito próximos à 0 na Figura 34 d, que compreende todo o período entre 1925 e 1999, valendo destaque apenas para uma língua com águas um pouco mais negativas ( $-0,2 \%$ ) localizadas a 100m de profundidade, língua esta também observada, porém, com maior intensidade, entre os anos de 1950 a 1999 (Figuras 34b e 34c).

Já para a radial W2, foi possível verificar, nos quatro períodos analisados (Figura 35), uma língua de anomalias positivas penetrando à partir da Plataforma Continental na profundidade de 500m, merecendo destaque para o período entre 1975 e 1999, com seu núcleo atingindo valores de $\sim 0,3 \%$ (Figura 356). Além desta feição específica, nas regiões mais superficiais foram encontrados valores positivos penetrando pela porção norte da radial em todos os períodos porém, esse núcleo positivo é sobreposto por um núcleo de anomalias negativas no período compreendido entre 1925 e 1949 (Figura 35a). Ainda é interessante notar uma língua de anomalias negativas localizada logo abaixo da feição descrita acima, com valores chegando a atingir $-1 \%$ (Figuras $35 \mathrm{~b}, 35 \mathrm{c}$ e $35 \mathrm{~d}$ ). 
(a)

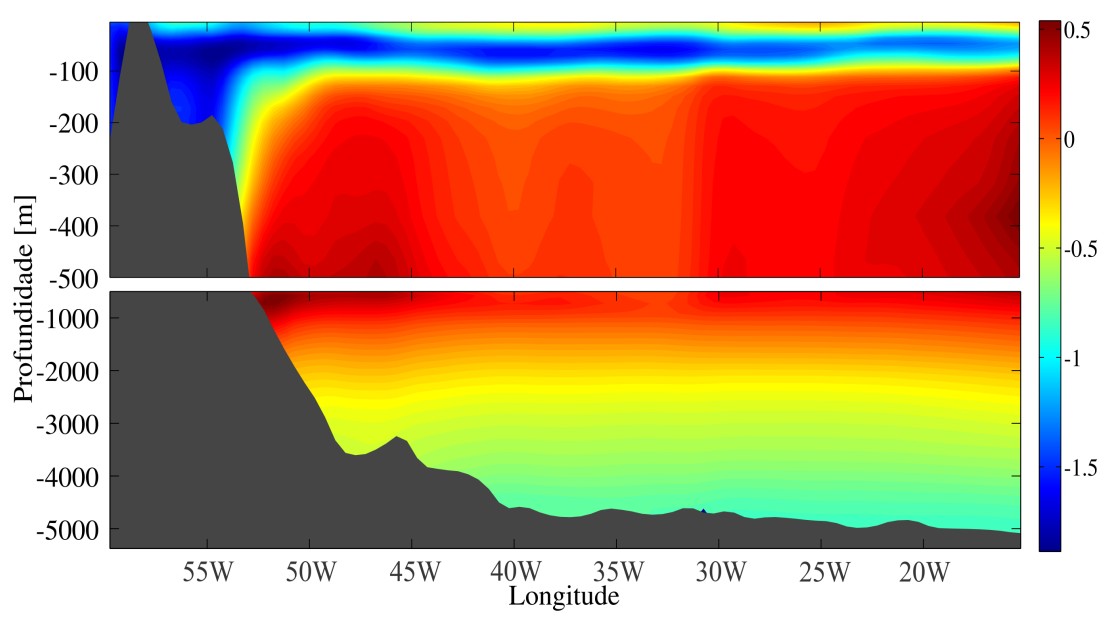

(b)

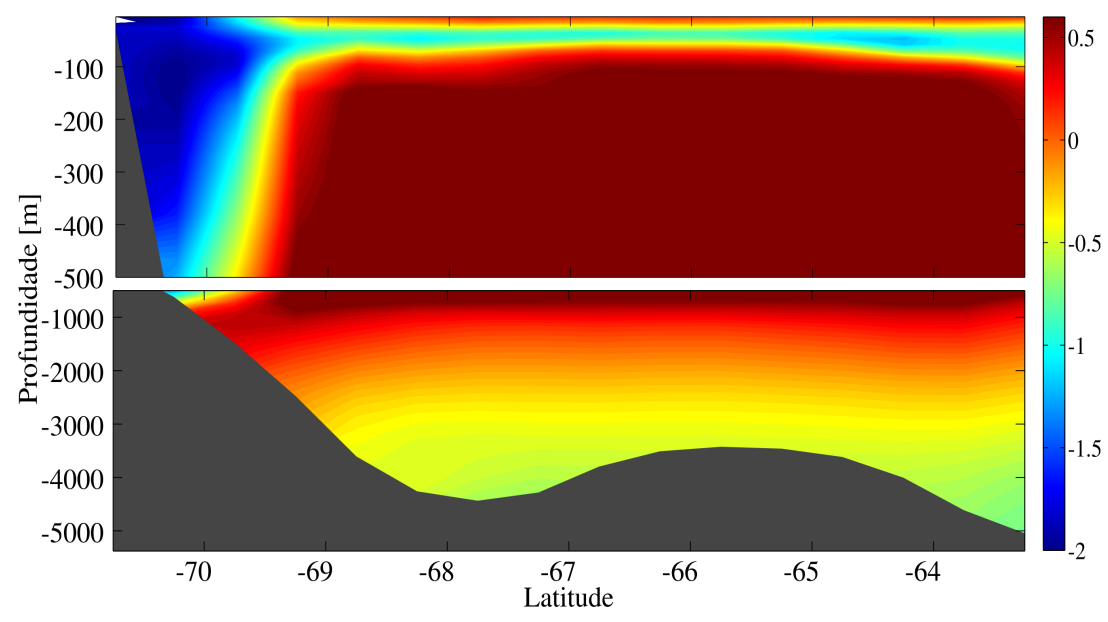

Figura 33: (a) Média climatológica (1871-2008) da temperatura $\left({ }^{\circ} \mathrm{C}\right)$ na radial $\mathrm{W} 1$; (b) Média temporal da temperatura $\left({ }^{\circ} \mathrm{C}\right)$ na radial $\mathrm{W} 2$ 
(a)

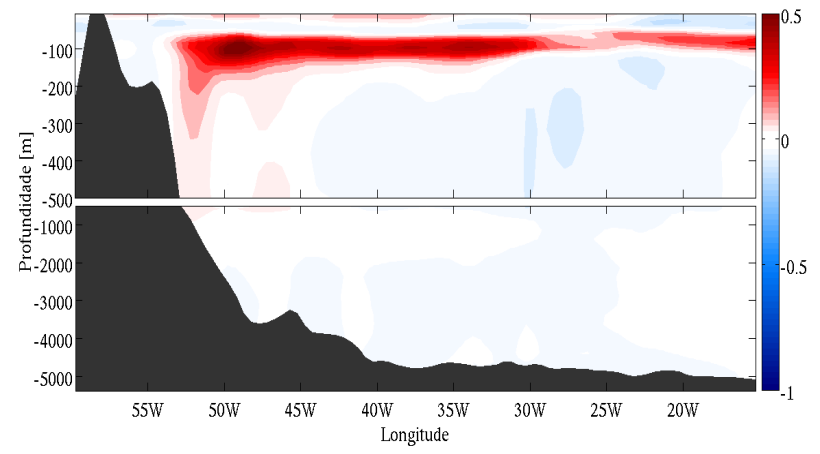

(b)

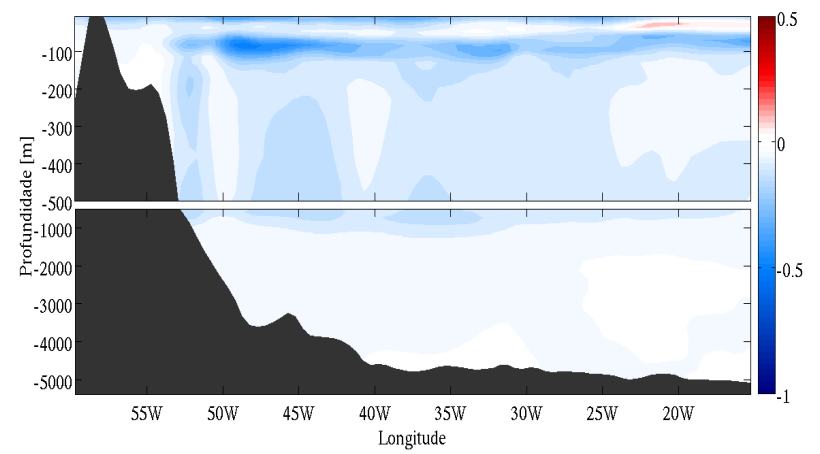

(c)

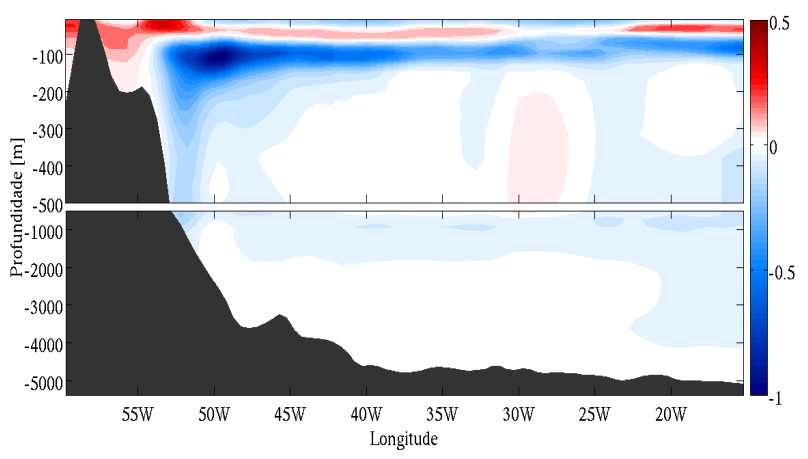

(d)

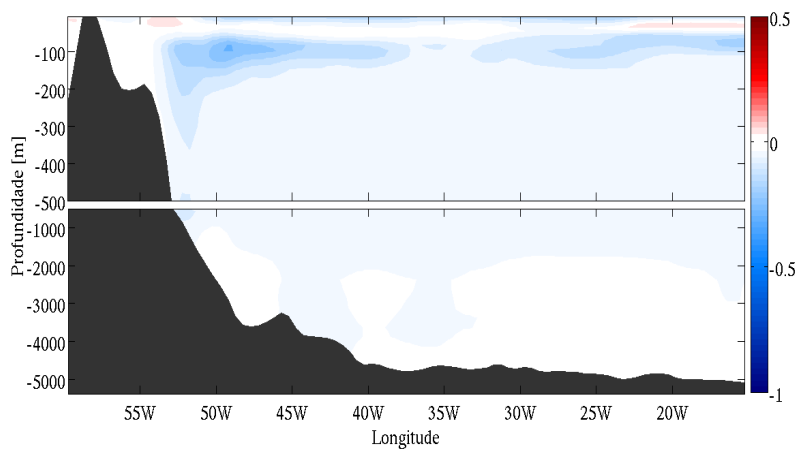

Figura 34: (a) Anomalia de temperatura $\left({ }^{\circ} \mathrm{C}\right)$ na $\mathrm{W} 1$ relativa à média climatológica (18712008) para o período entre 1925 e 1949; (b) 1950-1974; (c) 1975-1999; (d) 1925-1999. 
(a)

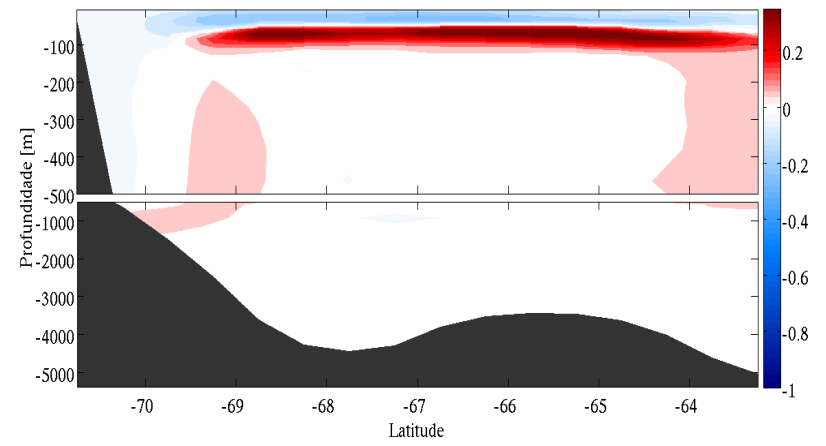

(b)

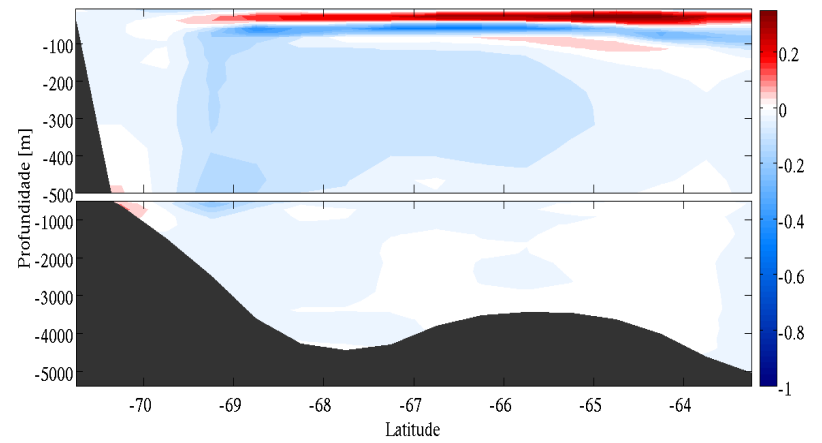

(c)

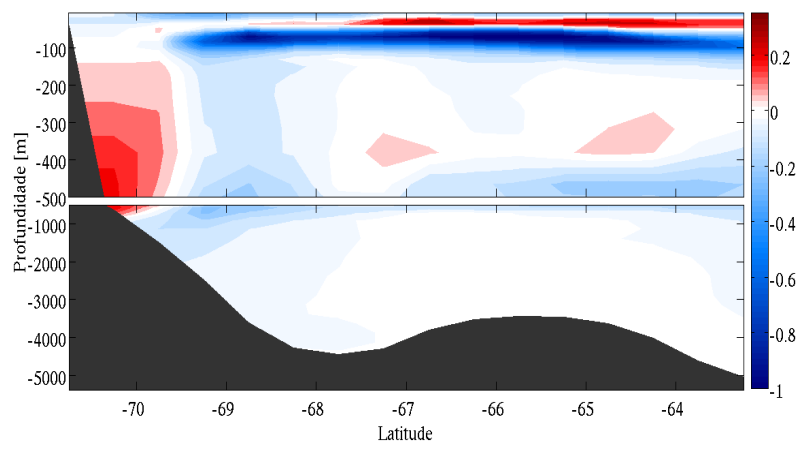

(d)

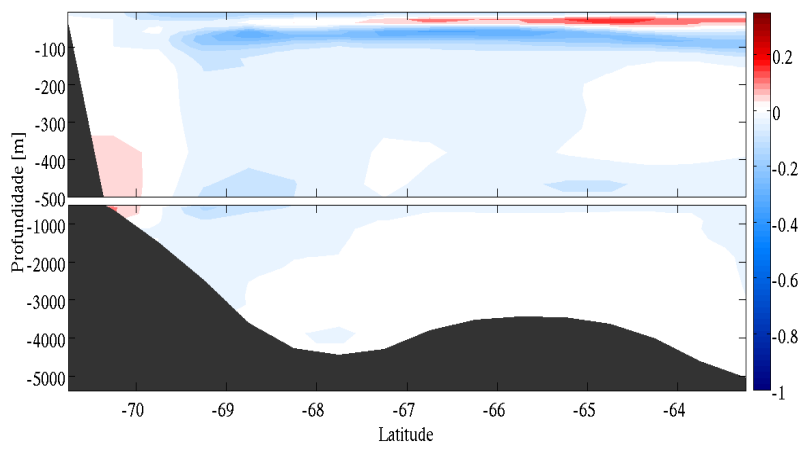

Figura 35: (a) Anomalia de temperatura $\left({ }^{\circ} \mathrm{C}\right)$ na $\mathrm{W} 2$ relativa à média climatológica (18712008) para o período entre 1925 e 1949; (b) 1950-1974; (c) 1975-1999; (d) 1925-1999. 


\subsubsection{Seções de Salinidade}

Semelhante ao observado e descrito no MR, no MW também é possível notar uma língua de águas menos salinas se desprendendo das plataformas, devido ao derretimento do gelo marinho, fluindo apenas nas camadas bem superficias das seções (Figuras 36a e 36b). Gordon (1998) descreve esta água como água de baixa salinidade da picnoclina superior", que pode ter sido gerada na estreita plataforma ao Sul do Mar de Weddell.

A partir da camada superficial, as águas apresentam um padrão de estratificação bem definido, com valores de salinidade aumentando até a profundidade entre 500 e $1000 \mathrm{~m}$, atingindo a casa dos 34,7. E é exatamente entre as profundidades de 500 e $1000 \mathrm{~m}$ que se encontra a WDW, caracterizada principalmente por seus altos valores de salinidades e temperatura, observados em ambas seções. Partindo destas profundidades, e indo em direção ao fundo, a salinidade tende a diminuir progressivamente, atingindo valores de 34,6 bem próximo ao assoalho oceânico.

Segundo Absy et al. (2008), tanto o fluxo regional que é fortemente barotrópico, quanto a própria topografia do fundo do MW, permitem que ocorra um aprisionamento de águas de baixas salinidades na plataforma continental, e isto pode ser observado claramente em ambas Figuras 36a e 36b. As possíveis fontes formadoras destas águas com baixo nível de salinidade são o derretimento do gelo marinho, a precipitação líquida, o derretimento dos glaciais da Península Antártica (Figura 36a) e o derretimento de icebergs.

Analisando os resultados das anomalias de salinidade para os quatro períodos (1925 -1949; 1950-1974; 1975-1999) é possível concluir que durante o primeiro período em ambas radiais W1 e W2 (Figuras 37a e 38a) são encontradas anomalias positivas em profundidades inferiores à 100m, valores estes atingindo no máximo 0,1. Além disso, outra feição que vale a pena ressaltar é uma língua com valores positivos se desprendendo da plataforma continental da W2 durante o terceiro período em questão (Figura( 38 c). Para o restante dos períodos, nas duas radiais, foram apenas observados valores negativos de anomalias, chegando a atingir um percentual de $-0,15$ (Figuras $37 \mathrm{~b}, 37 \mathrm{k}, 37 \mathrm{~d}$, 38b e 38d). 
(a)

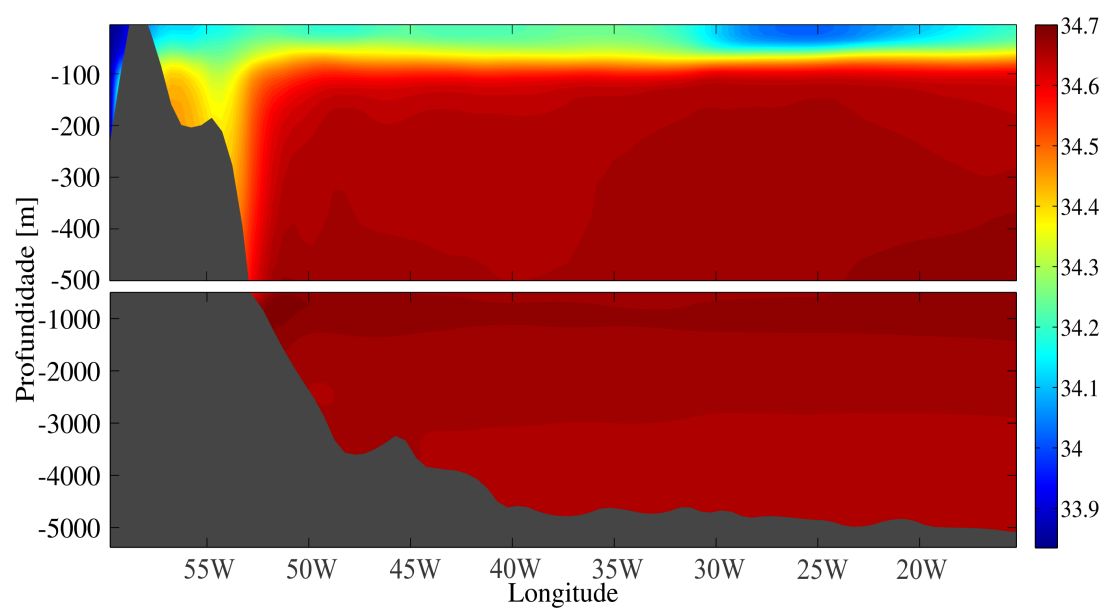

(b)

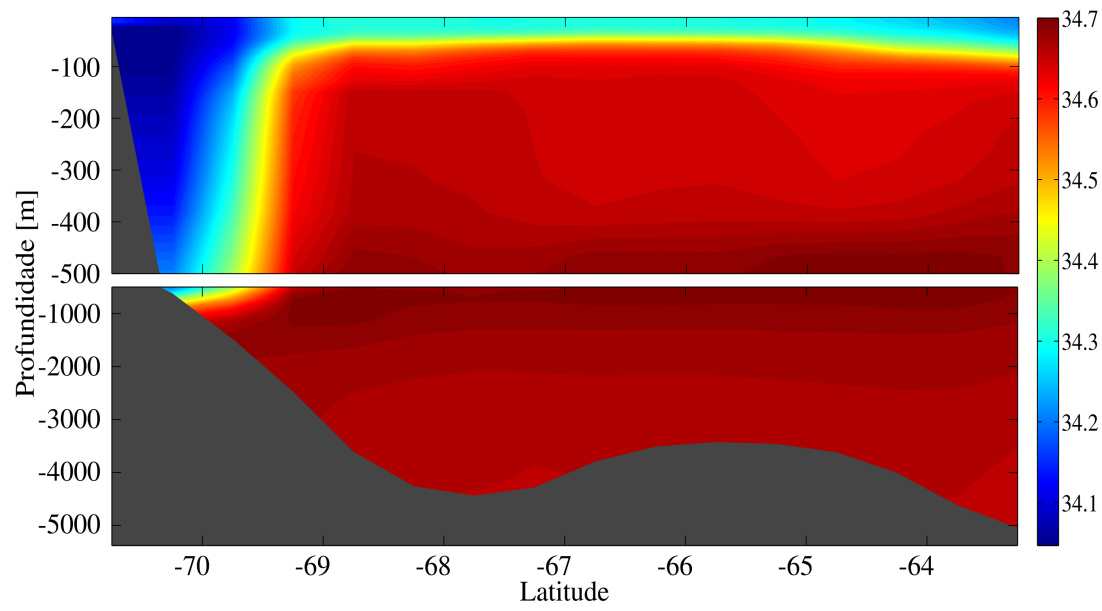

Figura 36: (a) Média climatológica (1871-2008) da salinidade na radial W1; (b) Média climatológica (1871-2008) da salinidade na radial W2. 
(a)

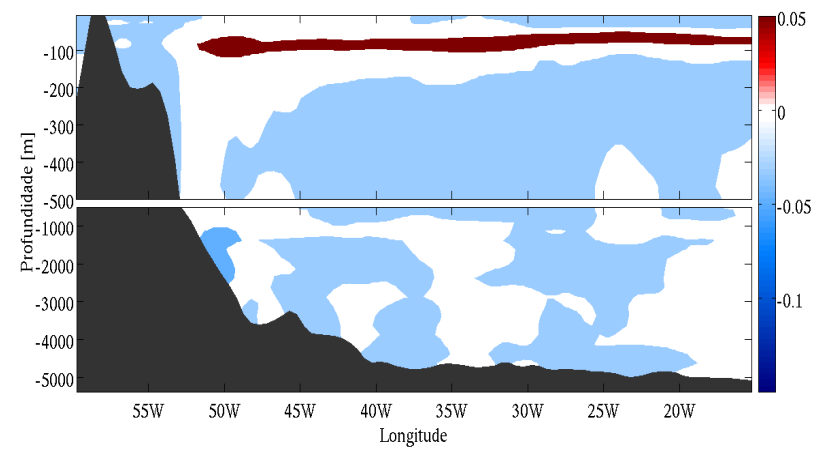

(b)

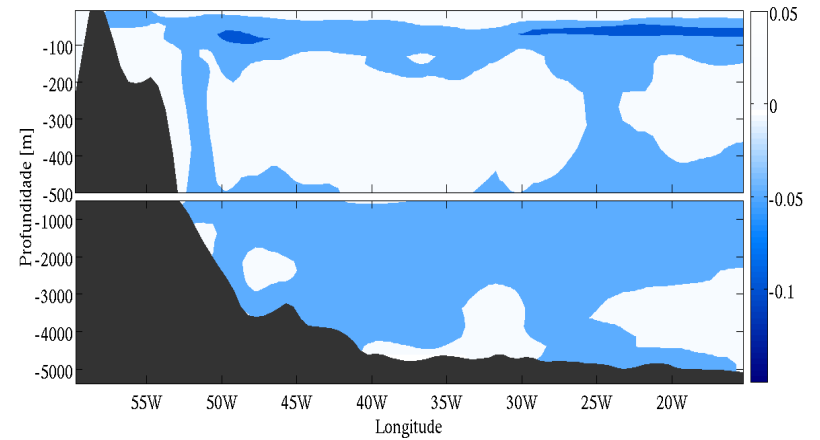

(c)

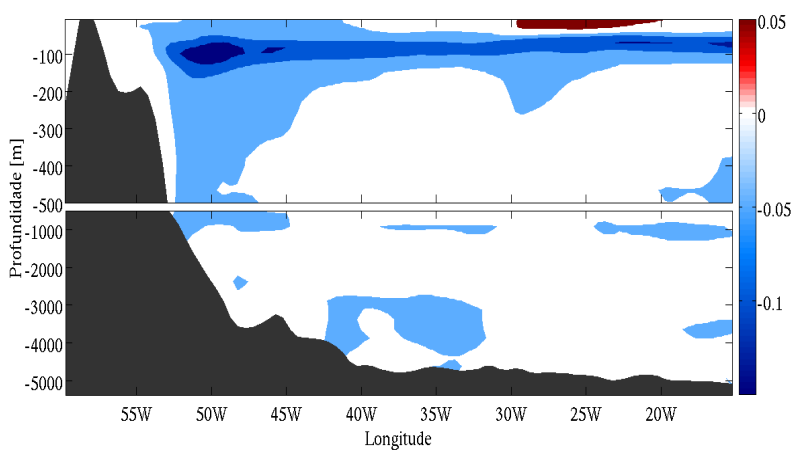

(d)

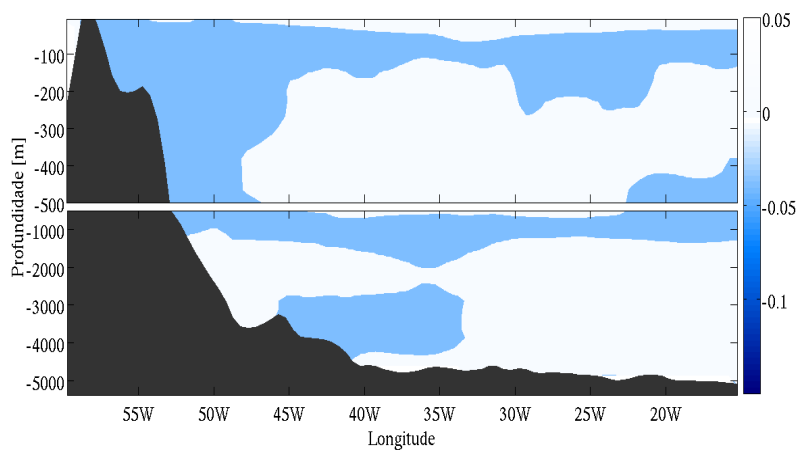

Figura 37: (a) Anomalia de salinidade na W1 relativa à média climatológica (1871-2008) para o período entre 1925 e 1949; (b) 1950-1974; (c) 1975-1999; (d) 1925-1999. 
(a)

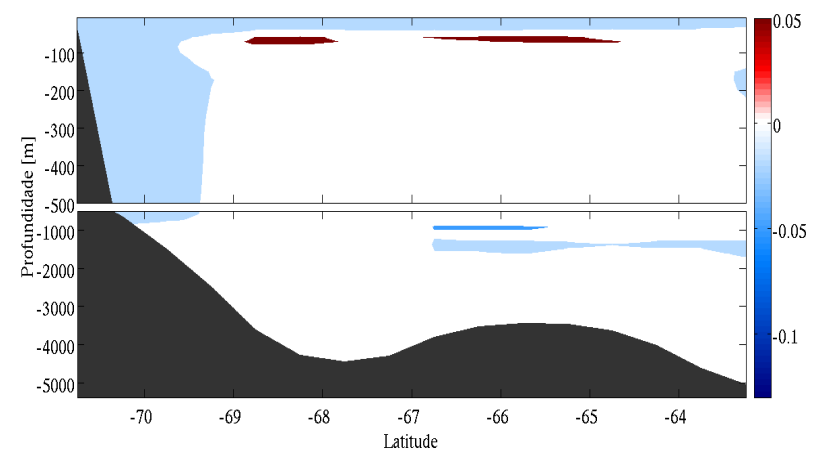

(b)

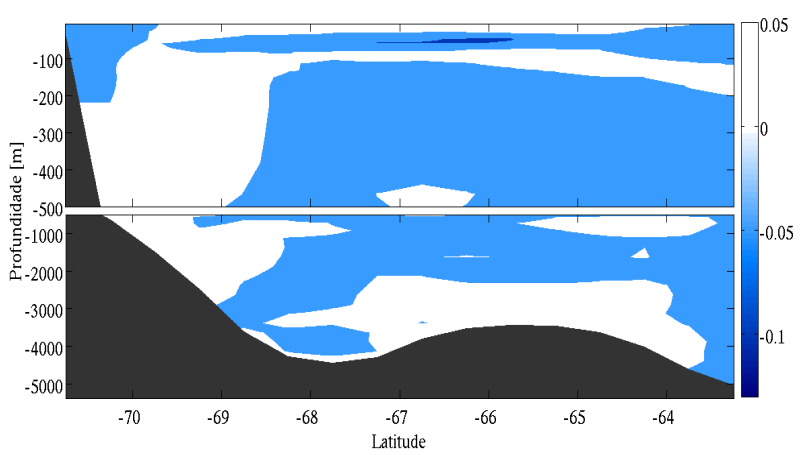

(c)

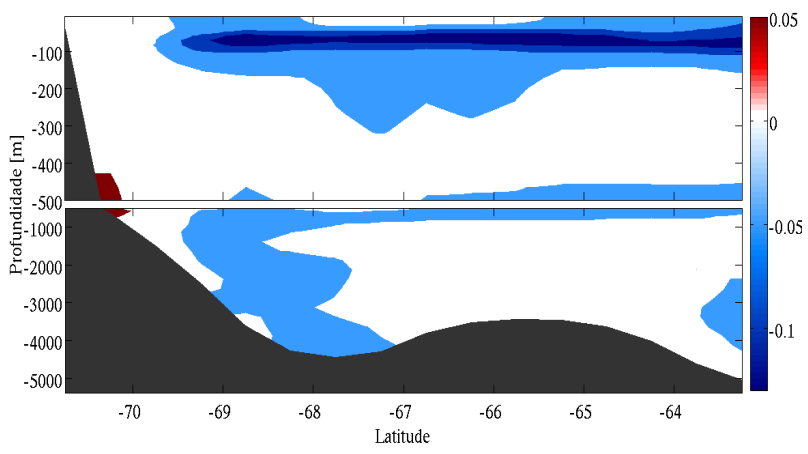

(d)

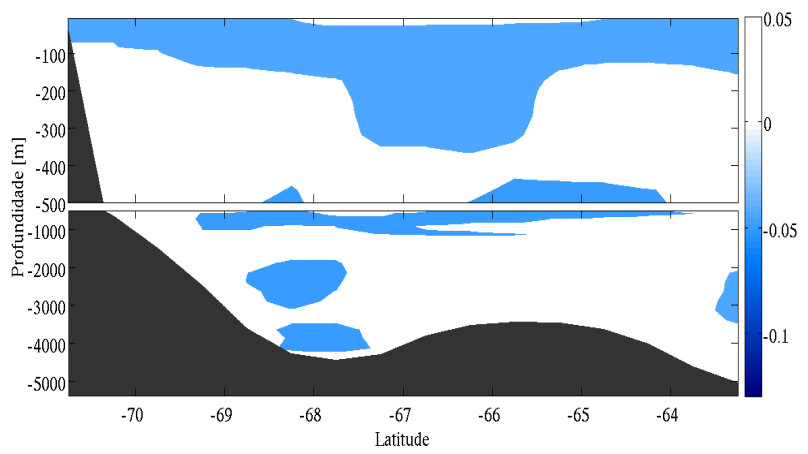

Figura 38: (a) Anomalia de salinidade na W2 relativa à média climatológica (1871-2008) para o período entre 1925 e 1949; (b) 1950-1974; (c) 1975-1999; (d) 1925-1999. 


\subsubsection{Diagramas TS}

A Figura 39 apresenta o diagrama TS gerado para a média climatológica entre os anos de 1871 e 2008 do MW, a partir dos dados da reanálise SODA. O diagrama foi inicialmente comparado aos trabalhos de Absy et al. (2008); Huhn et al. (2008); Kerr et al. (2009a); Kerr et al. (2009b); Kerr et al. (2012a); Kerr et al. (2012b); Robertson et al. (2002), que também realizaram inúmeros estudos observacionais na região do MW. Este diagrama serviu para nortear a identificação das massas de água WDW, WSDW e WSBW, cujos índices termohalinos (Tabela 2) foram considerados na investigação da AMO. A Figura 39 exibe um formato esperado onde pode se identificar a presença da WDW, ocupando a camada intermediária da coluna d' água, caracterizada por apresentar valores de temperatura e salinidade mais elevados se comparados às outras águas. Abaixo da WDW, as decrescentes temperaturas indicam a presença da WSDW, e, seguindo a curva, temperaturas potenciais menores que $-0,7^{\circ} \mathrm{C}$ caracterizam a massa de água mais densa obtida pela reanálise, WSBW. Esta separação faz-se necessária, pois as características hidrográficas apresentadas por cada uma destas águas são diferentes.

A Figura 40a exibe o diagrama TS gerado com dados de três períodos obtidos a partir da reanálise (1925-1949, 1950-1974 e 1975-1999). Como uma primeira observação da variabilidade das massas de água representadas, é possível notar que, durante o período analisado, a região ocupada pela WDW sofria de temperaturas mais elevadas nos dois primeiros períodos se comparado ao último período analisado (1975-1999), temperaturas máximas estas na casa de $0,5^{\circ} \mathrm{C}$ maiores que as máximas do último período em questão.

O diagrama TS contínuo da Figura $40 \mathrm{~b}$ mostra que a região ocupada pelas massas de água densas (WDW, WSDW e WSBW) sofreu um aumento de ambos os parâmetros, salinidade e temperatura, com a variação temporal, porém não linear. Nesta região os menores valores de temperatura e salinidade foram ocupados pela década de 1880, seguidos pelas décadas de 1900, 1920, 1960, 2000, 1940 e 1980 ocupando a região com maiores os valores. A amplitude de temperatura chegou na casa dos $1,5^{\circ} \mathrm{C}$ e de salinidade na casa dos 0,2 . 


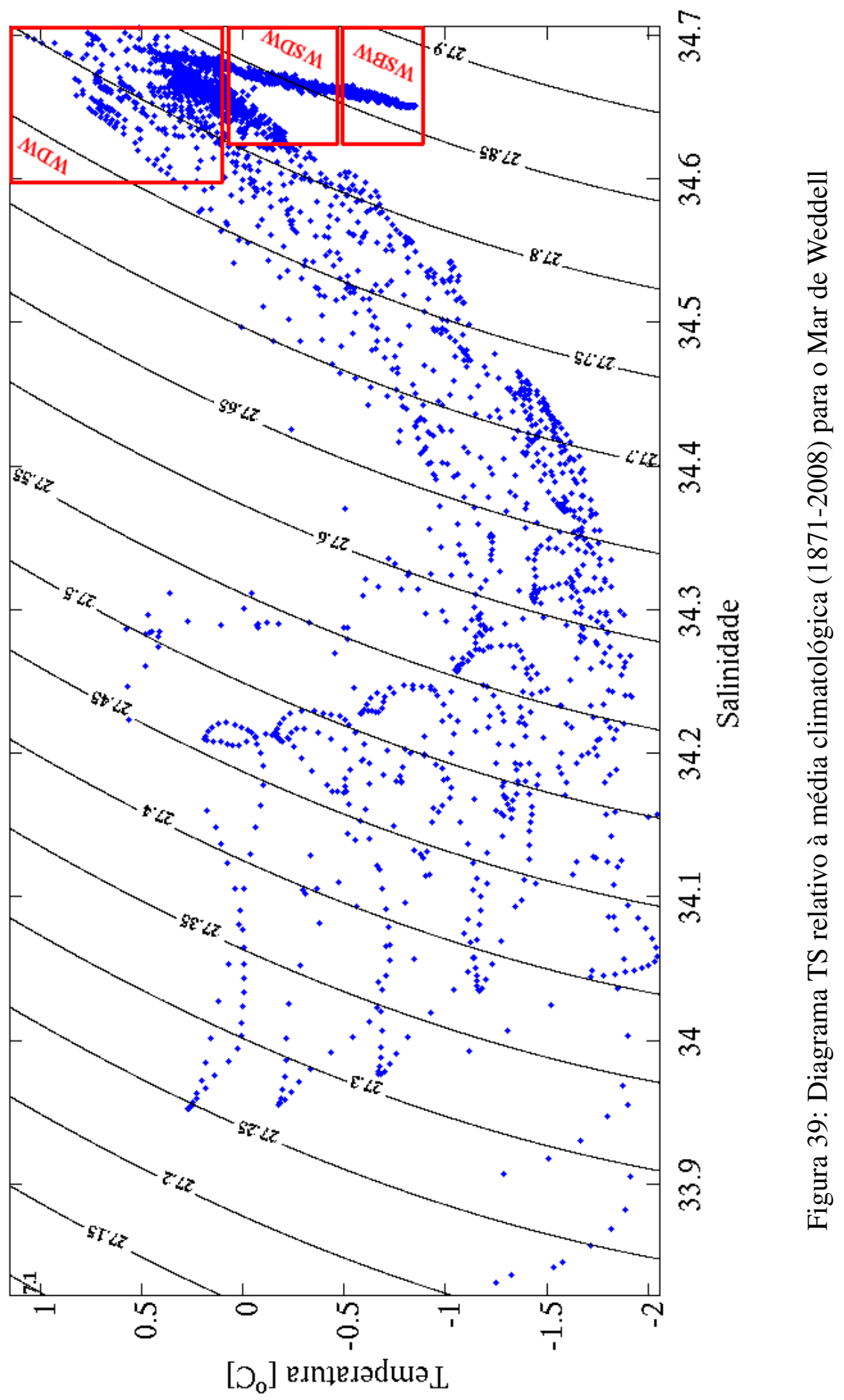


(a)

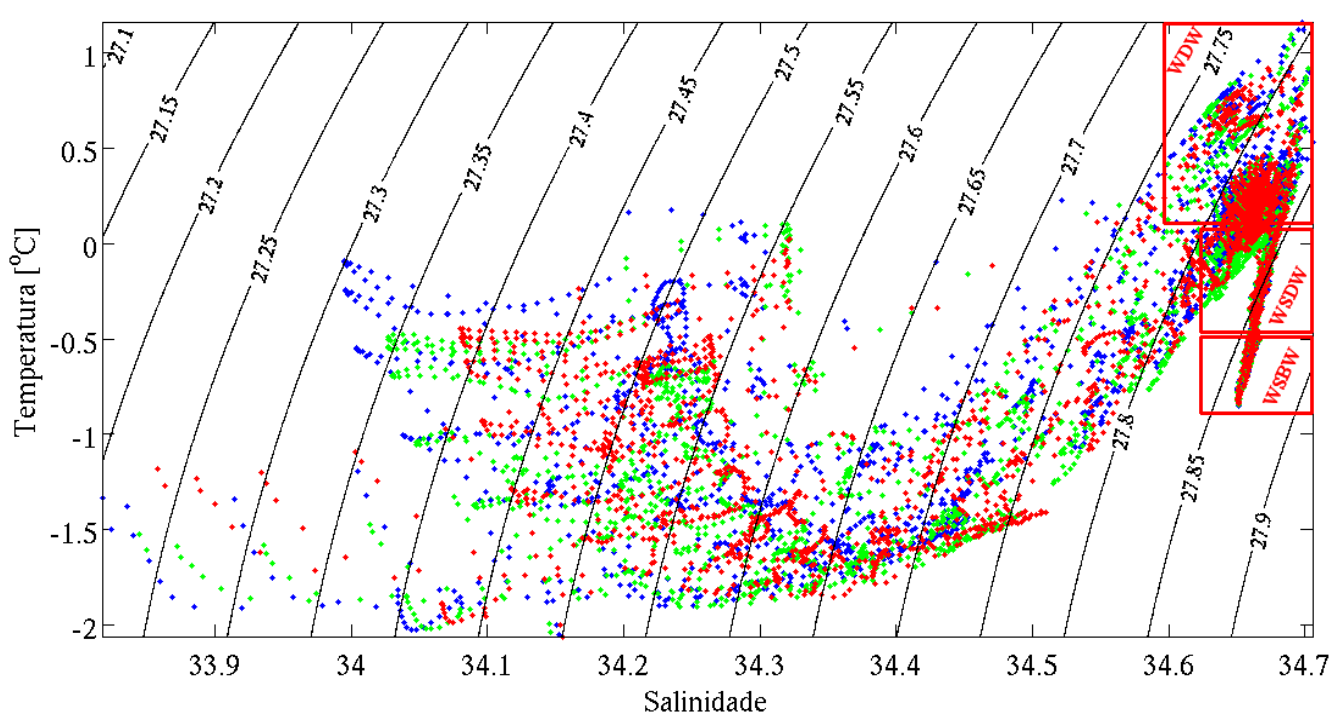

(b)

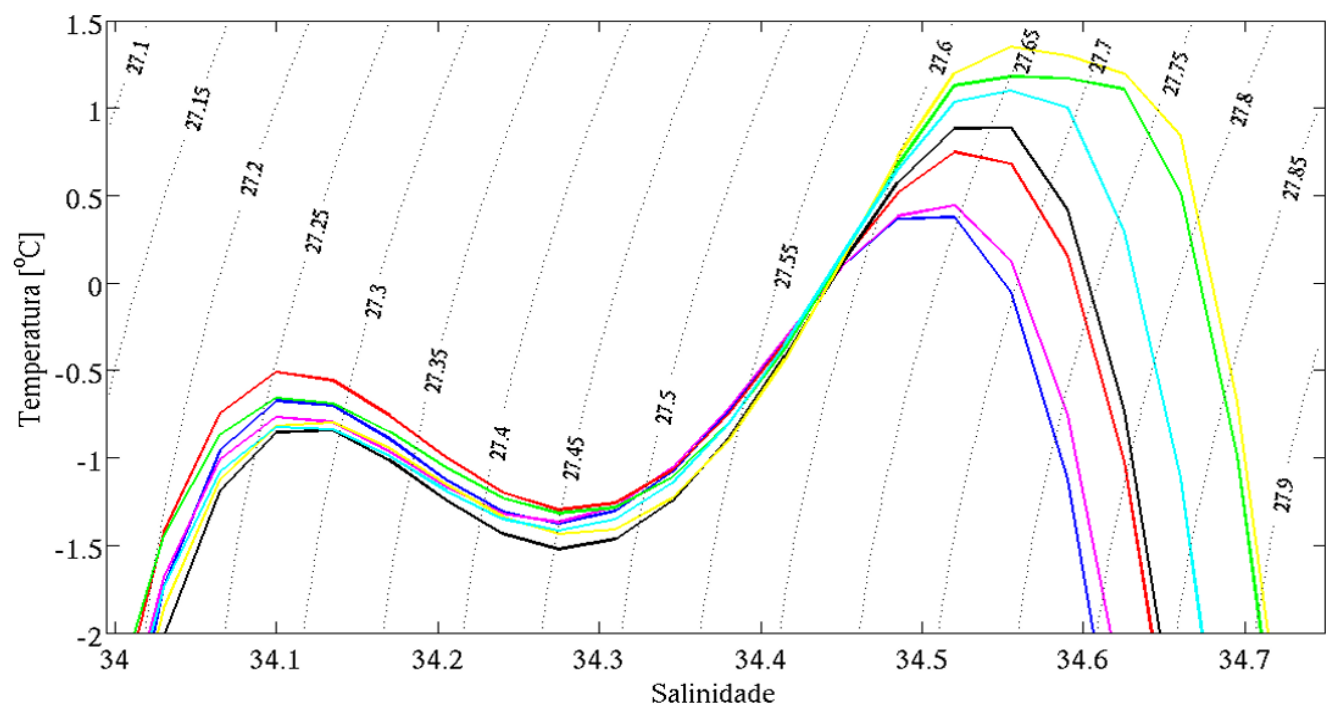

Figura 40: (a) Diagrama TS para os três períodos: 1925-1949 (azul), 1950-1974 (verde) e 1975-1999 (vermelho); (b) Diagrama TS contínuo para 7 décadas: 1880 (azul), 1900 (rosa), 1920 (vermelho), 1940 (verde), 1960 (preto), 1980 (amarelo) e 2000 (azul claro). 


\subsubsection{Distribuição das Massas de Água}

A Figura 41 apresenta a distribuição média da Água Profunda Cálida (WDW), da Água Profunda do Mar de Weddell (WSDW) e da Água de Fundo do Mar de Weddell (WSBW) para a radial W1. Optou-se por apresentar somente as distribuições médias para esta radial, porque representa melhor a localização e distribuição das massas de água no Mar de Weddell. A estrutura de massas de água desta seção é bem marcante, e, por isto, para uma melhor visualização da representatividade de cada massa de água foram plotados somente as contribuições acima de $30 \%$.

A Figura 41a mostra a WDW ocorrendo em uma camada intermediária, atingindo até a profundidade de $\sim 1700 \mathrm{~m}$. Diferente da WDW, a WSDW (Figura 41p) apresenta seu núcleo principal com contribuições acima de 90\%, ocupando toda uma área entre 1000 e $3500 \mathrm{~m}$ de profundidade, corroborando com os resultados observados por Kerr et al. (2009a) e Kerr et al. (2012b), porém, diferindo dos resultados encontrados Kerr et al. (2009b) que apontaram uma contribuição máxima somente de $70 \%$.

A WSBW faz-se presente a partir dos 2300m, com contribuição de aproximadamente $30 \%$ nesta altura, aumentando para praticamente $100 \%$ a partir dos $4000 \mathrm{~m}$; valores estes não atingidos por Kerr et al. (2009a) e Kerr et al. (2009b), pois a contribuição máxima da WSBW encontrada no trabalho citado é de somente $70 \%$. Como a WSBW é bem mais salina se comparado às outras águas, Gordon (1998) atribui a HSSW (Água de Plataforma de Alta Salinidade), proveniente da região mais sudoeste da plataforma continental, como a principal fonte da densa WSBW; e Huhn et al. (2008) indica que a WSBW com temperaturas inferiores à $1,6^{\circ} \mathrm{C}$ consiste entre $50-70 \%$ de pura HSSW. Por sua vez, estudos como o de Weppernig et al. (1996) e o de Huhn et al. (2008) apontam a Plataforma de Gelo Filchner-Ronne como uma das principais fontes também da WSBW.

Nas próximas seções serão apresentadas especificamente as distribuições de cada massa de água e suas respectivas anomalias. Em uma análise comparativa preliminar entre os resultados obtidos, é possível afirmar que a WDW na seção W1 (Figura 42) foi a que maior apresentou variabilidade temporal, se comparado às outras seções e períodos analisados (Figuras 44, 47, 49, 52, e 54). Esta variabilidade pode se dar pelo fato de o Giro de Weddell carrear boa parte das águas nesta seção. Fazendo esta mesma análise 
para a WSDW e WSBW (Figuras 47, 49, 52 e 54) é possível aferir que o grau de variabilidade é bem pequeno entre os períodos analisados, porém, é totalmente visível que suas tendências são opostas, principalmente entre as Figuras 51] 56, tendências estas também obtidas por Kerr et al. (2009b).

Apesar dos bons resultados obtidos com o produto de assimilação do SODA neste trabalho, é interessante pontuar que, de acordo com Dee (2005) todos sistemas de assimilação de dados podem ser afetados por erros, que podem estar diretamente relacionados à: (i) limitações dos modelos de assimilação; (ii) problemas com os dados; (iii) aproximações relativas às observações e, (iv) a metodologia da assimilação. Portanto, as massas de água descritas aqui neste trabalho podem ter sido afetadas por um ou mais destes erros (KERR et al., 2012b). 
(a)

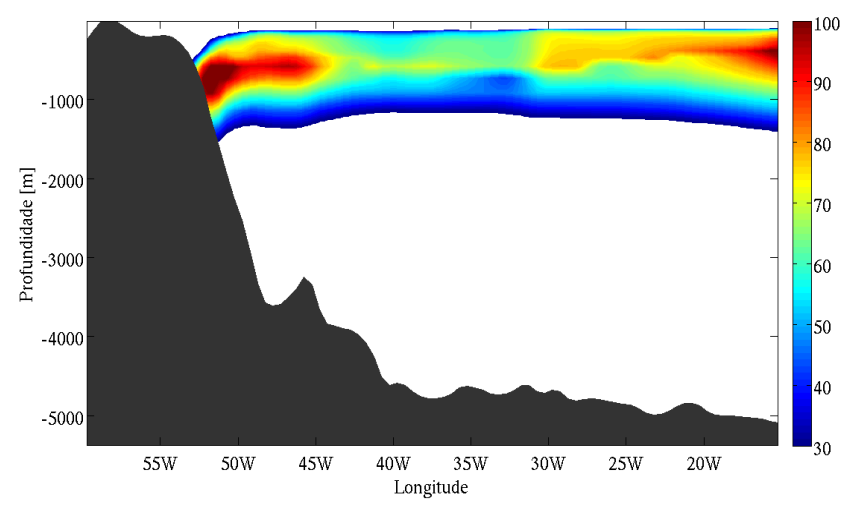

(b)

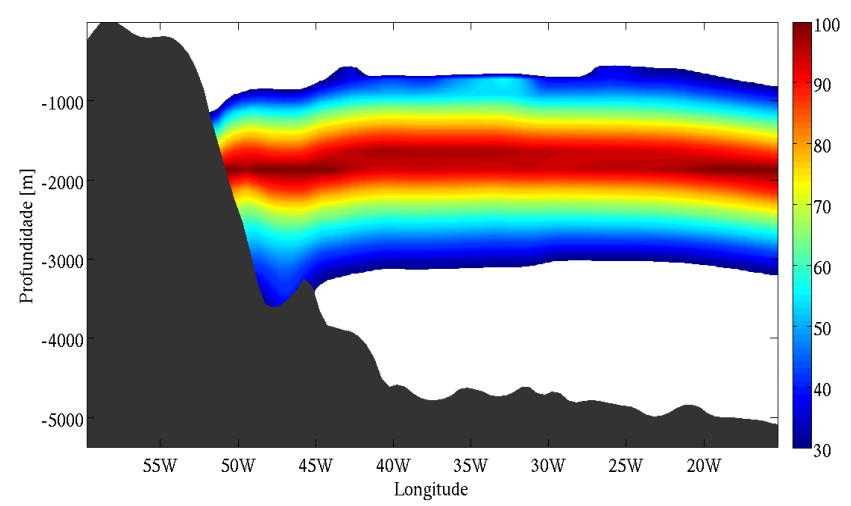

(c)

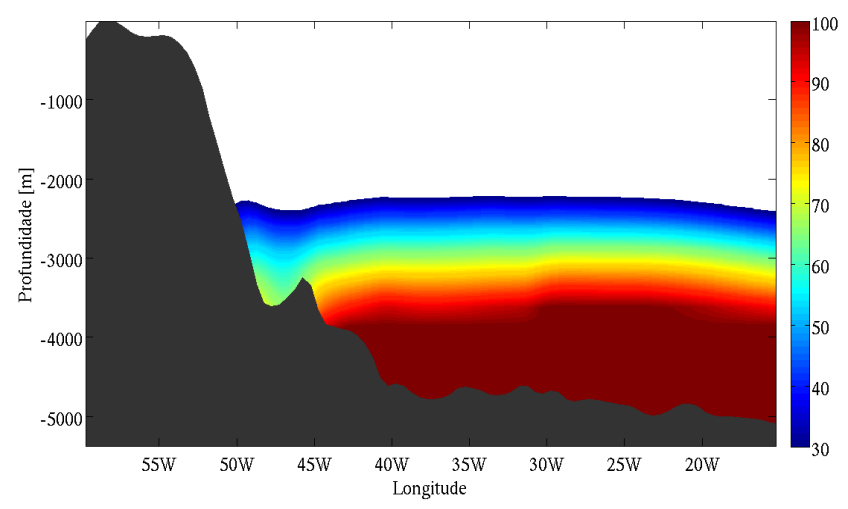

Figura 41: (a) Distribuição média (\%) da WDW na radial W1 para todo o período entre 1870 e 2008; (b) Distribuição média (\%) da WSDW na radial W1 para o mesmo período; (c) Distribuição média (\%) da WSBW na radial W1 para o mesmo período. 


\subsubsection{Distribuição da WDW}

Observando a distribuição zonal da WDW na seção W1 (Figura 42) é possível notar que nos perídos analisados a WDW na W1 foi observada até cerca de $1500 \mathrm{~m}$ de profundidade alcançando um percentual de mistura de $30 \%$, confirmando os resultados obtidos por Kerr et al. (2009b) e Kerr et al. (2012b) para a mesma região analisada. Considerando como limite inferior uma contribuição acima de 50\%, a WDW é encontrada por volta de $1200 \mathrm{~m}$ de profundidade em quase toda a extensão da seção. Além disso, vale ressaltar que a WDW pôde ser encontrada com quase total exclusividade e contribuição alcançando valores acima de $70 \%$ por volta de $800 \mathrm{~m}$ em média de profundidade.

A Figura 43 apresenta as distribuições de anomalias para a seção W1, com padrões bastante semelhantes apresentados pelos três períodos, é possível verificar um recuo da WDW nas camadas superiores e um avanço dela nas camadas inferiores. Porém, entre os anos de 1950 à 1974 (Figura 43b) este recuo foi mais acentuado, não permitindo que águas com anomalias de valores positivos ocupassem toda a seção.

Analisando agora a seção meridional W2 (Figura 44) é possível verificar que nos três períodos a distribuição da WDW foi muito mais evidenciada se comparada à W1, atingindo percentuais muito mais elevados desde à superfície até profundidades de aproximadamente $1100 \mathrm{~m}$. Estes valores diminuem à medida que as massas de água começam a atingir maiores latitudes e, por consequencia, o fundo marinho e a plataforma de gelo, reduzindo também a própria extensão vertical da WDW (ABSY et al., 2008). Ainda segundo Absy et al. (2008), a mistura diapicnal existente entre a WDW e as camadas superiores atua como um mecanismo fundamental de fornecimento de calor da quente WDW para o oceano superior.

As variações temporais na distribuição da WDW são pequenas. Porém analisando seus respectivos campos de anomalias, é interessante notar um aumento da contribuição da WDW nos períodos entre 1925-1949, 1975-1999 e 1925-1999 (Figuras $43 \mathrm{a}, 43 \mathrm{k}, 43 \mathrm{~d}, 45 \mathrm{a}, 45 \mathrm{k}$ e 45d) e uma diminuição na contribuição entre os anos de 19501974 (Figuras 43b e 45b). Esta diminuição talvez esteja relacionada à ocorrência da polynia de Weddell, que entre as décadas de 1960/1970 ocasionou um leve resfriamento das temperaturas da WDW à oeste do Meridiano de Greenwich (GORDON, 1982). 
O aumento da contribuição da WDW observado principalmente nas camadas inferiores (Figuras 43a, 43, $43 \mathrm{~d}, 45 \mathrm{c}$ e $45 \mathrm{~d}$ ) e em toda a superfície da Figura 45a ocorre em virtude de processos de larga-escala que são originados externamente ao Giro de Weddell. O principal processo está relacionado ao transporte da CDW para dentro do MW, que se pode dar por dois principais fatores: (i) instabilidades na ACC próximas à borda Norte do Giro de Weddell; (ii) intensificação da ACC na borda leste do Giro (20-30 E) (FAHRBACH et al., 2004; KERR et al., 2009b).

As distribuições espaciais da WDW apresententadas em cortes específicos de profundidade $(1000 \mathrm{~m}, 2000 \mathrm{~m}, 3000 \mathrm{~m}$ e $4000 \mathrm{~m})$ podem ser visualizadas na Figura 46. Observando a Figura 46a é possível concluir que nesta profundidade esta água é inteiramente formada na porção mais à Leste da plataforma continental, e segue por toda a margem desta plataforma até a ponta superior da Península Antártica, obedecendo os contornos batimétricos da plataforma de gelo, e apresentando percentuais superiores à 90\% em toda esta região. A partir deste núcleo de altas concentrações as contribuições tendem a diminuir à medida que se afastam para o Norte, tendo seu núcleo de menores percentuais $(\sim 40 \%)$ localizado na região central do Giro de Weddell.

A região ocupada pela WDW na profundidade de 2000m (Figura 46b) apresentou uma contribuição reduzida em todo o MW, com valores inferiores à $40 \%$ na região mais ao Sul, seguindo novamente todo o contorno da plataforma continental. Já na profundidade de 3000m (Figura 46c) a WDW apresentou uma contribuição praticamente nula em todo o MW, com exceção de um pequeno núcleo, com contribuições inferiores à $25 \%$, encontrado ao Sul entre as longitudes de 40 e $30^{\circ} \mathrm{W}$. E, por fim, na profundidade de 4000m (Figura 46d) a contribuição da WDW foi totalmente nula.

Nas três primeiras profundidades analisadas (Figuras 46a, 46b e 46c) é possível ainda notar fortes concentrações à oeste da Península Antártica. De acordo com Orsi et al. (1999), estas concentrações são devidas a presença da CDW, que circula com a ACC e ocorre justamente até a profundidade de 3000m. Segundo Kerr (2006) a marcação desta água somente foi possível em virtude de a CDW ser a água precursora da WDW, que por sua vez possui índices termohalinos consideravelmente mais elevados se comparados às outras massas de água analisadas. 
Por fim, de acordo com Kerr et al. (2009b), uma melhor compreensão das causas da variabilidade da WDW é fundamental para o entendimento da variabilidade das massas de água profundas e de fundo, em virtude de a WDW ser uma das fontes das mesmas. Portanto, qualquer alteração nestas águas intermediárias pode ser diretamente relacionada às mudanças das características da WSBW, por exemplo. 
(a)

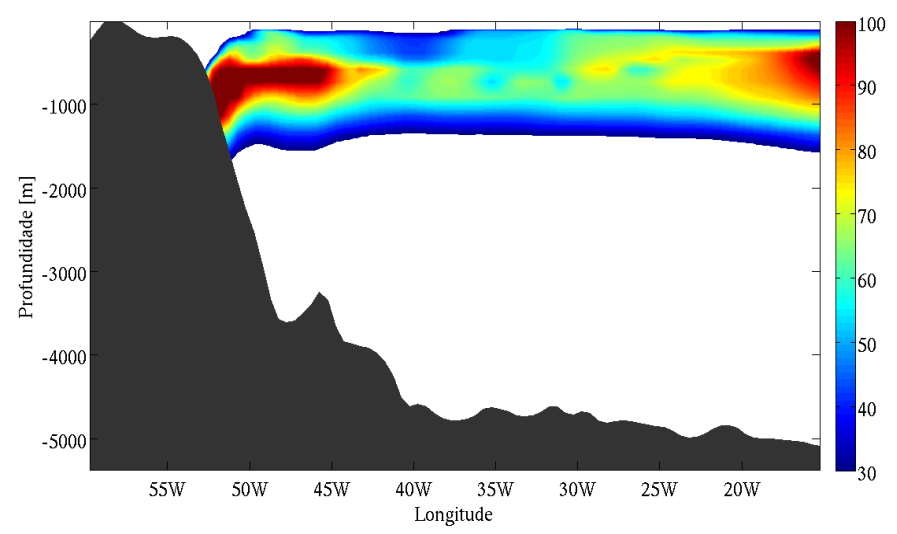

(b)

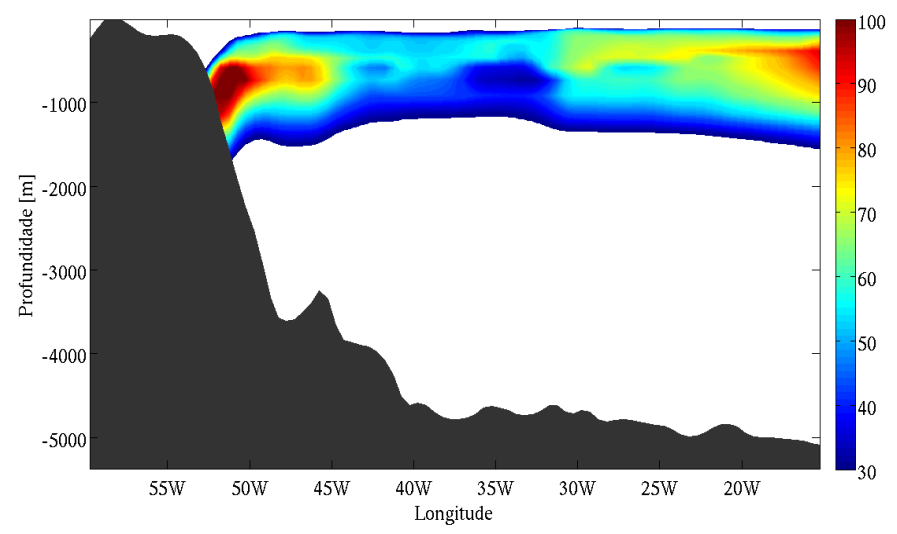

(c)

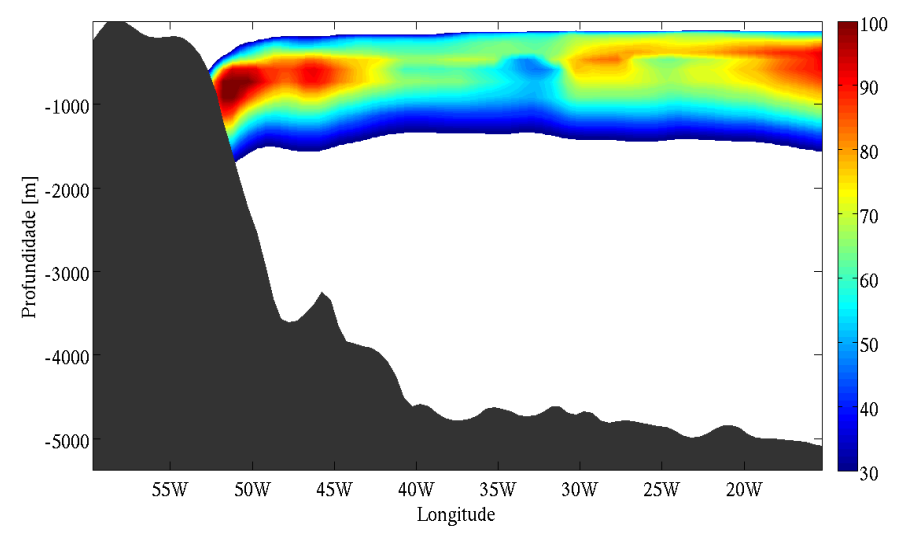

Figura 42: (a) Distribuição (\%) da WDW na W1 para o período entre 1925 e 1949; (b) 1950-1974; (c) 1975-1999 
(a)

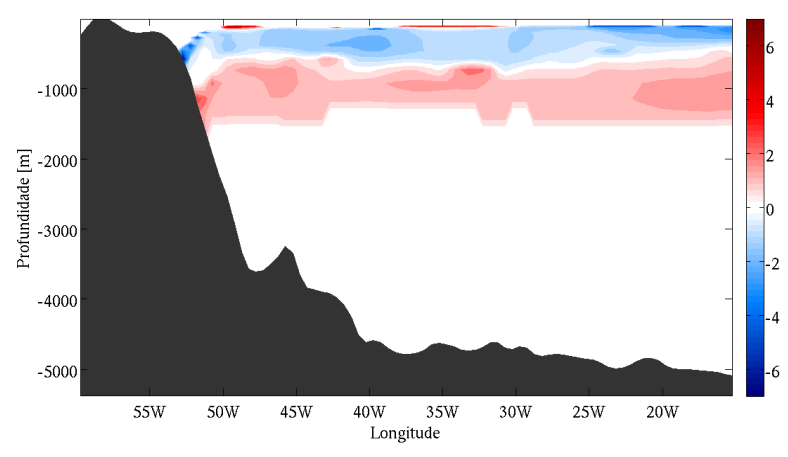

(b)

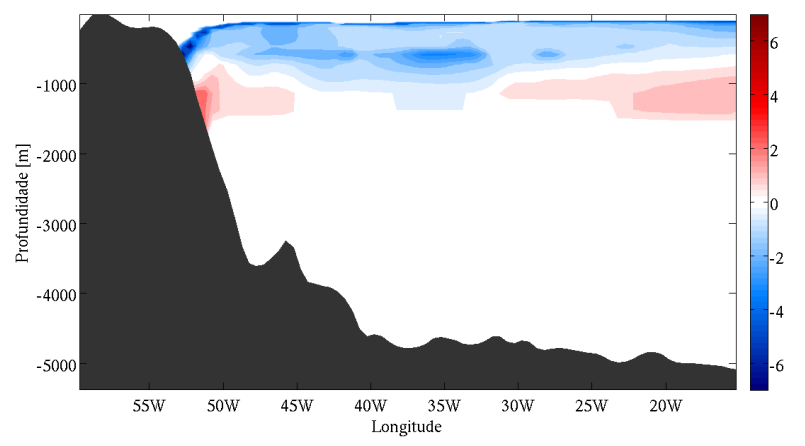

(c)

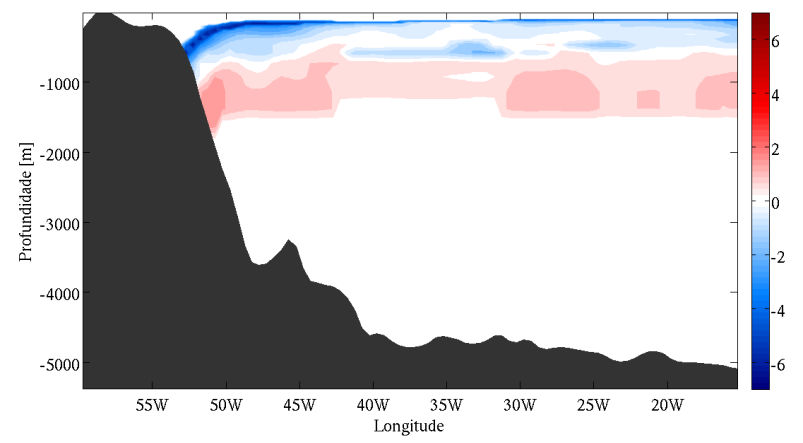

(d)

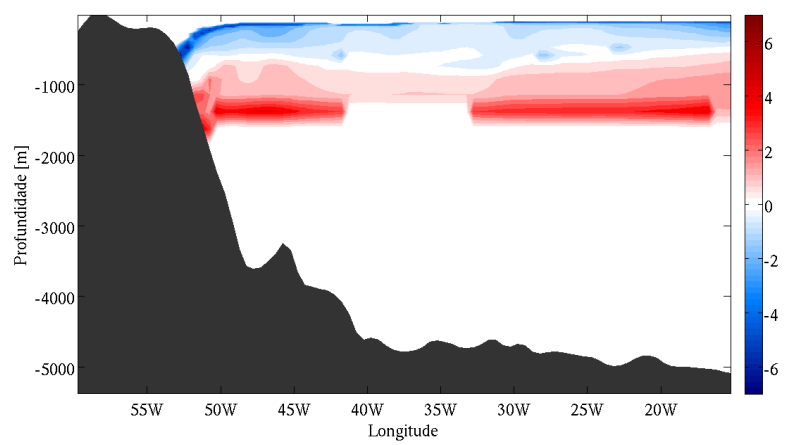

Figura 43: (a) Anomalia da distribuição (\%) da WDW na W1 relativa à média climatológica (1871-2008) para o período entre 1925 e 1949; (b) 1950-1974; (c) 1975-1999; (d) 1925-1999. 
(a)

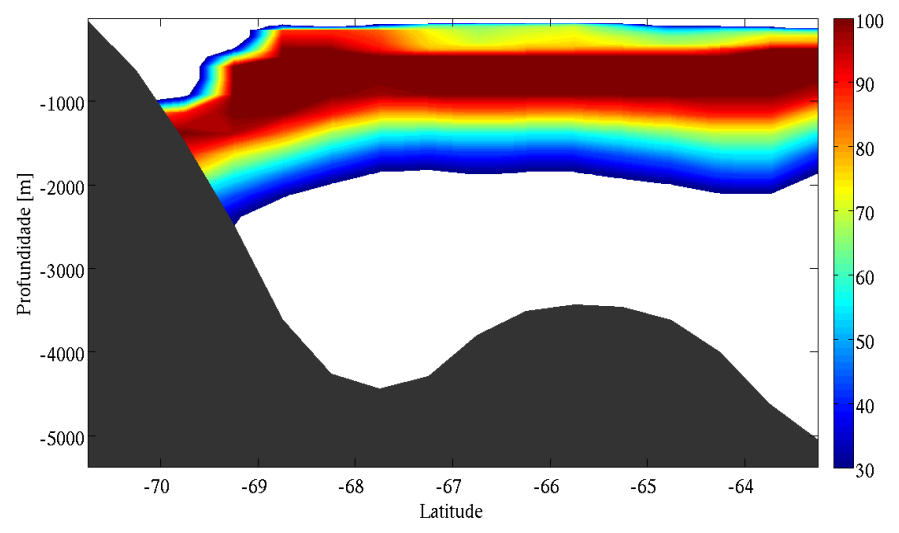

(b)

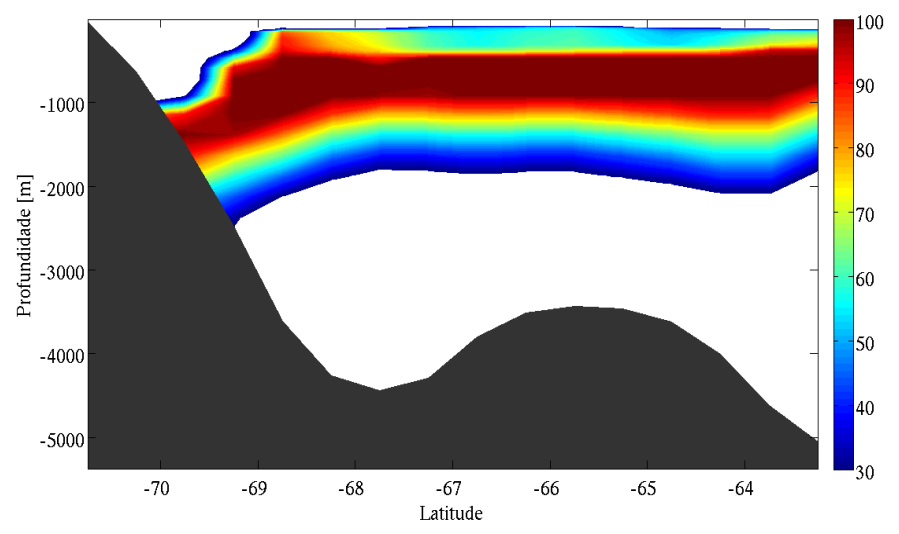

(c)

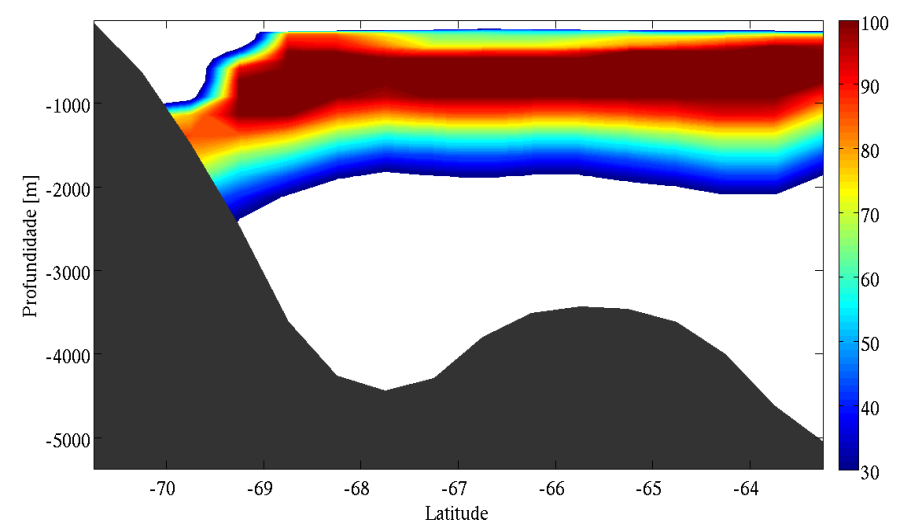

Figura 44: (a) Distribuição (\%) da WDW na W2 para o período entre 1925 e 1949; (b) 1950-1974; (c) 1975-1999 
(a)

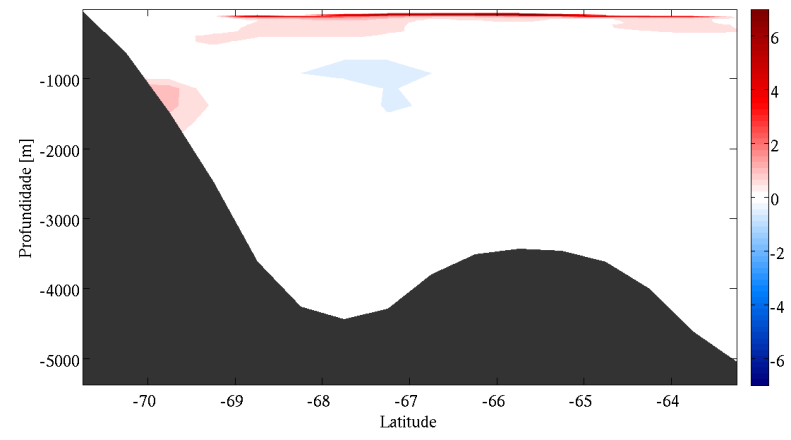

(b)

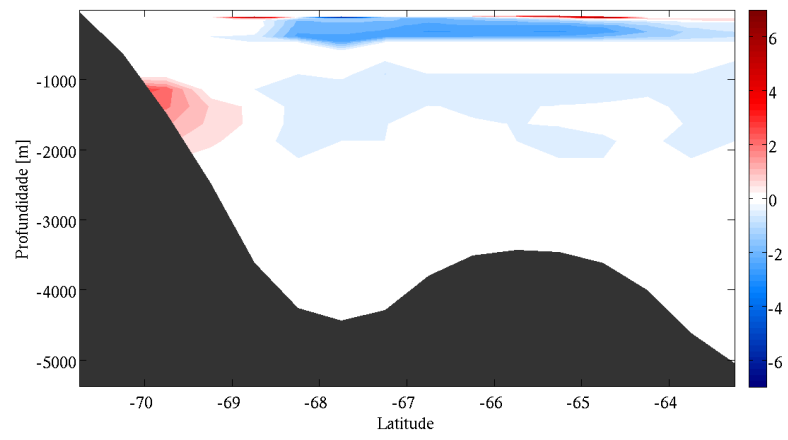

(c)

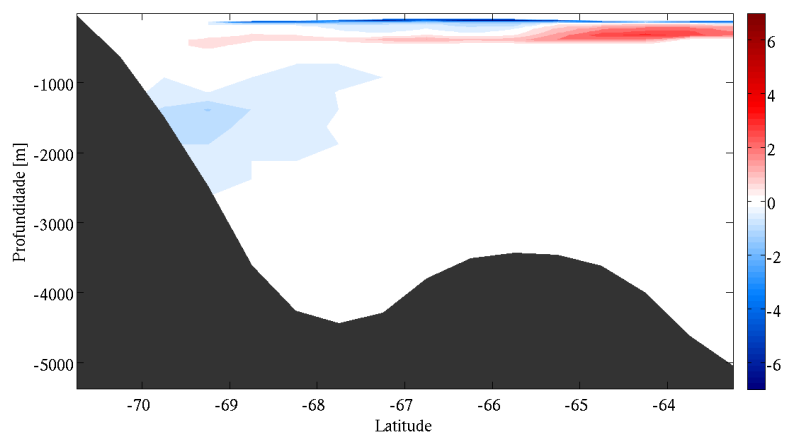

(d)

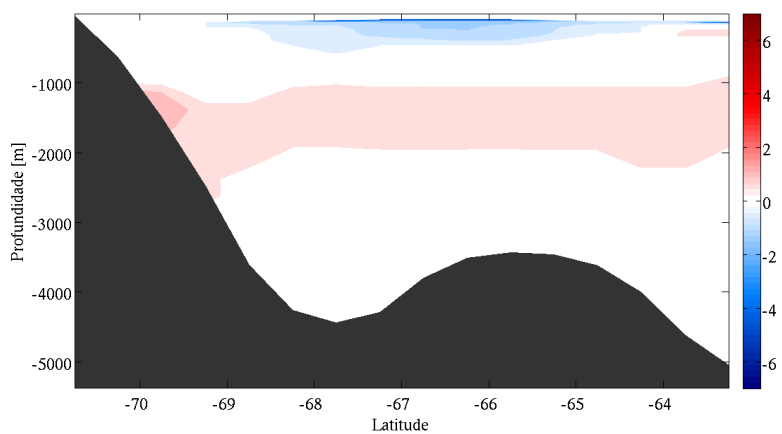

Figura 45: (a) Anomalia da distribuição (\%) da WDW na W2 relativa à média climatológica (1871-2008) para o período entre 1925 e 1949; (b) 1950-1974; (c) 1975-1999; (d) 1925-1999. 
(a)

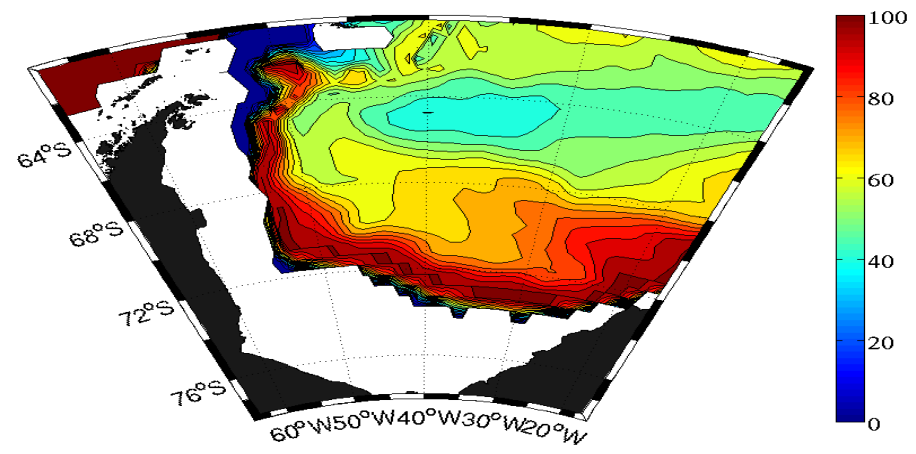

(b)

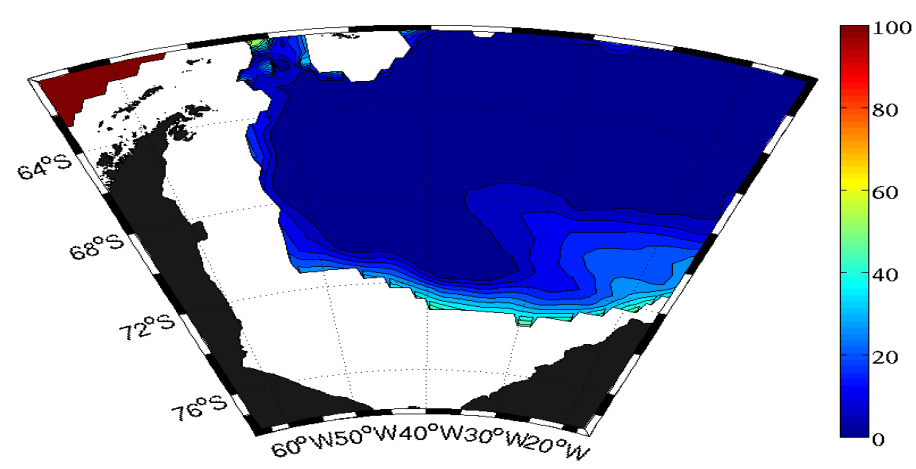

(c)

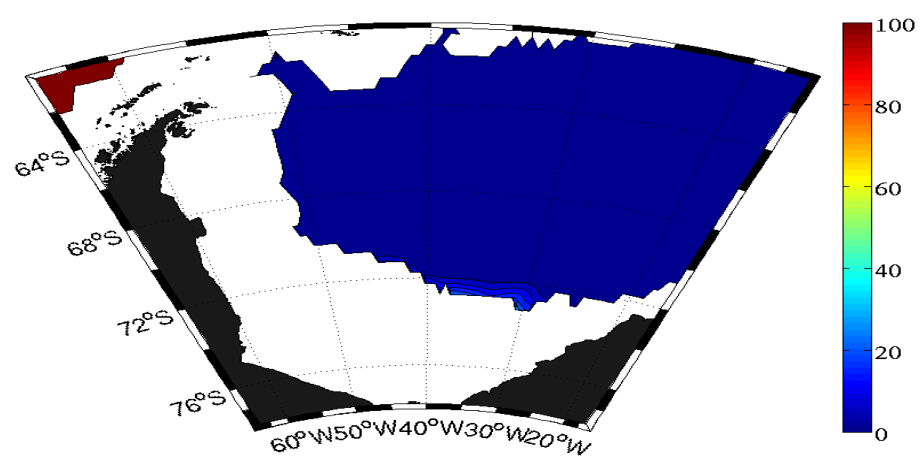

(d)

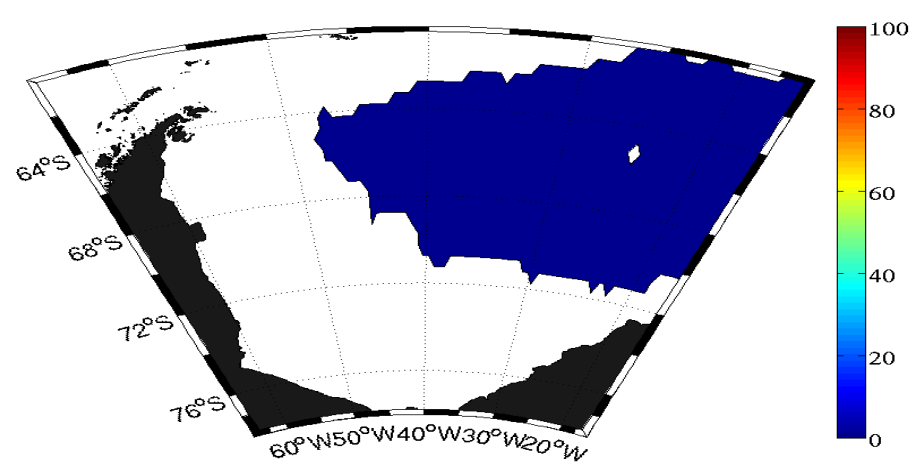

Figura 46: (a) Distribuição (\%) média (1871-2008) da WDW no Mar de Weddell para a profundidade de 1000m; (b) 2000m; (c) 3000m; (d) 4000m 


\subsubsection{Distribuição da WSDW}

A distribuição da WSDW observada tanto na seção W1 (Figura 47) quanto na seção W2 (Figura 49) pouco variou temporalmente. Porém, sua presença se dá notavelmente em ambas seções, atingindo núcleos com contribuição máxima entre 90-100\% entre 2000 e 3500m, resultados estes também obtidos por Kerr et al. (2009b). Como contribuições de $\sim 30 \%$ são encontradas em regiões mais rasas que $1200 \mathrm{~m}$ e mais profundas que $4000 \mathrm{~m}$ na seção W1 e mais rasas que $1800 \mathrm{~m}$ e mais profundas que $4500 \mathrm{~m}$ na seção W2, é possível confirmar a existência de uma mistura diapicnal desta massa de água tanto com a WDW como com a WSBW (Ver Figuras 42, 44, 52 e 54). Além disso, pode-se notar uma inclinação na distribuição da WSDW, de forma que esta ocorre mais profundamente em latitudes maiores que $68^{\circ} \mathrm{S}$, elevando-se à medida que se afasta da plataforma continental (Ver Figura 49).

As distribuições de anomalias da WSDW para a W1 (Figura 48) apontaram padrões bastante semelhantes entre os quatro períodos analisados, e, assim como a WDW, apresentaram um recuo nas camadas superiores e um avanço nas inferiores. O que é interessante notar são pulsos de anomalias positivas encontradas no topo das duas camadas, indicando um afloramento desta água nestes pontos entre os anos de 1950 a 1999 (Figuras 48p e 48c). Já as anomalias obtidas para a seção W2 apresentaram, além de um recuo da WSDW nas camadas superficiais, feições interessantes de núcleos de sinais opostos de anomalias saindo da plataforma (Figuras 50p e 50k). Por fim, nos períodos entre 19501974 e 1925-1999 (Figuras 50b e 50d) foi possível a observância apenas de anomalias negativas.

Comparando os resultados de ambas seções, com os resultados observacionais obtidos por Kerr et al. (2009a) e Kerr et al. (2012a), é possível afirmar que a espessura da camada da WSDW é subestimada entre $\sim 500-700 \mathrm{~m}$, devido aos resultados deste trabalho apresentarem suas contribuições variando de 1000 a $\sim 4200 \mathrm{~m}$ de profundidade, enquanto que as observações apontam a WSDW cobrindo de 500 a $~ 4200$ m. Portanto, pode-se concluir que a camada superior da WSDW não foi adequadamente representada, provavelmente em virtude de somente um tipo de água ter sido usado. De acordo com o próprio Kerr et al. (2009a), o traçamento da WSDW na coluna d'água se torna difícil, em 
virtude da ocorrência dessa massa de água em um intervalo bastante grande de profundidades ( 3000m) além de a mesma ocorrer em uma amplitude relativamente elevada de temperaturas (entre 0 e $-0,7^{\circ} \mathrm{C}$ ). Estes fatos podem indicar que mais de um tipo de água deveria ser utilizado para marcar algumas massas de água em particular no oceano.

É interessante ainda ressaltar que a formação da AABW se dá, dentre outros fatores, à partir da WSDW, pois a WSBW por ser uma água mais densa não consegue deixar a região, devido às características topográficas do fundo do MW (CARMACK e FOSTER, 1975a; FAHRBACH et al., 1995).

Analisando agora espacialmente a WSDW (Figura 51) e partindo dos cortes de maior profundidade (3000 e 4000m - Figuras 51c e 51d), é possível verificar claramente a influência da Plataforma Continental na formação desta massa de água, porém com uma contribuição não tão constante na Plataforma Continental Sul apresentada pelo corte à 3000m. Estes resultados corroboram com estudos pretéritos realizados por Foldvik et al. (1985), Kerr (2006) e Kerr et al. (2012a) que afirmam que regiões de quebra de plataforma continental próximo à região da Plataforma de Gelo Ronne-Filchner (FRIS) são realmente áreas de formação tanto da WSDW como da WSBW, principalmente devido à interação da WDW com a ISW.

Na profundidade de 2000m (Figura 51p) a WSDW ocupa percentuais acima de $80 \%$ em praticamente todo o MW, com exceção da região bem próxima à Plataforma Continental Sul, que apresenta contribuições na faixa de 60\%. Como a maior parte desta massa de água é formada em regiões profundas, pouca influência ela tem na profundidade de 1000m (Figura 519), pois suas contribuições não ultrapassam os 60\%, no centro do Giro de Weddell, chegando até atingir valores quase nulos ao redor de toda a Plataforma Continental. 
(a)

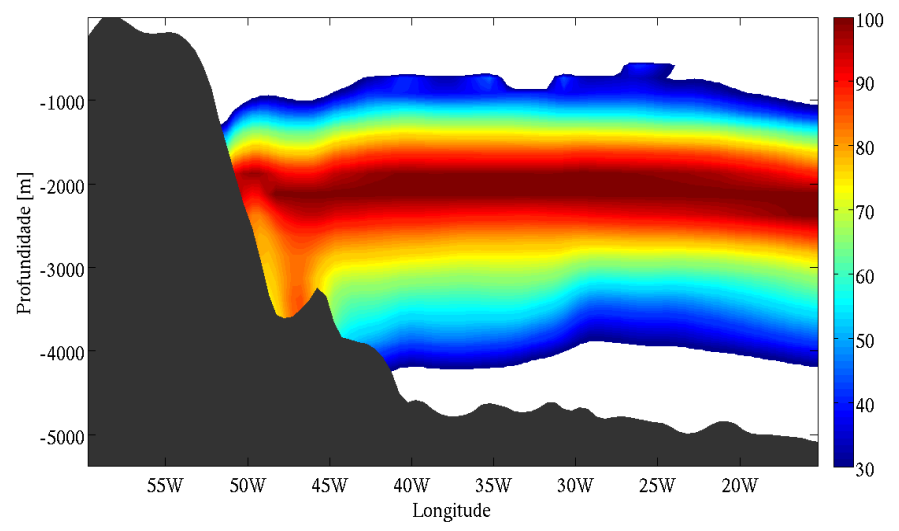

(b)

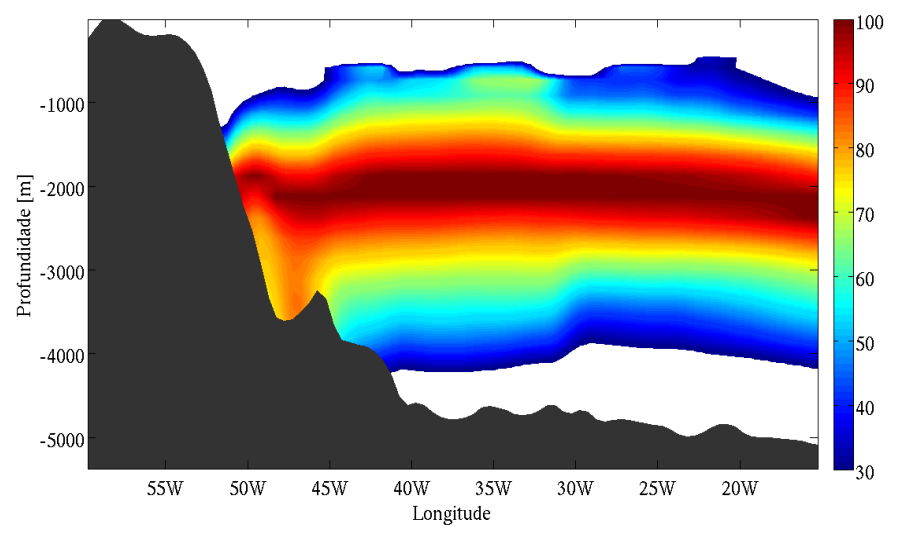

(c)

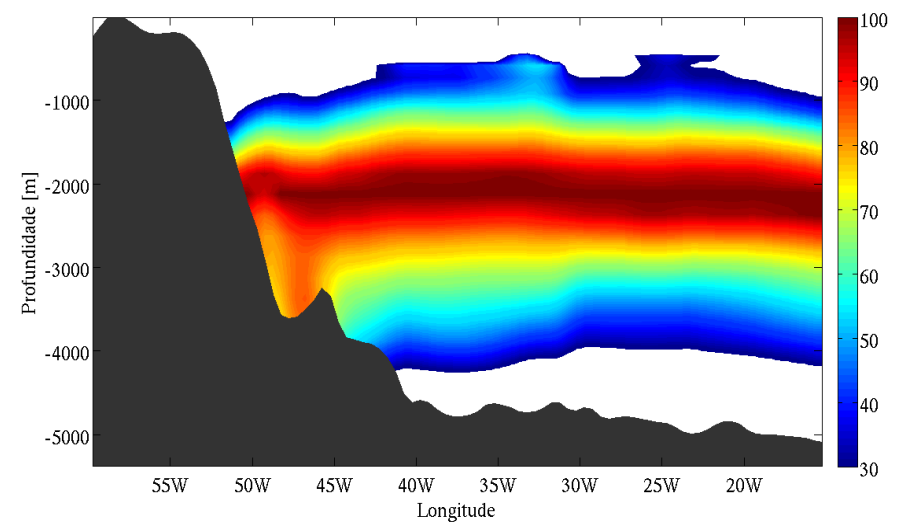

Figura 47: (a) Distribuição (\%) da WSDW na W1 para o período entre 1925 e 1949; (b) 1950-1974; (c) 1975-1999 
(a)

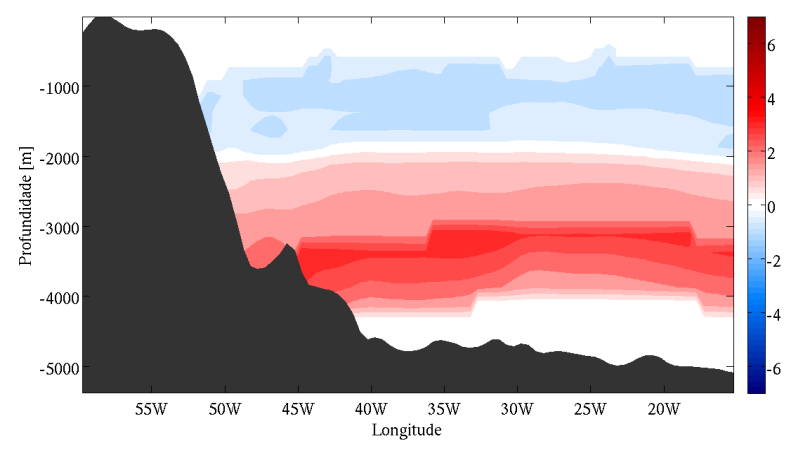

(b)

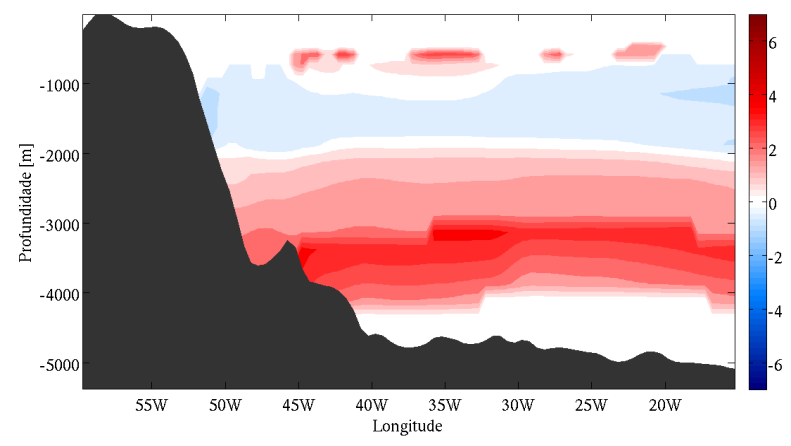

(c)

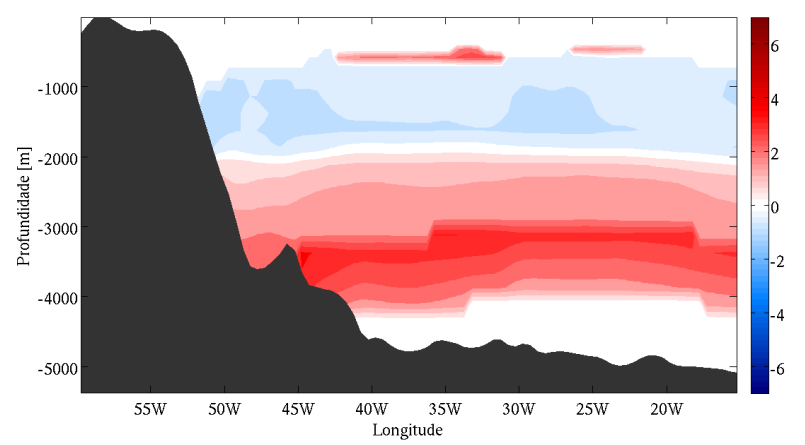

(d)

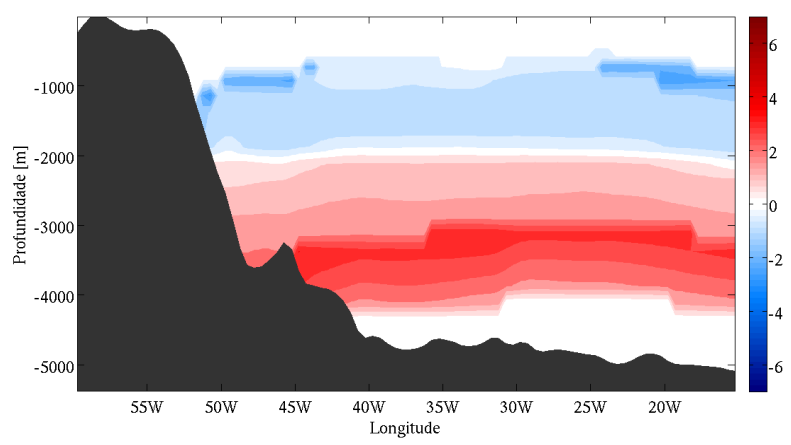

Figura 48: (a) Anomalia da distribuição $(\%)$ da WSDW na W1 relativa à média climatológica (1871-2008) para o período entre 1925 e 1949; (b) 1950-1974; (c) 1975-1999; (d) 1925-1999. 
(a)

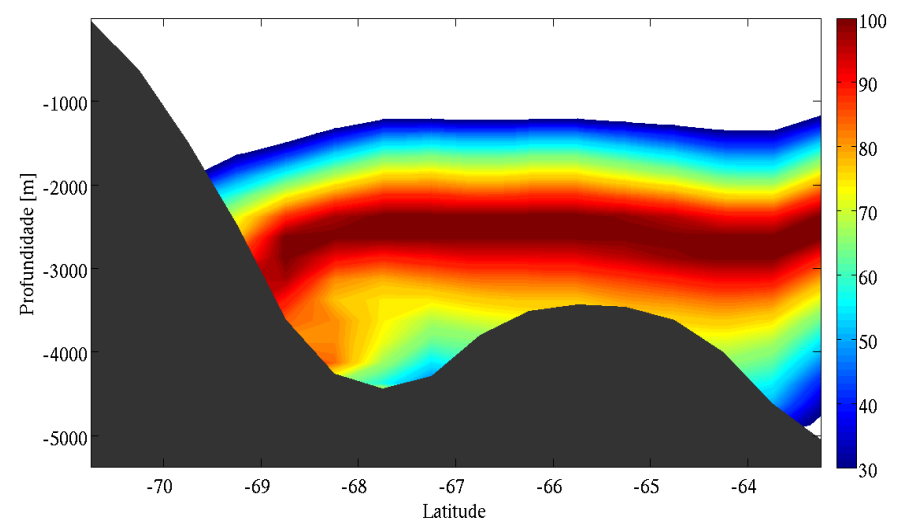

(b)

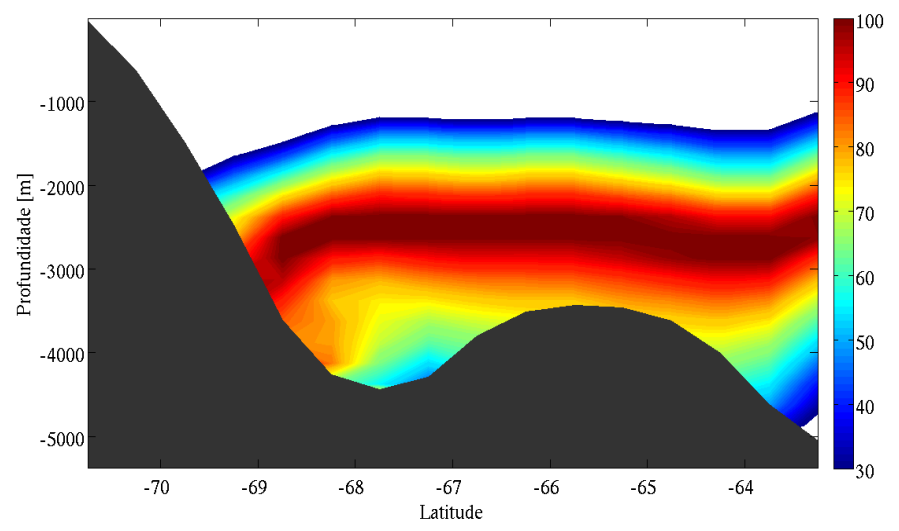

(c)

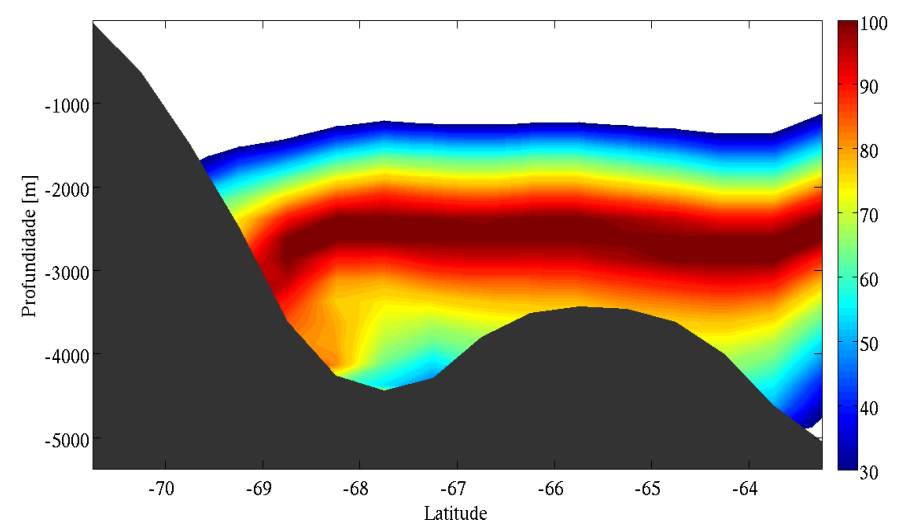

Figura 49: (a) Distribuição (\%) da WSDW na W2 para o período entre 1925 e 1949; (b) 1950-1974; (c) 1975-1999 
(a)

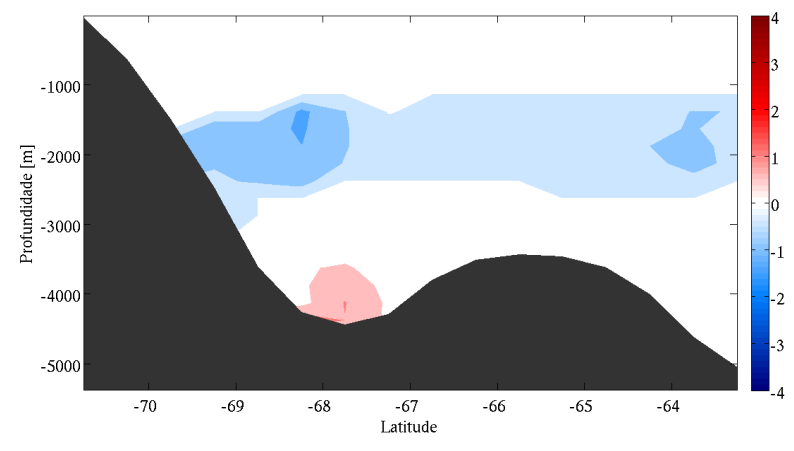

(b)

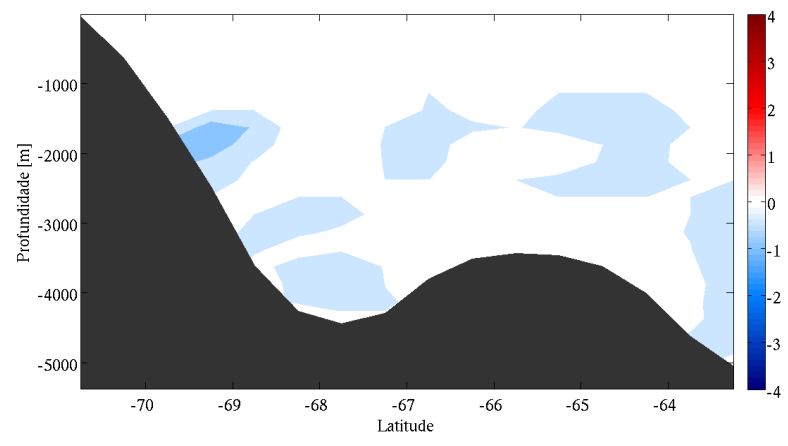

(c)

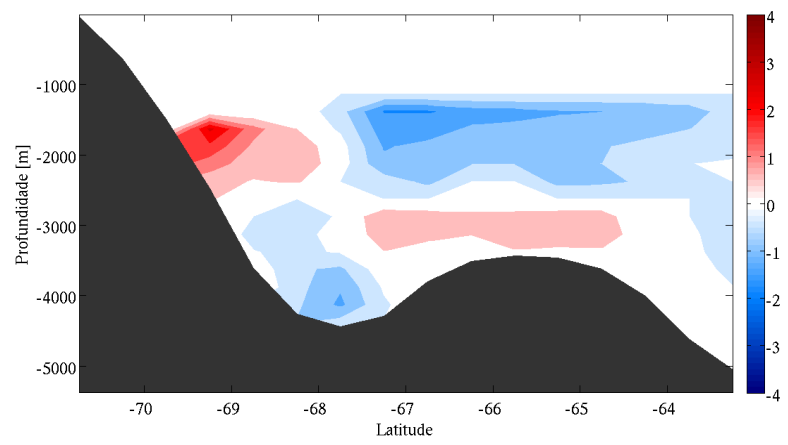

(d)

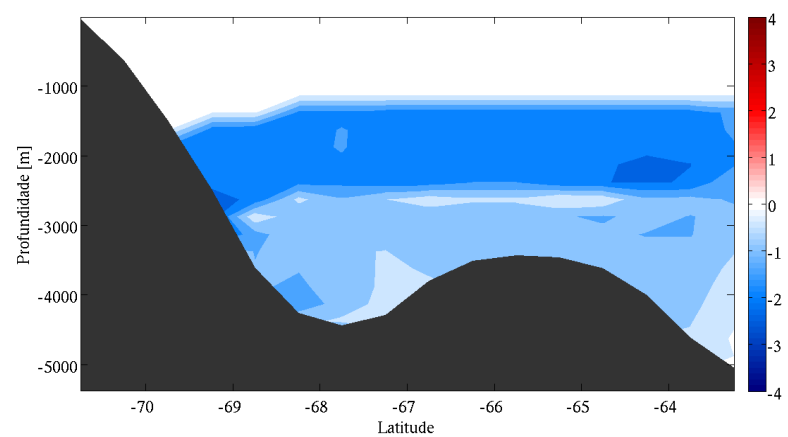

Figura 50: (a) Anomalia da distribuição (\%) da WSDW na W2 relativa à média climatológica (1871-2008) para o período entre 1925 e 1949; (b) 1950-1974; (c) 1975-1999; (d) $1925-1999$. 
(a)

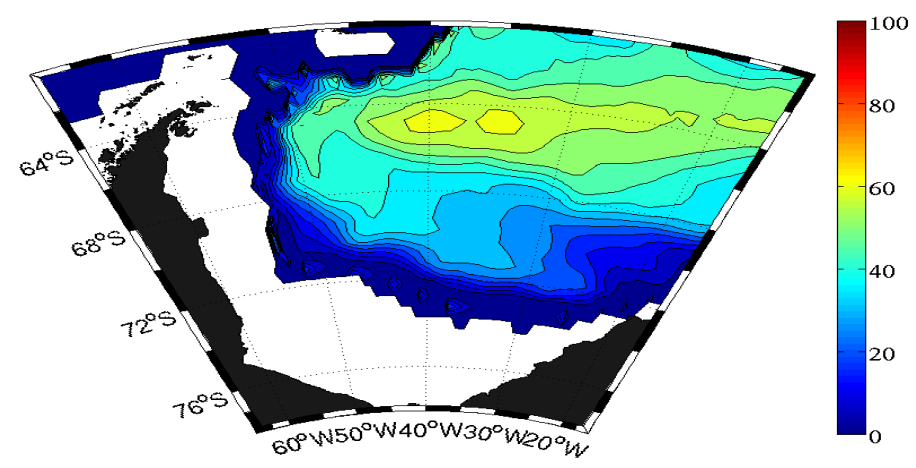

(b)

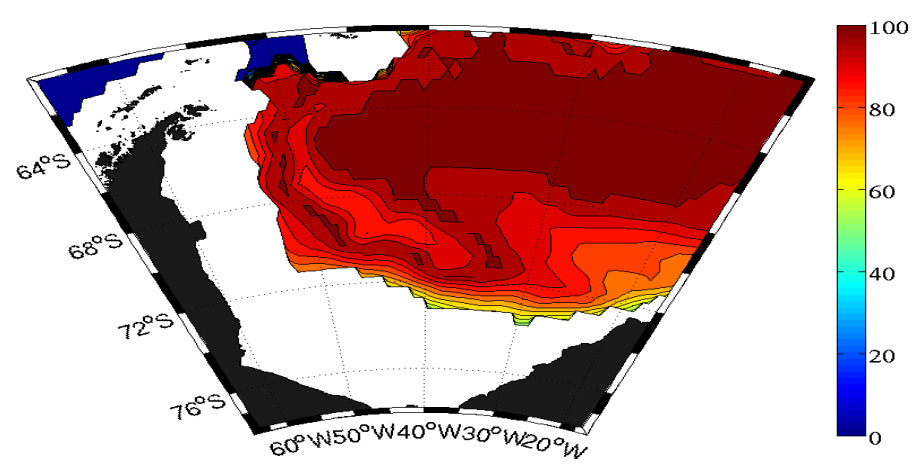

(c)

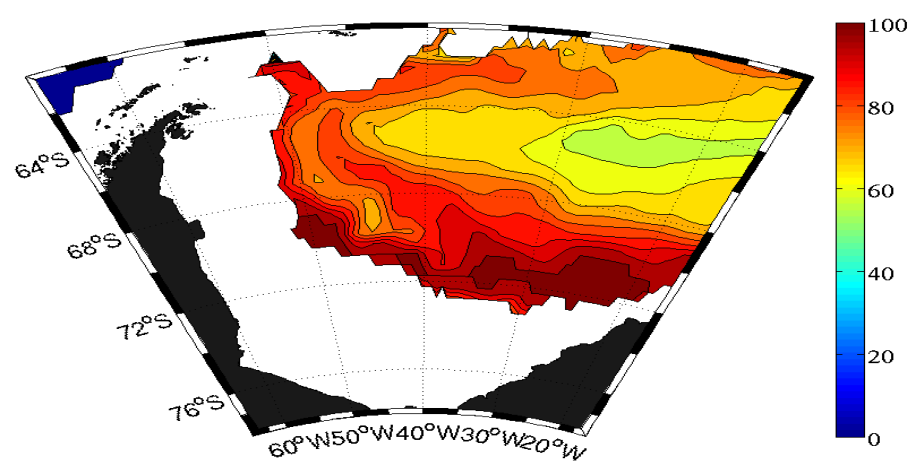

(d)

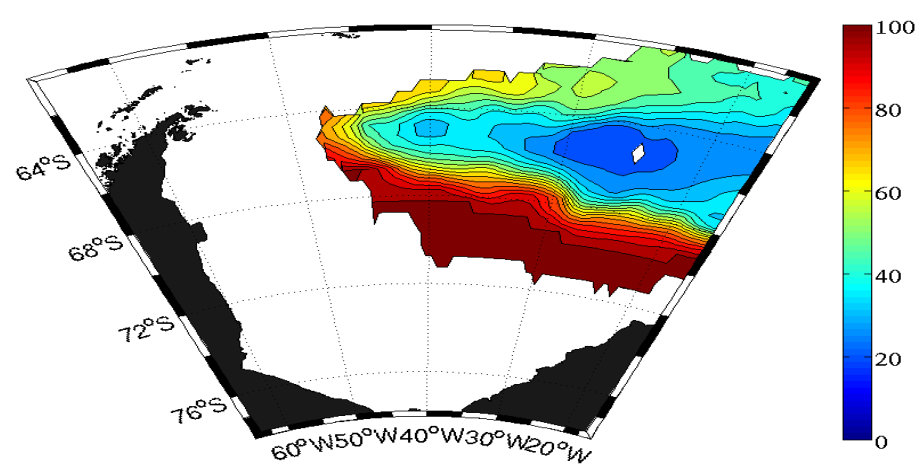

Figura 51: (a) Distribuição (\%) média (1871-2008) da WSDW no Mar de Weddell para a profundidade de 1000m; (b) 2000m; (c) 3000m; (d) 4000m 


\subsubsection{Distribuição da WSBW}

Analisando a radial W1 (Figura 52) é possível observar que percentuais superiores à 70\% da WSBW ficam aprisionados no fundo da bacia oceânica, em profundidades superiores à $3000 \mathrm{~m}$, entre as longitudes de $45^{\circ} \mathrm{W}$ e $15^{\circ} \mathrm{W}$. Também, vale ressaltar que a WSBW foi encontrada com contribuição variando entre $30-50 \%$ entre profundidades de 2500-3000m. Abaixo de 3000m de profundidade até o fundo oceânico a contribuição da WSBW variou entre 50 e $100 \%$.

Em uma primeira visualização das distribuições da WSBW na W2 (Figura 54) é possível verificar que percentuais maiores que $90 \%$ da massa de água não atingem latitudes maiores que $68^{\circ} \mathrm{S}$. Vale ressaltar também que a WSBW foi encontrada com contribuição contribuição variando entre 30-50\% em maiores profundidades entre 30003500m. E, em profundidades superiores à 3500m a contribuição da WSBW variou também entre entre 50 e 100\%. Assim como observado em Kerr et al. (2009a) e em Kerr et al. (2009b), a WSBW na seção do Meridiano de Greenwich ficou confinada na bacia oceânica profunda, ao norte da Elevação de Maud. Como as variações temporais foram muito pequenas entre os três períodos tanto na W1 como na $\mathrm{W} 2$, foram plotadas anomalias que são apresentadas nas Figuras 53 e 55. Em uma primeira visualização, o que se pode inferir, já que todas apresentaram somente valores negativos de anomalias, é que realmente houve um recuo da WSBW do ano de 1925 para o ano de 1999, indicando realmente uma diminuição da contribuição desta massa de água com o passar dos anos para esta região em específico; recuo este que pode ser mais bem visualizado na Figura 55d, onde é possível observar uma intensificação das águas com anomalias negativas no período compreendido do estudo (1925-1999).

A Figura 56 apresenta as distribuições espaciais da WSBW nos cortes específicos de profundidade. Como o próprio nome já diz, a WSBW é encontrada no fundo. Sabendo que os dados da reanálise atingem até a profundidade de $5300 \mathrm{~m}$, foram feitas diversas tentativas de representação da distribuição até esta profundidade máxima, porém a resolução encontrada após 4000m não foi a esperada para a região. Por isso, optou-se por utilizar somente a distribuição até os 4000m (Figura 56d), onde suas contribuições máximas atingiram $\sim 80 \%$ no centro do Giro de Weddell e mínimas muito próximas à 0 ao Sul do MW, 
nas proximidades da Plataforma Continental. Portanto, pode-se concluir que para estas profundidades a WSBW acompanha o padrão de circulação ciclônico do giro de Weddell, apresentando elevadas contribuições à leste de $30^{\circ} \mathrm{W}$ e abaixo de $3000 \mathrm{~m}$ (ABSY et al., 2008; FAHRBACH et al., 1995; HUHN et al., 2008; KERR, 2006; MUENCH et al., 2002).

À medida que a profundidade da coluna d'água vai diminuindo, os percentuais da WSBW também vão diminuindo e, aos 3000m (Figura 56c), seus valores máximos não passam de 50\%. Analisando o corte para a profundidade de 2000m (Figura 56), é possível notar a existência de duas feições interessantes: um núcleo com contribuições de $20 \%$ na borda Oeste do Giro de Weddell, núcleo este também presente no corte de 3000m e um segundo núcleo bem ao Norte da Península Antártica, com contribuições superiores à $80 \%$, podendo este até representar a $\mathrm{CDW}$ proveniente da $\mathrm{ACC}$ em virtude da profundidade em questão. Já na profundidade de 1000m (Figura 56a) a contribuição foi praticamente nula em todo o Mar de Weddell. 
(a)

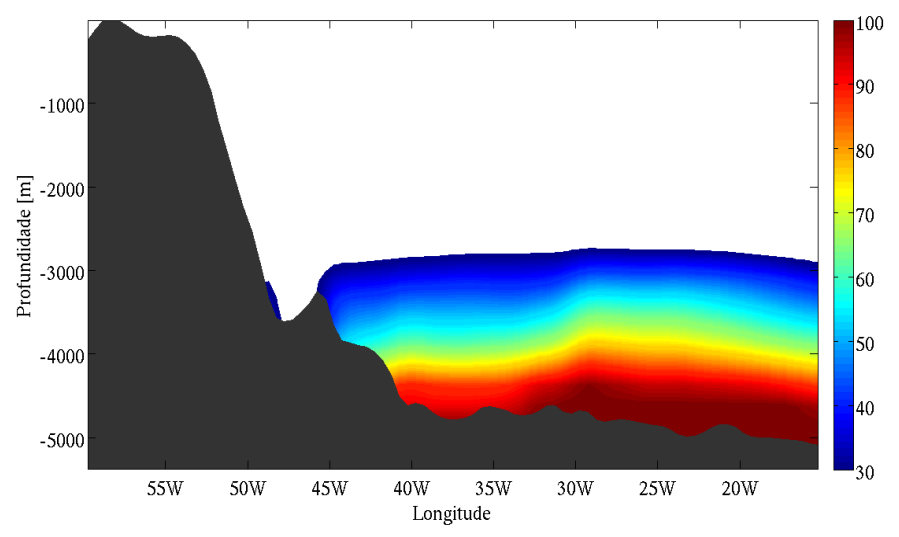

(b)

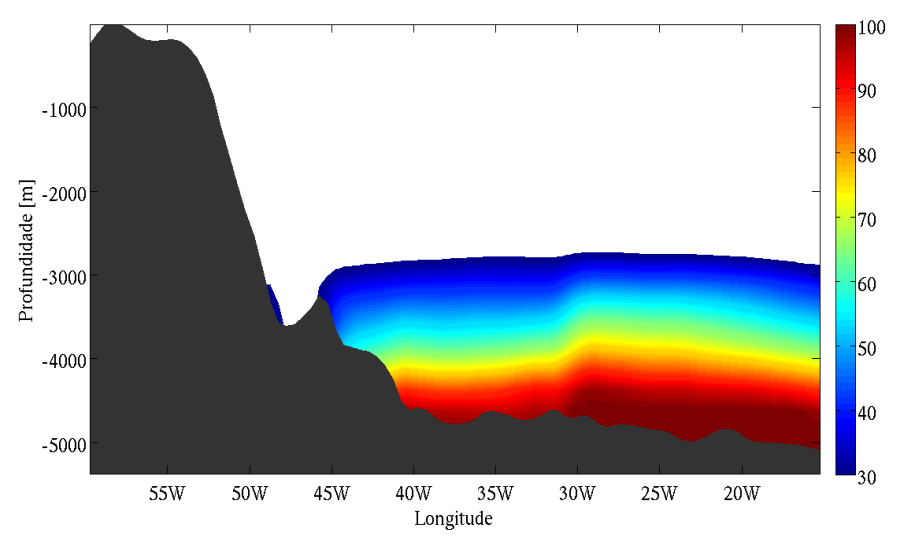

(c)

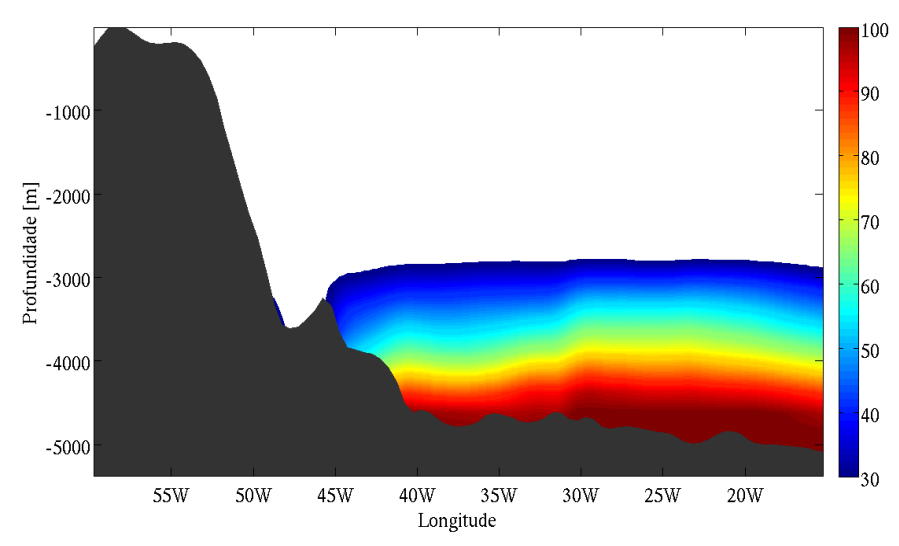

Figura 52: (a) Distribuição (\%) da WSBW na W1 para o período entre 1925 e 1949; (b) 1950-1974; (c) 1975-1999 
(a)

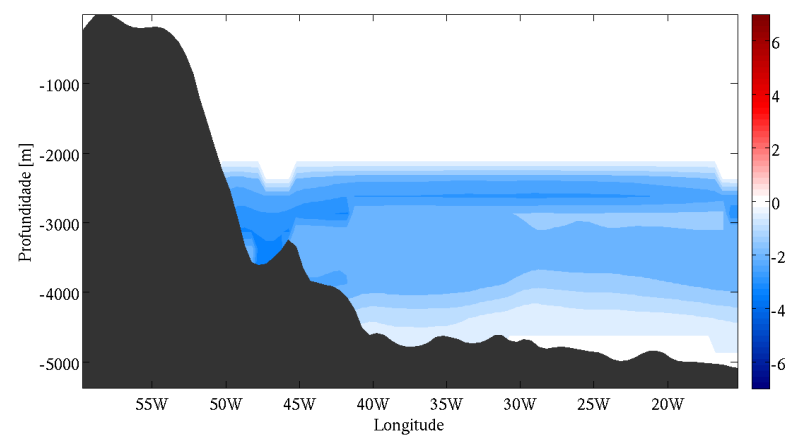

(b)

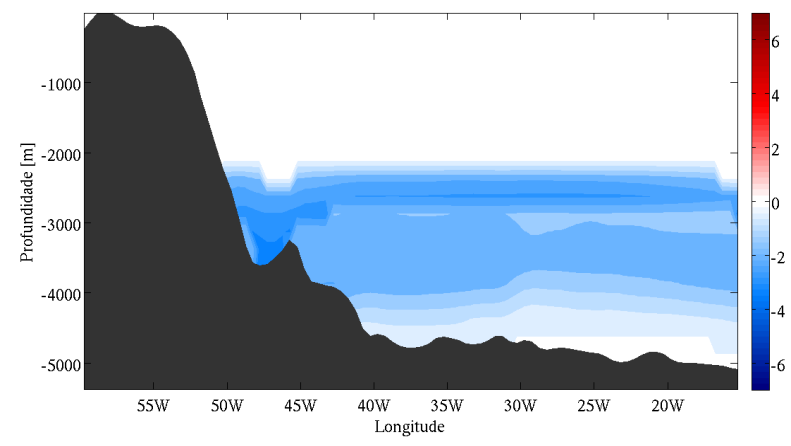

(c)

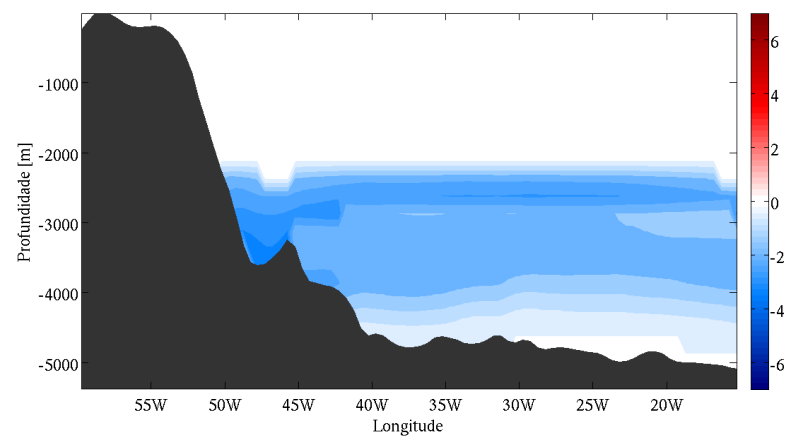

(d)

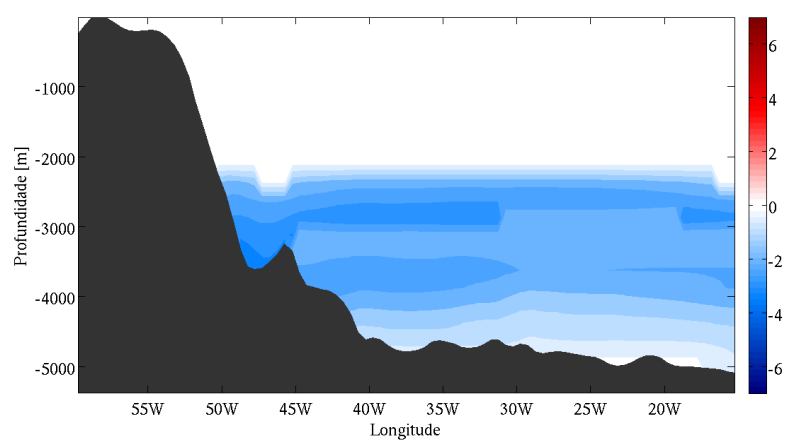

Figura 53: (a) Anomalia da distribuição $(\%)$ da WSBW na W1 relativa à média climatológica (1871-2008) para o período entre 1925 e 1949; (b) 1950-1974; (c) 1975-1999; (d) 1925-1999. 
(a)

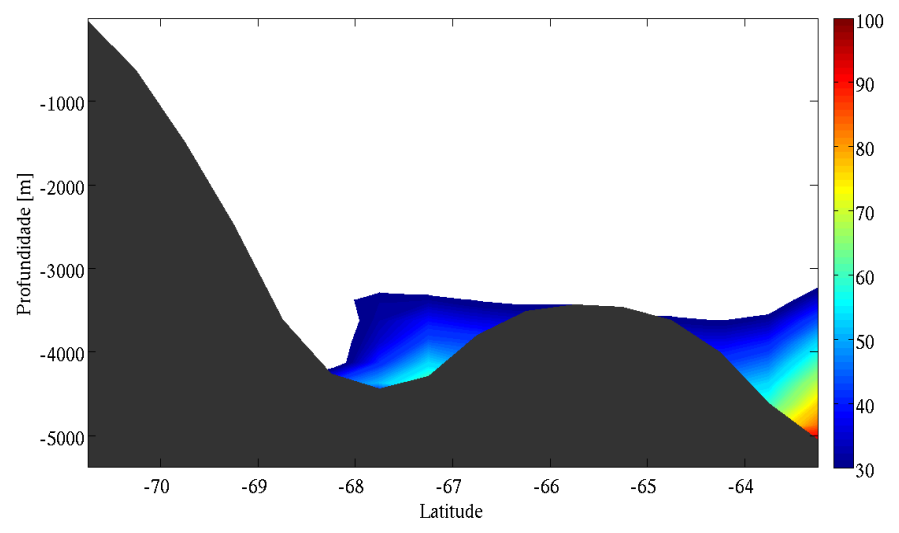

(b)

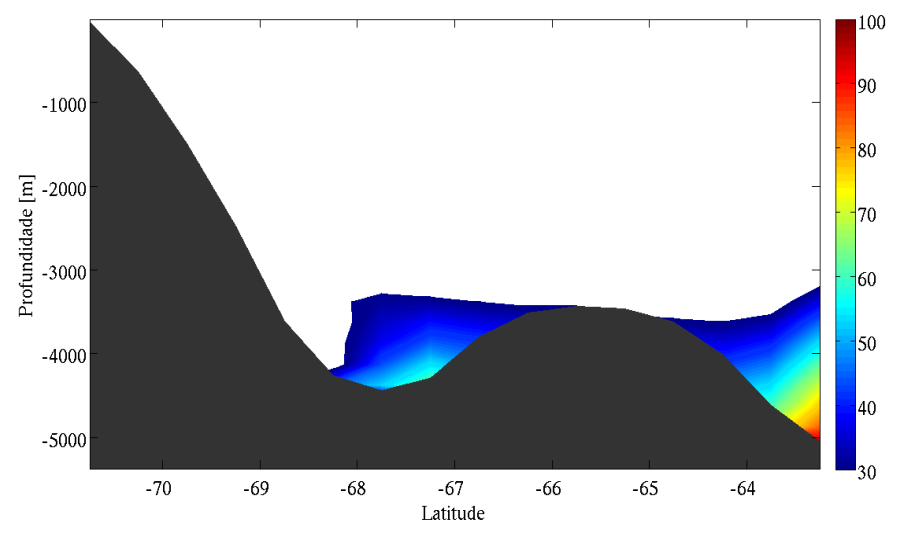

(c)

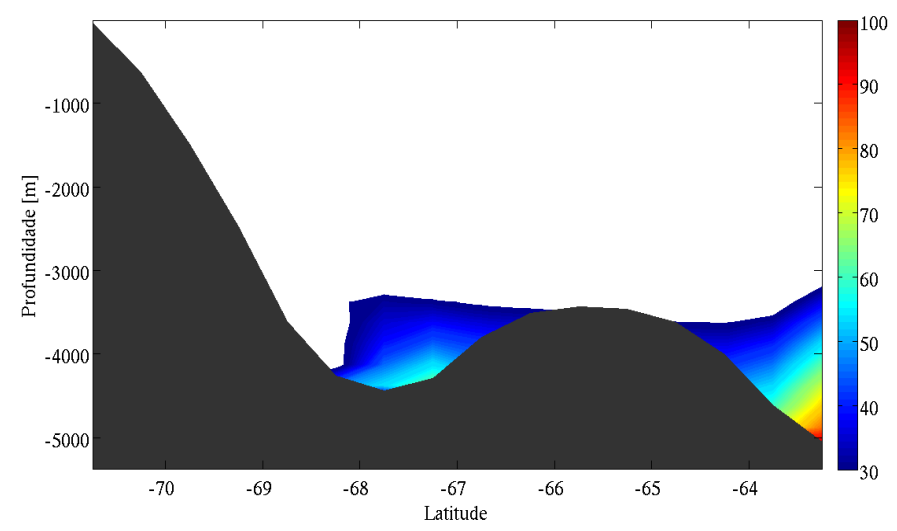

Figura 54: (a) Distribuição (\%) da WSBW na W2 para o período entre 1925 e 1949; (b) 1950-1974; (c) 1975-1999 
(a)

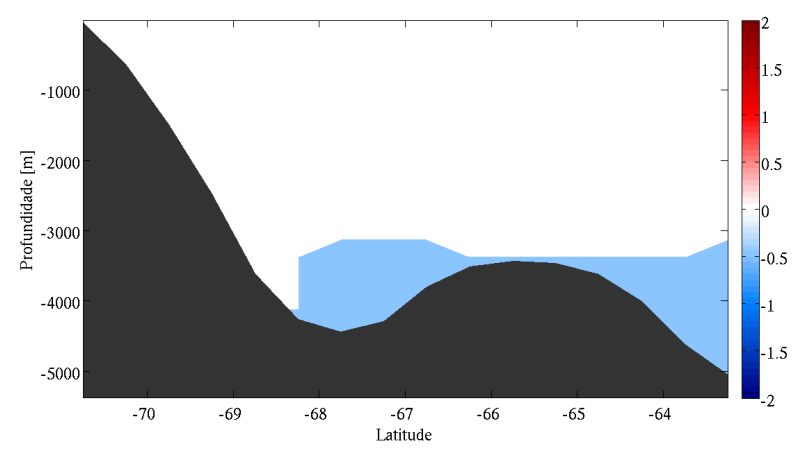

(b)

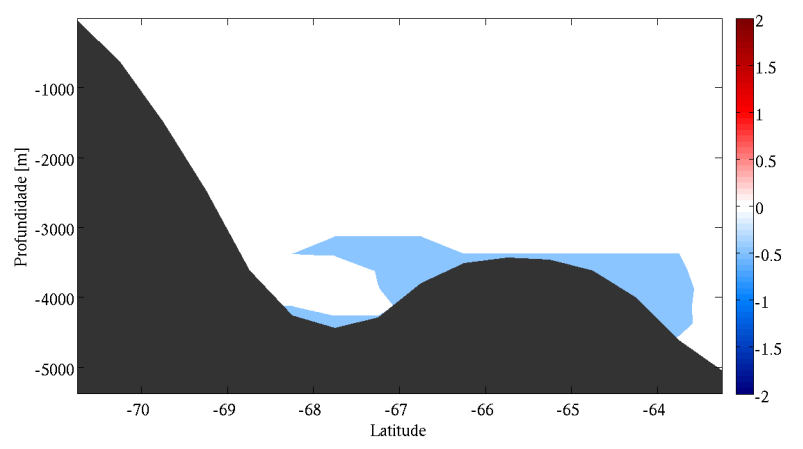

(c)

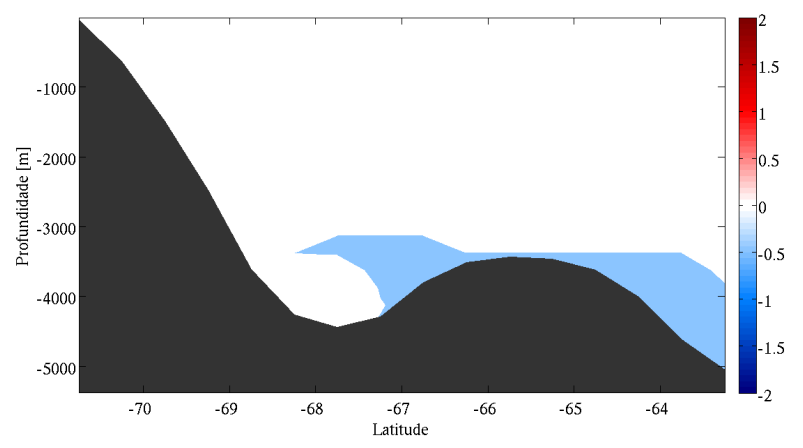

(d)

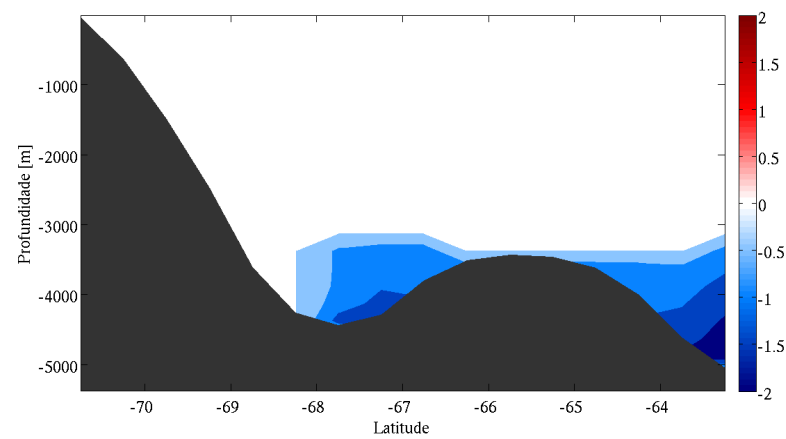

Figura 55: (a) Anomalia da distribuição (\%) da WSBW na W2 relativa à média climatológica (1871-2008) para o período entre 1925 e 1949; (b) 1950-1974; (c) 1975-1999; (d) 1925-1999. 
(a)

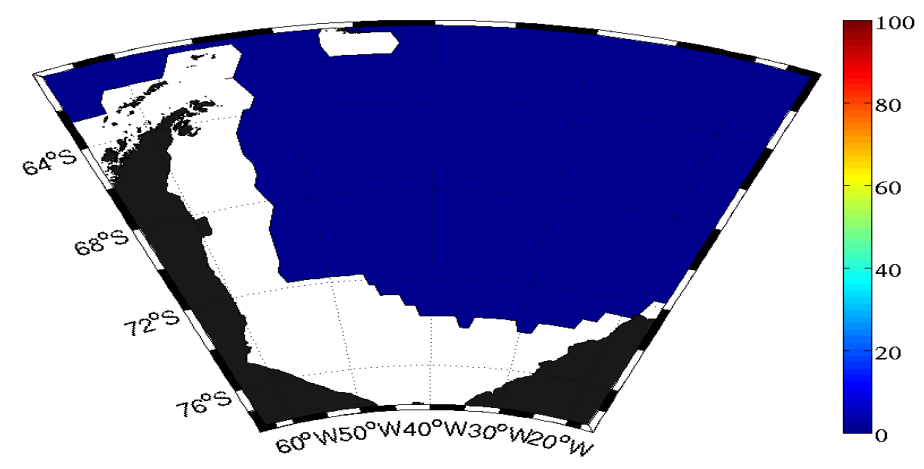

(b)

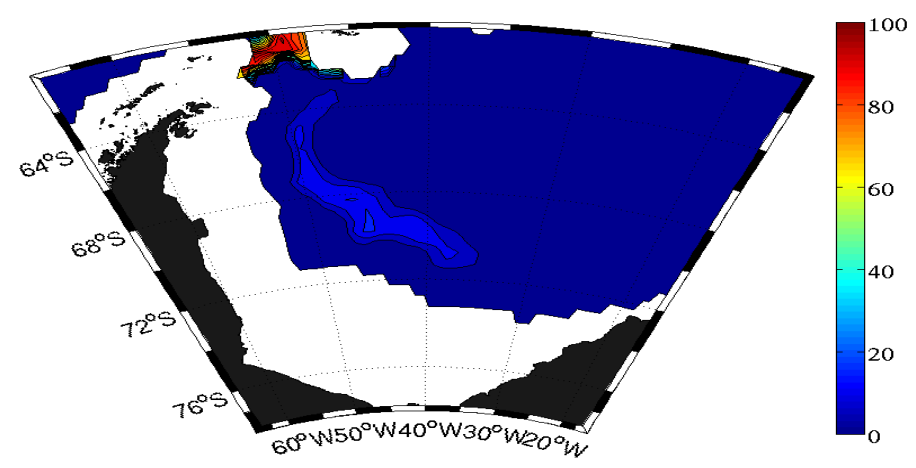

(c)

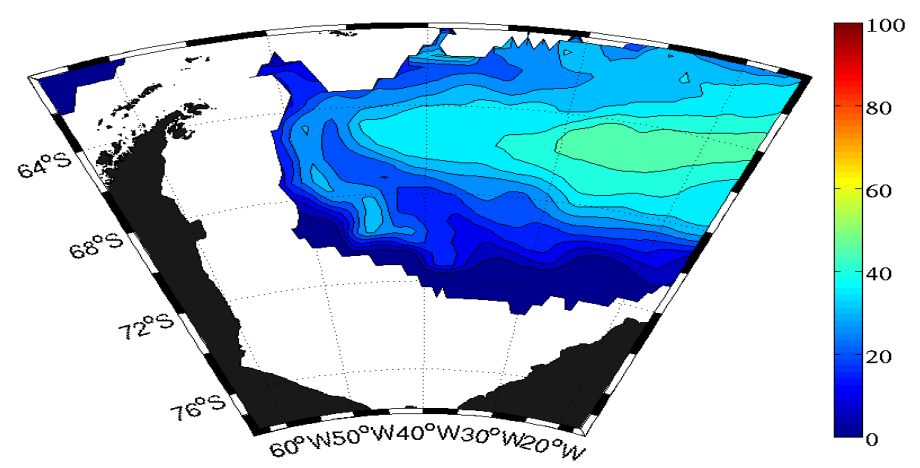

(d)

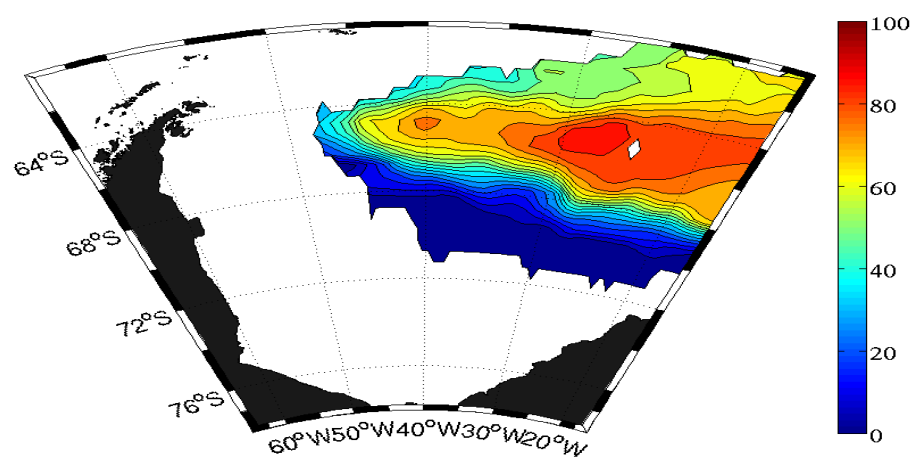

Figura 56: (a) Distribuição (\%) média (1871-2008) da WSBW no Mar de Weddell para a profundidade de 1000m; (b) 2000m; (c) 3000m; (d) 4000m 


\section{Conclusões}

Os objetivos propostos de caracterização das massas de água nos Mares de Ross e Weddell a partir dos dados do SODA, a fim de determinar a distribuição espacial, caracterizar quantitativamente e determinar o percentual de mistura entre as diferentes massas de água foram alcançados, e os resultados conduziram às seguintes conclusões:

-A reanálise oceânica SODA apresentou resultados consistentes com padrões de distribuição de massas de água obtidos em estudos observacionais pretéritos, como por exemplo Callahan (1972); Fahrbach et al. (1995); Budillon et al. (2002); Assmann et al. (2003); Absy et al. (2008); Huhn et al. (2008); Orsi e Wiederwohl (2009); Kerr et al. (2009b), entre outros trabalhos.

-O método da AMO é adequado para a obtenção de uma melhor compreensão com relação aos processos de mistura e variabilidade das águas profundas, de fundo e de plataforma aqui estudados.

-No Mar de Ross foi possível a separação das massas de água em UCDW, LCDW e LSSW, de forma consistente com a posição das mesmas reportadas pela literatura (SMITH et al., 1999; BUDILLON et al., 2003; KLINCK et al., 2004; ORSI e WIEDERWOHL, 2009).

-De todas as massas de água analisadas para os dois mares, a UCDW foi a que apresenou uma maior variabilidade entre os períodos de 25 anos escolhidos, não atingindo a Plataforma de Gelo do MR durante os anos de 1950-1974, devido à um enfraquecimento da borda leste do Giro de Ross ocorrido nesta época.

-Com a redução da UCDW na plataforma durante este período citado acima, a LCDW e a LSSW puderam ocupar seu lugar, apresentando anomalias positivas na região anteriormente ocupada pela UCDW.

•Os resultados obtidos confirmam então que a introdução da CDW na plataforma é dada por três principais fatores que agem conjuntamente: (i) topografia variável; (ii) presença da ACC; (iii) presença e intensidade do Giro de Ross. 
•Contribuições acima de $90 \%$ da LSSW foram encontradas na porção leste da Plataforma de Gelo do Mar de Ross, confirmando esta ser realmente uma região de formação da LSSW, que por sua vez é precursora da AASW.

-A estrutura das massas de água profundas do Mar de Weddell também foi bem representada. A WDW foi encontrada atingindo valores $>70 \%$ por volta de $800 \mathrm{~m}$. Já a WSDW apresenta seu núcleo com valores acima de $90 \%$ em profundidades entre 2000 e $3500 \mathrm{~m}$. A WSBW, por sua vez, apresenta percentuais $\sim 100 \% \mathrm{em}$ profundidades acima de 4000m, porém, a WSBW fica aprisionada no fundo da bacia devido às feições de fundo ocorrentes no MW (e.g. Elevação de Maud).

Por fim, os resultados obtidos por este trabalho mostram que de fato há, embora não seja marcante, evidências do impacto das mudanças climáticas no período de estudo (1871-2008), como pode ser visto nas Figuras $10 \mathrm{~d}$ e $10 \mathrm{~d}$, além das próprias distribuições de massa de água. Desta forma, a hipótese do trabalho pode ser testada e os objetivos propostos atingidos. 


\section{Referências}

ABSY, J. et al. Early summer thermohaline characteristics and mixing in the western weddell sea. Deep Sea Research II, v. 55, p. 1117-1131, 2008.

ASSMANN, K.; HELLMER, H. H.; BECKMANN, A. Seasonal variation in circulation and water mass distribution on the ross sea continental shelf. Antarctic Science, v. 15(01), p. 3-11, 2003.

BERGAMASCO, A. et al. Downslope flow across the ross sea shelf break (antarctica). AGU Fall Meeting Abstracts, p. C414+, 2003.

BROECKER, W. S. The great ocean conveyor. Oceanography, v. 4, p. 79-89, 1991.

BROMWICH, D. H.; KURTZ, D. D. Katabatic wind forcing of the terra nova bay polynya. Journal of Geophysical Research, v. 89, p. 3561-3572, 1984.

BUDILLON, G.; CORDERO, S. G.; SALUSTI, E. On the dense water spreading off the ross sea shelf (antarctica). EGS XXVII General Assembly, Nice, 21-26 April 2002, n. \#944, p. 27, 2002.

BUDILLON, G.; FUSCO, G.; SPEZIE, G. A study of surface heat fluxes in the ross sea (antarctica). Antarctic Science, v. 12, p. 243-254, 2000.

BUDILLON, G. et al. An optimum multiparameter mixing analysis of the shelf waters in the ross sea. Antarctic Science, v. 15(01), p. 105-118, 2003.

CALLAHAN, J. E. The structure and circulation of deep water in the antarctic. Deep Sea Research and Oceanographic Abstracts, v. 19, p. 563-575, 1972.

CARMACK, E. C. Water characteristics of the southern ocean south of the polar front. A voyage of discovery, v. 70, p. 15-41, 1977.

CARMACK, E. C.; FOSTER, T. On the flow of water out of the weddell sea. Deep Sea Research, v. 22, p. 711-724, 1975a.

CARTER, L.; MCCAVE, I. N.; WILLIAMS, M. J. M. Circulation and water masses of the southern ocean: A review. Developments in Earth and Environmental Sciences, v. 8, p. 85-114, 2008. 
CARTON, J.; CAO, X. A simple ocean data assimilation analysis of the global upper ocean 1950-95. part ii: Results. Journal of Physical Oceanography, v. 30, p. 311-326, 2000b.

CARTON, J. A.; CAO, X. A simple ocean data assimilation analysis of the global upper ocean 1950-95. part i: Methodology. Journal of Physical Oceanography, v. 30, p. 294-309, 2000.

CARTON, J. A.; GIESE, B. S. Soda: a reanalysis of ocean climate. Journal of Geophysical Research - Oceans, 2006.

CARTON, J. A.; GIESE, B. S. A reanalysis of ocean climate using simple ocean data assimilation (soda). Monthly Weather Review, v. 136(8), p. 2999-3017, 2008.

CONKRIGH, M. E. et al. World ocean database 2001 and world ocean atlas 2001. AGU Fall Meeting Abstracts, p. B220+, 2002.

DEACON, G. E. R. Physical and biological zonation in the southern ocean. Deep Sea Research Part A. Oceanographic Research Papers, v. 29(1), p. 1-15, 1982.

DEE, D. P. Bias and data assimilation. Quarterly Journal of the Royal Meteorological Society, v. 131, p. 3323-3343, 2005.

DIAZ, H. et al. Workshop on advances in the use of historical marine climate data. Bulletin of the World Meteorological Organization, v. 51(4), p. 377-379, 2002.

DINNIMAN, M.; KLINCK, J.; Smith Jr., W. Influence of sea ice cover and icebergs on circulation and water mass formation in a numerical circulation model of the ross sea, antarctica. Journal of Geophysical Research, v. 112(C11), p. C11013, 2007.

DINNIMAN, M. S.; KLINCK, J. M. A model study of circulation and crossshelf exchange on the west antarctic peninsula continental shelf. Deep Sea Research Part II: Topical Studies in Oceanography, v. 51, p. 1925-1946, 2004.

FAHRBACH, E. et al. Decadal-scale variations of water mass properties in the deep weddell sea. Ocean Dynamics, v. 54(1), p. 77-91, 2004.

FAHRBACH, E. et al. Suppression of bottom water formation in the southeastern weddell sea. Deep Sea Research Part I: Oceanographic Research Papers, v. 41(2), p. 
389-411, 1994a.

FAHRBACH, E. et al. Formation and discharge of deep and bottom water in the northwestern weddell sea. Journal of Marine Research, v. 53(4), p. 515-538, 1995.

FAHRBACH, E. et al. Transport and structure of the weddell gyre. Annales Geophysicae, v. 12, p. 840-855, 1994b.

FERRERO, B.; WAINER, I. Estudo comparativo da temperatura e salinidade entre os resultados do community climate system model, os dados hidrográficos do world ocean data atlas 2001 e da reanálise oceânica simple ocean data assimilation. Atlântica, v. 30(2), p. 89-100, 2008.

FOLDVIK, A. et al. Ice shelf water overflow and bottom water formation in the southern weddell sea. Journal of geophysical research, v. 109, p. C02015, 2004.

FOLDVIK, A.; GAMMELSRØD, T.; TØRRESEN, T. Circulation and water masses on the southern weddell sea shelf. Antarctic Research Series, v. 43, p. 5-20, 1985.

FOSTER, T.; CARMACK, E. C. Frontal zone mixing and antarctic bottom water formation in the southern weddell sea. Deep Sea Research, v. 23, p. 301-317, 1976b.

FOSTER, T. D.; CARMACK, E. C. Temperature and salinity structure in the weddell sea. Journal of Physical Oceanography, v. 6, p. 36-44, 1976a.

FUSCO, G. et al. Dynamics and variability of terra nova bay polynya. Marine Ecology, v. 23, p. 201-209, 2002.

GILL, A. E. Circulation and bottom water production in the weddell sea. Deep Sea Research and Oceanographic Abstracts, v. 20(2), p. 111-140, 1973.

GILLE, S. T. Mean sea surface height of the antarctic circumpolar current from geosat data: Method and application. Journal of geophysical research, v. 99, p. 1822518273., 1994.

GORDON, A. L. Structure of Antarctic waters between $20 \mathrm{~W}$ and $170 \mathrm{~W}$. [S.1.]: Antarctic Map Folio Series, 1967. 
GORDON, A. L. Weddell deep water variability. Journal of Marine Research, v. 40, p. 199-217, 1982.

GORDON, A. L. Western weddell sea thermohaline stratification. Ocean, Ice and Atmosphere: Interactions at the Antarctic Continental Margin, Antarct. Res. Ser, v. 75 , p. $215-240,1998$.

HINRICHSEN, H. H.; TOMCZAK, M. Optimum multiparameter analysis of the water mass structure in the western north atlantic ocean. Journal of Geophysical Research, v. 98(C6), p. 10155, 1993.

HUHN, O. et al. Evidence of deep-and bottom-water formation in the western weddell sea. Deep Sea Research Part II: Topical Studies in Oceanography, v. 55, p. 1098-1116, 2008.

JACOBS, S. Observations of change in the southern ocean. Philosophical Transactions of the Royal Society A: Mathematical, Physical and Engineering Sciences, v. 364, p. 1657-1681, 2006.

JACOBS, S. S.; AMOS, A. F.; BRUCHHAUSEN, P. M. Ross sea oceanography and antarctic bottom water formation. Deep Sea Research and Oceanographic Abstracts, v. 17, p. 935-962, 1970.

JACOBS, S. S.; COMISO, J. C. Sea ice and oceanic processes on the ross sea continental shelf. Journal of Geophysical Research, v. 94(C12), p. 18195, 1989.

JACOBS, S. S.; FAIRBANKS, R. G.; HORIBE, Y. Origin and evolution of water masses near the antarctic continental margin: Evidence from $\mathrm{h} 218 \mathrm{o} / \mathrm{h} 2160$ ratios in seawater. Antarctic Research Series, v. 43, p. 59-85, 1985.

JACOBS, S. S.; GIULIVI, C. F. Thermohaline data and ocean circulation on the ross sea continental shelf. Oceanography of the Ross Sea, Antarctica, p. 3-16, 1999.

JACOBS, S. S.; GIULIVI, C. F.; MELE, P. A. Freshening of the ross sea during the late 20th century. Science, v. 297, p. 386-389, 2002.

JOHNSON, G. C. Quantifying antarctic bottom water and north atlantic deep water volumes. Journal of Geophysical Research, v. 113, p. C05027, 2008. 
KARSTENSEN, J.; TOMCZAK, M. Ventilation processes and water mass ages in the thermocline of the southeast indian ocean. Geophysical Research Letters, v. 24, p. 2777-2780, 1997.

KARSTENSEN, J.; TOMCZAK, M. Age determination of mixed water masses using cfc and oxygen data. Journal of Geophysical Research, v. 103, p. 18599-18610, 1998.

KERR, R. Distribuição, mistura e variabilidade das massas de água profundas do Mar de Weddell, Antártica. Dissertação de Mestrado - Fundação Universidade Federal do Rio Grande (FURG), 2006. 146 pp.

KERR, R. et al. On the outflow of dense water from the weddell and ross seas in occam model. Ocean Science, v. 8, p. 369-388, 2012a.

KERR, R.; MATA, M. M.; GARCIA, C. A. E. On the temporal variability of the weddell sea deep water masses. Antarctic Science, Cambridge Univ Press, v. 21, n. 4, p. 383-400, 2009b.

KERR, R.; WAINER, I.; MATA, M. M. Representation of the weddell sea deep water masses in the ocean component of the ncar-ccsm model. Antarctic Science, Cambridge Univ Press, v. 21, n. 03, p. 301-312, 2009a.

KERR, R. et al. Quantifying antarctic deep waters in soda reanalysis product. Pesquisa Antartica Brasileira, v. 5, p. 47-59, 2012b.

KLINCK, J. et al. Water-mass properties and circulation on the west antarctic peninsula continental shelf in austral fall and winter 2001. Deep Sea Research Part II: Topical Studies in Oceanography, v. 51, p. 1925-1946, 2004.

KURTZ, D. D.; BROMWICH, D. H. Satellite observed behavior of the terra nova bay polynya. Journal of geophysical research, v. 88, p. 9717-9722, 1983.

KURTZ, D. D.; BROMWICH, D. H. A recurring, atmospherically forced polynya in terra nova bay. Antarctic Research Series, v. 43, p. 177-201, 1985.

LEFFANUE, H.; TOMCZAK., M. Using omp analysis to observe temporal variability in water mass distribution. Journal of Marine Systems, v. 48, p. 3-14, 2004. 
LOCARNINI, R. A. Water masses and circulation in the Ross Gyre and environs. [S.1.]: Texas A \& M University, Office of Graduate Studies, 1994.

MAMAYEV, O. I. Temperature-salinity analysis of world ocean waters. [S.1.]: Elsevier Publishing Company, 1975.

MANIGHETTI, B. Ocean circulation: the planet's great heat engine. Water \& Atmosphere, v. 9, p. 12-14, 2001.

MCCARTNEY, M. S. A voyage of discovery, george deacon 70th anniversary volume. In: [S.1.]: Pergamon, Oxford, UK., 1977. cap. Subantartic mode water, p. $103-119$.

MENSCH, M. et al. Transient tracer observations from the western weddell sea during the drift and recovery of ice station weddell. Antarctic Research Series, v. 75, p. 241-256, 1998.

MUENCH, R. et al. A dense water outflow from the ross sea, antarctica: Mixing and the contribution of tides. Journal of Marine Systems, v. 77, n. 4, p. 369-387, 2009.

MUENCH, R. et al. Upper ocean diapycnal mixing in the northwestern weddell sea. Deep Sea Research Part II: Topical Studies in Oceanography, v. 49(21), p. 48434861, 2002.

ORSI, A. H.; JOHNSON, G. C.; BULlISTER, J. L. Circulation, mixing, and production of antarctic bottom water. Progress in Oceanography, v. 43(1), p. 55-109, 1999.

ORSI, A. H.; NOWLIN, W. D.; WHITWORTH, T. T. On the circulation and stratification of the weddell gyre. Deep-sea research. Part A. Oceanographic research papers, v. 40, p. 169-203, 1993.

ORSI, A. H. et al. On the meridional extent and fronts of the antarctic circumpolar current. Deep Sea Research Part I: Oceanographic Research Papers, v. 42(5), p. 641-673, 1995.

ORSI, A. H.; WIEDERWOHL, C. L. A recount of ross sea waters. Deep Sea Research Part II: Topical Studies in Oceanography, v. 56, p. 778-795, 2009. 
ØSTERHUS, S. Monitoring of bottom water formation in the southern weddell sea. CLIVAR Exchanges, v. 10, p. 61-63, 2005.

PARDO, P. C. et al. Water masses distribution in the southern ocean: Improvement of an extended omp (eomp) analysis. Progress in Oceanography, v. 103, p. 92-105, 2012.

PEDLOSKY, J. Geophysical Fluid Dynamics. [S.1.: s.n.], 1982.

POOLE, R.; TOMCZAK, M. Optimum multiparameter analysis of the water mass structure in the atlantic ocean thermocline. Deep Sea Research Part I: Oceanographic Research Papers, v. 46(11), p. 1895-1921, 1999.

RAHMSTORF, S. Ocean circulation and climate during the past 120,000 years. Nature, v. 419, p. 207-214, 2002.

REDFIELD, A.; KETCHUM, B.; RICHARDS, F. The influence of organisms on the composition of sea-water. [S.1.: s.n.], 1963.

REID, J. L.; NOWLIN, W. D. J.; PATZERT, W. C. On the characteristics and circulation of the southwestern atlantic ocean. Journal of Physical Oceanography, v. 7, p. 62-91, 1977.

ROBERTSON, R. et al. Long-term temperature trends in the deep waters of the weddell sea. Deep Sea Research Part II: Topical Studies in Oceanography, v. 49(21), p. 4791-4806, 2002.

SCHMITZ, W. J. On the interbasin-scale thermohaline circulation. Rev. Geophys., v. 33, p. 151-173, 1995.

SIEVERS, H. A.; NOWLIN, W. D. The stratification and water masses at drake passage. Journal of Geophysical Research, v. 89, p. 10489-10514, 1984.

SMETHIE, W. M.; JACOBS, S. Circulation and melting under the ross ice shelf: estimates from evolving cfc, salinity and temperature fields in the ross sea. Deep Sea Research Part I: Oceanographic Research Papers, v. 52(6), p. 959-978, 2005.

SMITH, D. A. et al. Hydrography and circulation of the west antarctic peninsula continental shelf. Deep-sea research. Part I, Oceanographic research papers, v. 46, p. 
925-949, 1999.

SMITH, R.; GENT, P. Reference manual for the parallel ocean program (pop), ocean component of the community climate system model $(\operatorname{ccsm} 2.0$ and 3.0). Los Alamos National Laboratory Technical Report, v. 3, p. 02-2484, 2002.

TOMCZAK, M. A multi-parameter extension of temperaturesalinity diagram techniques for the analysis of non-isopycnal mixing. Progress in Oceanography, v. 10(3), p. 147-171, 1981.

TOMCZAK, M. Some historical, theoretical and applied aspects of quantitative water mass analysis. Journal of Marine Research, v. 57(2), p. 275-303, 1999a.

TOMCZAK, M.; LARGE, D. G. B. Optimum multiparameter analysis of mixing in the thermocline of the eastern indian ocean. Journal of Geophysical Research, v. 94(C11), p. 16141, 1989.

TOMCZAK, M.; LARGE, D. G. B.; NANCARROW, N. Identification of diapycnal mixing through optimum multiparameter analysis 1 . test of feasibility and sensitivity. Journal of Geophysical Research, v. 99(C12), p. 25267, 1994.

TONELli, M. Estudo Numérico da Variabilidade das Massas de Água do Mar de Ross nos Séculos XX e XXI. Dissertação de Mestrado - Universidade de São Paulo (IO-USP), 2009. 90 pp.

VASQUEZ, J.; SUMAGAYSAY, R.; PERRY, K. NOAANASA AVHRR Ocean Pathfinder Sea Surface Ocean Data Set - User's Reference Manual. [S.1.], 1998.

WEPPERNIG, R. et al. Isotope data from ice station weddell: Implications for deep water formation in the weddell sea. Journal of Geophysica, v. 101, p. 25723-25739, 1996.

WHITWORTH, T.; NOWLIN, W. Water masses and currents of the southern ocean at the greenwich meridian. Journal of Geophysical Research, v. 92(C6), p. 64626476, 1987.

WOERT, M. L. V. Wintertime dynamics of the terra nova bay polynya. Journal of geophysical research, v. 104, p. 7753-7769, 1999. 
YOU, Y.; TOMCZAK, M. Thermocline circulation and ventilation in the indian ocean derived from water mass analysis. Deep Sea Research Part I: Oceanographic Research Papers, v. 40(1), p. 13-56, 1993. 